\title{
THE
}

\section{Advances in the application of amino acid nitrogen isotopic analysis in ecological and biogeochemical studies}

Naohiko Ohkouchi

Yoshito Chikaraishi

Hilary Close

Brian Fry

Thomas Larsen

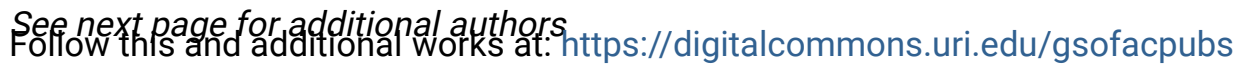

The University of Rhode Island Faculty have made this article openly available.

Please let us know how Open Access to this research benefits you.

This is a pre-publication author manuscript of the final, published article.

Terms of Use

This article is made available under the terms and conditions applicable towards Open Access

Policy Articles, as set forth in our Terms of Use.

\section{Citation/Publisher Attribution}

Ohkouchi, N., Chikaraishi, Y., Close, H., Fry, B., Larsen, T., Madigan, D. J., McCarthy, M. D.,...Yokoyama, Y. (2017). Advances in the application of amino acid nitrogen isotopic analysis in ecological and biogeochemical studies. Organic Chemistry, 113, 150-174. doi: 10.1016/j.orggeochem.2017.07.009. Available at: https://doi.org/10.1016/j.orggeochem.2017.07.009

This Article is brought to you for free and open access by the Graduate School of Oceanography at DigitalCommons@URI. It has been accepted for inclusion in Graduate School of Oceanography Faculty Publications by an authorized administrator of DigitalCommons@URI. For more information, please contact digitalcommons-group@uri.edu. 


\section{Authors}

Naohiko Ohkouchi, Yoshito Chikaraishi, Hilary Close, Brian Fry, Thomas Larsen, Daniel J. Madigan,

Matthew D. McCarthy, Kelton McMahon, Toshi Nagata, Yuichi I. Naito, Nanako O. Ogawa, Brian N. Popp,

Shawn Steffan, Yoshinori Takano, Ichiro Tayasu, Alex S. J. Wyatt, Yasuhiko T. Yamaguchi, and Yusuke

Yokoyama

This article is available at DigitalCommons@URI: https://digitalcommons.uri.edu/gsofacpubs/295 


\section{Advances in the application of amino acid nitrogen isotopic analysis}

\section{2 in ecological and biogeochemical studies}

4 Naohiko Ohkouchi ${ }^{\mathrm{a}, *}$, Yoshito Chikaraishi ${ }^{\mathrm{a}, \mathrm{m}}$, Hilary Close $^{\mathrm{b}}$, Brian Fry ${ }^{\mathrm{c}}$, Thomas Larsen ${ }^{\mathrm{d}}$, Daniel J.

5 Madigan $^{\mathrm{e}}$, Matthew D. McCarthy ${ }^{\mathrm{f}}$, Kelton W. McMahon ${ }^{\mathrm{g}}$, Toshi Nagata ${ }^{\mathrm{h}}$, Yuichi I. Naito ${ }^{\mathrm{a}, \mathrm{n}}$,

6 Nanako O. Ogawa ${ }^{\mathrm{a}}$, Brian N. Popp ${ }^{\mathrm{i}}$, Shawn Steffan ${ }^{\mathrm{j}, \mathrm{k}}$, Yoshinori Takano ${ }^{\mathrm{a}}$, Ichiro Tayasu ${ }^{1}$, Alex S.J.

7 Wyatt $^{\mathrm{h}}$, Yasuhiko T. Yamaguchi ${ }^{\mathrm{h}, \mathrm{o}}$, Yusuke Yokoyama ${ }^{\mathrm{h}}$

${ }^{a}$ Department of Biogeochemistry, Japan Agency for Marine-Earth Science and Technology, Japan

${ }^{\mathrm{b}}$ Rosenstiel School of Marine and Atmospheric Science, University of Miami, USA

${ }^{c}$ Australian Rivers Institute, Griffith University, Australia

${ }^{\mathrm{d}}$ Leibniz-Laboratory, University of Kiel, Germany

${ }^{\mathrm{e}}$ Harvard University Center for the Environment, USA

${ }^{\mathrm{f}}$ Department of Ocean Sciences, University of California, Santa Cruz, USA

${ }^{\mathrm{g}}$ Graduate School of Oceanography, University of Rhode Island, USA

${ }^{\mathrm{h}}$ Atmosphere and ocean Research Institute, The University of Tokyo, Japan

${ }^{\mathrm{i}}$ Department of Geology and Geophysics, University of Hawaii, USA

${ }^{\mathrm{j}}$ US Department of Agriculture, Agricultural Research Service, USA

${ }^{\mathrm{k}}$ Department of Entomology, University of Wisconsin-Madison, USA

${ }^{1}$ Research Institute of Humanity and Nature, Japan

${ }^{\mathrm{m}}$ Institute of Low Temperature Science, Hokkaido University, Japan

${ }^{\mathrm{n}}$ Nagoya University Museum, Japan

${ }^{\mathrm{o}}$ Lake Biwa Environmental Research Institute, Japan

*Corresponding author

Naohiko Ohkouchi

Department of Biogeochemistry

Japan Agency for Marine-Earth Science and Technology

2-15 Natsushima-cho

Yokosuka 237-0061

Japan

Phone: +81-46-867-9790

Fax: +81-46-867-9775

Email: nohkouchi@jamstec.go.jp 


\section{Abstract}

Compound-specific isotopic analysis of amino acids (CSIA-AA) has emerged in the last decade as a powerful approach for tracing the origins and fate of nitrogen in ecological and biogeochemical studies. This approach is based on the empirical knowledge that source AAs (i.e., phenylalanine), fractionate ${ }^{15} \mathrm{~N}$ very little $(<0.5 \%$ ) during trophic transfer, whereas trophic AAs (i.e., glutamic acid), are greatly ( $\sim 6-8 \%$ ) enriched in ${ }^{15} \mathrm{~N}$ during each trophic step. The differential fractionation of these two AA groups can provide a valuable estimate of consumer trophic position that is internally indexed to the baseline $\delta^{15} \mathrm{~N}$ value of the integrated food web. In this paper, we critically review the analytical methods for determining the nitrogen isotopic composition of AAs by gas chromatography/isotope-ratio mass spectrometry. We also discuss methodological considerations for accurate trophic position assessment of organisms using CSIA-AA. We then discuss the advantages and challenges of the CSIA-AA approach by examining published studies including trophic position assessment in various ecosystems, reconstruction of ancient human diets, reconstruction of animal migration and environmental variability, and assessment of marine organic matter dynamics. It is clear that the CSIA-AA approach can provide unique insight into the sources, cycling, and trophic modification of organic nitrogen as it flows through systems. However, some uncertainty still exists in how biochemical, physiological, and ecological mechanisms affect isotopic fractionation of trophic AAs. We end this review with a call for continued exploration of the mechanisms of AA isotopic fractionation, through various studies to promote the evolution of the rapidly growing field of CSIA-AA.

\section{Abbreviations}

AA: amino acid, EAA: essential amino acid, SAA: source amino acids, TAA: trophic amino acids, Ala: alanine, Arg: arginine, Asn: asparagine, Asp: aspartic acid, Cys: cysteine, His: histidine, Glu: glutamic acid, Gly: glycine, Ile: isoleucine, Leu: leucine, Lys: lysine, Met: methionine, Phe: phenylalanine, Pro: proline, Ser: serine, Thr: threonine, Trp: tryptophan, Val: valine, CSIA: compound-specific isotope analysis, TFA: trifluoroacetic acid, TFAA: trifluoroacetic acid anhydride, Pv: pivaloyl, MOC: methoxycarbonyl, iPr: isopropyl, GC/IRMS: gas chromatography/isotope-ratio mass spectrometry, HPLC: high-performance liquid chromatography, TP: trophic position, TDF: trophic discrimination factor, OM: organic matter, POM: particulate organic matter, DOM: dissolved organic matter, THAA: total hydrolysable amino acid

\section{Key words} amino acid, nitrogen isotopic composition, trophic discrimination factor, trophic position, ecology, biogeochemistry

\section{Introduction}


The stable nitrogen isotopic composition of organisms was first applied in the field of biogeoscience more than half a century ago (e.g., Parwel et al., 1957; Hoering and Ford, 1960; Cheng et al., 1964). Miyake and Wada (1967) first reported that marine animals preferentially incorporate ${ }^{15} \mathrm{~N}$ relative to

${ }^{14} \mathrm{~N}$ during metabolic processing of dietary nitrogen. These initial findings were later confirmed in several seminal papers based on diet-controlled laboratory culture experiments and field studies that provided further evidence of ${ }^{15} \mathrm{~N}$ enrichment during heterotrophic processes (e.g., DeNiro and Epstein 1981; Minagawa and Wada 1984; Fry, 2006 and references therein). The stable nitrogen isotopic composition provides unique insight into the dietary habits of animals, as well as biogeochemical cycling of nitrogen because ${ }^{15} \mathrm{~N}$ enrichment during trophic transfer integrates a number of biochemical processes accompanying isotopic fractionation during nitrogen metabolism. The nitrogen isotopic composition of organisms provides a unique approach for describing the dietary habits of animals, a macroscale ecological phenomenon. Beyond ecological studies, this approach has been widely applied to biogeochemical studies investigating the fate of nitrogen in oceanographic, terrestrial and freshwater systems (e.g., Cline and Kaplan, 1975; Wada et al., 1975; Wada, 1980; Altabet and Francois, 1994).

These early stable nitrogen isotope studies were based on bulk isotope analysis, which integrates across all nitrogen containing entities in a sample. While certainly informative for many applications, interpretation of bulk $\delta^{15} \mathrm{~N}$ data can be challenging as multiple independent factors including baseline isotope values, trophic transfer, and microbial degradation, all can influence bulk $\delta^{15} \mathrm{~N}$ values. Compound-specific isotopic analysis of amino acids (CSIA-AA) has emerged as a powerful approach in many ecological and biogeochemical applications (e.g., Gaebler et al., 1963, 1966; Macko and Estep, 1984; Macko et al., 1986, 1987), because the differential fractionation of individual amino acids can disentangle the relative influences of baseline and trophic variability on consumer $\delta^{15} \mathrm{~N}$ values. The nitrogen in an organism is predominantly contained in proteins, which are long chains of amino acids (AAs) linked by peptide bonds. Consequently, the CSIA-AA approach is based on the fact that the nitrogen isotopic composition of individual AAs in organic matter reflects isotopic fractionation associated with various biochemical reactions of different individual AA involved in nitrogen metabolism. An organism's $\delta^{15} \mathrm{~N}$ value also inherently reflects the isotopic composition of inorganic nitrogen sources (e.g., nitrate, nitrite, ammonia, and urea) assimilated by primary producers at the base of the food web. With appropriate calibrations, CSIA-AA can therefore provide uniquely specific information about multiple aspects of nitrogen metabolism in organisms and ecosystem properties. CSIA-AA now has a broad range of applications, including the trophic position assessment of a broad range of consumers in aquatic (e.g., McClelland and Montoya, 2002; Chikaraishi et al., 2009; 2014; Hannides et al., 2009, 2013; Bradley et al., 2014; 
al. 2013), the identification of baseline isoscapes (the spatial pattern in isotopic signatures, Bowen,

111 2010) of nitrogen in marine systems, the assessment of the source and transformation of dissolved

112 and detrital organic matter in marine waters and sediments (e.g., Lorrain et al., 2009; McCarthy et al.,

113 2007; Calleja et al., 2013; Hannides et al., 2013; Sherwood et al. 2014; Batista et al., 2014;

114 Vokhshoori et al., 2014), tracing of animal migration (e.g., Dale et al., 2011; Madigan et al., 2014,

115 2016), and the reconstruction of food resource consumption by ancient humans (e.g., Hare et al.,

116 1991; Fogel et al., 1997; Naito et al., 2013a; Styling et al., 2010). While these studies clearly

117 demonstrated the potential of the CSIA-AA approach, they have also opened up many new questions

118 that suggest a wide range of potential future applications, as well as areas that need further research

119 to improve the interpretation of CSIA-AA data. Future work to address these case-specific problems

120 and the associated overarching challenges will push the evolution of this rapidly growing field and

121 improve CSIA-AA applications across a variety of scientific disciplines.

122 This paper reviews the most recent information about CSIA-AA analytical methods and

123 their applications to ecology, biogeochemistry, and related fields. It is an outcome of the workshop

124 "Technical Issues Integrating Advanced Isotope Analyses into Ecological Studies" organized in

125 association with the $10^{\text {th }}$ International Conference on the Applications of Stable Isotope Techniques

126 to Ecological Studies (IsoEcol 10) held in Tokyo in April 2016. At the workshop, investigators with

127 widely different expertise discussed a broad range of issues related to the CSIA-AA methods and

128 reached the conclusion that it is now time to review both the analytical methods, as well as

129 underlying theoretical grounding of CSIA-AA applications, as a guide for future research. The

130 review covers many broad issues, but emphasis is placed on nitrogen isotopic composition of AAs

131 where greatest consensus has been reached. We also discuss how carbon isotopic composition of

132 AAs may also provide unique insights in ecological and biogeochemical studies and can be a

133 complementary approach to nitrogen CSIA-AA. The paper first explores analytical methodologies

134 and related issues (Sections 2 and 3), then follows with applications and case studies in various

135 fields (Section 4), before concluding with remarks addressing future perspectives and directions

136 (Section 5).

137

138

2. Analytical Considerations

139

140

\subsection{Amino acid extraction and separation}

141

AAs in sample material, such as an organism's tissue (e.g., muscle), are extracted by a

142 simple hydrolysis procedure that breaks the peptide bonds of the constituent proteins. The hydrolysis

143 is generally conducted with 6 to $12 \mathrm{M} \mathrm{HCl}$ at $100^{\circ}$ to $150^{\circ} \mathrm{C}$ for $1 \mathrm{~h}$ to 1 day. The AAs are

144 hydrophilic because of their short carbon skeletons and zwitterionic functional groups, including

$145-\mathrm{COOH},-\mathrm{NH}_{2},-\mathrm{SH},-\mathrm{OH}$, and imino groups (-NH-). Hydrophobic molecules produced by acid 
hydrolysis (e.g., lipids) should be eliminated, for example, with organic solvents by liquid/liquid extraction prior to derivatization procedures.

In biological and most geochemical samples, AAs mostly exist as a "bound" form (e.g., protein and peptide), with "free" AAs being a minor fraction. Some biological samples, such as calcareous and siliceous fossils, aggregated microbial samples, soils, sediments, and some biological tissue, contain large amounts of interfering materials. In such samples, solid phase extraction is required before derivatization. Cation-exchange chromatography is an effective method of removing interfering materials from the extracts with sufficient recovery (e.g., Dowex WX-8, 200-400 mesh, Metges and Petzke, 1997; Biorad AG50 W-X8, 200-400 mesh, Hare et al., 1991; Takano et al., 2010). Alternatively, target AAs can be separated by high-performance liquid chromatography (HPLC) equipped with the fraction collector (Broek et al., 2013; Takano et al., 2015; Bour et al., 2016). Significant nitrogen isotopic fractionation or exchange may occur with some types of column resin (Macko et al., 1987; Hare et al., 1991; Styring et al., 2012) and therefore use of such a column resin (e.g., C18) should be avoided unless the isotopic fractionation is carefully evaluated. Finally, for extremely complex geochemical sample matrixes, upstream HPLC isolation before derivatization (Broek et al., 2013) can be required to purify AA sufficiently for accurate CSIA-AA.

\subsection{AA derivatization for precise determination of nitrogen isotopic composition}

AAs require derivatization to reduce polarity and increase their volatility in order to be analyzed by GC/IRMS. The derivatization neutralizes polar carboxyl (-COOH), amino (-NH 2$)$, and hydroxyl (-OH) groups in AAs by replacing active hydrogen atoms with nonpolar moieties, resulting in significant improvement in their chromatographic separation. Esterification of carboxyl groups with an alcohol under acidic conditions and subsequent acylation of the amino group (and simultaneous acetylation of hydroxyl group if AAs have a hydroxyl group) with an acid anhydride or acid chloride, is a common chemical reaction for the derivatization (Fig. 1a). knowledge, the following three derivatization reagents are most widely used in ecological and geochemical studies: trifluoroacyl-isopropyl ester (TFA/AA/iPr, Fig. 1b, e.g., McCarthy et al., 2007; Popp et al., 2007), pivaloyl-isopropyl ester (Pv/AA/iPr, Fig. 1c, e.g., Metges et al., 1996; Chikaraishi et al., 2007), and methoxycarbonyl (MOC) AA ester (Fig. 1d, e.g., Walsh et al., 2014; Yarnes and Herszage, 2017). The first step of the derivatizations to TFA/AA/iPr and $\mathrm{Pv} / \mathrm{AA} / \mathrm{iPr}$ is the same esterification with isopropanol to form the isopropyl esters of AAs. A major advantage of the use of branched alcohol (i.e., isopropanol) is that stable AA esters are obtained. The second step in the

179 TFA/AA/iPr and Pv/AA/iPr derivatizations is acylation with trifluoroacetic acid anhydride (TFAA)

180 or pivaloyl chloride $(\mathrm{Pv}-\mathrm{Cl})$, respectively. Because three atoms of fluorine, which is highly electrophilic, increase the nucleophilicity of the carboxyl carbon of TFAA, acylation with TFAA is 
182

183

184

185

186

187

188

189

190

191

192

193

194

195

196

197

198

199

200

201

202

203

204

205

206

207

208

209

210

211

212

213

214

215

216

217

much faster than that with $\mathrm{Pv}-\mathrm{Cl}$. MOC AA ester requires a rapid one-step derivatization, which allows esterification of the carboxyl group and acylation of the amino group simultaneously at room temperature within $5 \mathrm{~min}$, although the hydroxyl group is not acetylated in this derivatization. The $\mathrm{TFA} / \mathrm{AA} / \mathrm{PPr}$ and Pv/AA/iPr require strict hydrophobic conditions, whereas MOC AA ester works well in both hydrophobic and hydrophilic conditions. Detailed derivatization procedures using each reagent are described in the literature (e.g., Silfer et al., 1991; Sacks and Brenna, 2005; Chikaraishi et al., 2007).

For all derivatizations, great care should be taken with respect to the chemical properties of the reagents and derivatives. First, because the ester groups in these derivatives are exchangeable with water, no alcohols or other ester compounds, including many polar solvents, can be used. For example, ethyl acetate, a convenient polar organic solvent, can exchange the isopropyl or methyl ester group in the AA derivatives with its ethyl ester group (Fig. 2a). In general, suitable solvents for the derivatives include ethers (e.g., diethyl ether and tetrahydrofuran, although these solvents are highly flammable) or chlorinated methanes (e.g., dichloromethane and chloroform, although these solvents are toxic). Second, most derivative reagents should be used in strict accordance with exposure controls. In particular, $\mathrm{Pv}-\mathrm{Cl}$ is acutely toxic. Third, because esterified AAs are unstable in $\mathrm{O}_{2}$ and water, even at $0^{\circ} \mathrm{C}$, the derivatives must be stored at $-20^{\circ} \mathrm{C}$ or lower (without $\mathrm{O}_{2}$ and water, if possible) until isotope analysis. Although TFA/AA/iPr and Pv/AA/iPr esters (i.e., branched alcohol esters) are relatively stable at low temperature (Fig. S1), they only survive for a few days to weeks at room temperature. Finally, these derivatizations are not equally applicable to the isotopic measurements of all 20 protein AAs. Arg, Asn, Cys, His, and Trp cannot be measured as $\mathrm{TFA} / \mathrm{AA} / \mathrm{iPr}$ and $\mathrm{Pv} / \mathrm{AA} / \mathrm{PPr}$ derivatives because of degradation (including conversion to other compounds) or less-quantitative reaction during derivatization. Although MOC AA esters can be useful for the isotope measurement of most of these AAs (Asn, Cys, His, and Trp, except for Arg), this derivatization is not appropriate for determining the isotope values of Glu, because two types of Glu derivatives are produced with distinct isotopic compositions (Fig. S2).

\subsection{Nitrogen isotopic measurements of AAs}

In GC/IRMS, the nitrogen isotopic compositions of AAs are determined by analyzing the ${ }^{15} \mathrm{~N}:{ }^{14} \mathrm{~N}$ ratios of $\mathrm{N}_{2}$ molecules generated by combustion-reduction of the derivatives. The instrument consists of a conventional gas chromatograph (GC) connected to a chemical reaction interface including combustion and reduction furnaces (Merritt and Hayes, 1994). Individual AA derivatives are separately eluted by $\mathrm{GC}$, and combusted mainly into $\mathrm{N}_{2}, \mathrm{NO}_{\mathrm{x}}, \mathrm{CO}_{2}$, and $\mathrm{H}_{2} \mathrm{O}$ ) in a combustion furnace with $\mathrm{CuO}$ and $\mathrm{NiO}$ with $\mathrm{Pt}$ at $950^{\circ}-1050^{\circ} \mathrm{C}$. The $\mathrm{NO}_{\mathrm{x}}$ generated by the combustion is subsequently reduced to $\mathrm{N}_{2}$ in a reduction furnace with $\mathrm{Cu}$ at $550^{\circ}-650^{\circ} \mathrm{C}$, and the $\mathrm{H}_{2} \mathrm{O}$ and $\mathrm{CO}_{2}$ generated during the combustion are eliminated using a liquid nitrogen trap. A countercurrent drier 
can be used for $\mathrm{H}_{2} \mathrm{O}$ elimination prior to the liquid nitrogen trap in some cases. To avoid isotopic

219 fractionation, a nucleophilic stationary phase (e.g., HP-5: phenyl-methyl polysiloxane;

220 HP-INNOWAX: polyethylene glycols) is required for the GC separation of AA derivatives

221 (Chikaraishi et al., 2010).

222

223

224

225

226

227

228

229

230

231

232

233

234

235

236

237

238

239

240

241

242

243

244

245

246

247

248

249

250

251

252

253

The nitrogen isotopic composition of AAs is expressed in the standard $\delta$ notation relative to atmospheric $\mathrm{N}_{2}\left(\delta^{15} \mathrm{~N}, \%\right.$ v $v$. AIR), which is calibrated to the internationally recognized scale through comparison of the $\delta^{15} \mathrm{~N}$ values of multiple reference AAs. In a typical sequence, derivatives of reference mixtures of 5-14 AAs with known $\delta^{15} \mathrm{~N}$ values, which should cover the $\delta^{15} \mathrm{~N}$ range of the samples, are analyzed every 4-8 sample runs. At the beginning and end of each chromatography run, 2-3 pulses of reference $\mathrm{N}_{2}$ gas are discharged for all reference mixtures and samples (Fig. 3). The regression line between the known (\%o, vs. AIR) and mean measured values (\%o, vs. reference $\mathrm{N}_{2}$ gas) represents the reproducibility of the isotope measurement (Fig. S3) and can be used to normalize the measured values (\%o, vs. reference $\mathrm{N}_{2}$ gas) to the internationally recognized scale (\%o, $v s$. AIR) for both the reference mixtures and samples. In some laboratories norleucine and aminoadipic acid with known $\delta^{15} \mathrm{~N}$ values are co-injected with each sample and additional internal reference compounds that can be used for normalization (e.g., Hannides et al., 2009; McCarthy et al., 2013). The average and standard deviation for the normalized values $(1 \sigma)$ and the difference in the normalized and known values $\left(\Delta_{\text {normalized-known }}\right)$ for the reference AAs are frequently used as evidence of the precision and accuracy of the isotope measurement. Detection limits to achieve this level of precision and accuracy depend on various factors, but they are highly correlated with the signal/noise ratio of the GC/IRMS chromatogram (Fig. S4, Chan et al., 2016).

Baseline separation between the AA peaks on the GC/IRMS chromatogram is required to obtain accurate $\delta^{15} \mathrm{~N}$ values of the AAs. When an AA peak is co-eluted with other AAs or impurities, the isotopically heavy tail of the first peak underlies the isotopically light front of the second peak (Hayes et al., 1990). For example, in case of Pv/AA/iPr derivatives, Glu and Phe generally show good baseline separation, whereas Asp, Thr, Ser, and Met on the same chromatogram are sequentially eluted without baseline separation (Fig. 3).

We should note that, in addition to the analysis by GC/IRMS, off-line process (Broek et al., 2013) and HPLC-IRMS coupling may be useful in the future to determine nitrogen isotope ratios of AAs (Federherr et al., 2016).

\section{Methodological considerations for trophic position assessment}

\subsection{Bulk versus CSIA-AA approach}

As noted above, stable nitrogen isotope analysis of bulk organisms and their tissues has been used extensively for conventional estimation of the trophic positions of organisms in food 
webs (e.g., Post, 2002; Fry 2006; Ohkouchi et al., 2015). The trophic position ( $T P_{\text {bulk }}$ ) is generally organisms tends to increase with each trophic transfer in food webs (e.g., DeNiro and Epstein, 1981; Minagawa and Wada, 1984).

258

where $\delta^{15} \mathrm{~N}_{\text {sample }}$ and $\delta^{15} \mathrm{~N}_{\mathrm{pp}}$ are the $\delta^{15} \mathrm{~N}$ values of a target organism and the primary producers at the base of the food web, respectively. $T D F_{\text {bulk }}$ is the trophic discrimination factor of $\delta^{15} \mathrm{~N}_{\text {bulk }}$ between prey and predator (DeNiro and Epstein, 1981; Minagawa and Wada, 1984). Many studies use a canonical $T D F_{\text {bulk }}$ value of 3-4\%, however, a variety of $T D F_{\text {bulk }}$ values are frequently used in studies focusing on specific tissues, such as collagen, or specific localized environments (e.g., Vander Zanden and Rasmussen, 2001; McCutchan et al., 2003; Martinez del Rio et al., 2009). The 'bulk method' has been successfully applied to various ecological studies and has thus helped expand our knowledge of feeding ecology greatly over the last four decades (Fry, 2006). However, the method suffers from several problems that can cause large uncertainty in the estimated $T P_{\text {bulk }}$ values. The most important problem is that the $\delta^{15} \mathrm{~N}$ values of bulk tissues intrinsically reflect i) the trophic changes in the $\delta^{15} \mathrm{~N}$ value in the food web and ii) temporal or spatial changes in the $\delta^{15} \mathrm{~N}$ value at the base of the food web (Fig. 4a). The former ( $3-4 \%$ ) is often much smaller than the latter (in some cases >10\%) (e.g., Hannides et al., 2009; Rolff, 2000; Dore et al., 2002; O’Reilly et al., 2002). In contrast, trophic position ( $\left.T P_{\mathrm{TAA} / \mathrm{SAA}}\right)$ estimated from CSIA-AA using equation 2 can constrain both trophic changes in the $\delta^{15} \mathrm{~N}$ value and baseline variation within a single organism (e.g., McClelland and Montoya, 2002; Chikaraishi et al., 2007; McCarthy et al., 2007; Popp et al., 2007).

$T P_{\mathrm{TAA} / \mathrm{SAA}}=\left[\left(\delta^{15} \mathrm{~N}_{\mathrm{TAA}}-\delta^{15} \mathrm{~N}_{\mathrm{SAA}}+\beta_{\mathrm{TAA} / \mathrm{SAA}}\right) / \Delta_{\mathrm{TAA} / \mathrm{SAA}}\right]+1$ single organism; $\beta_{\mathrm{TAA} / \mathrm{SAA}}$ is the isotopic difference between these AAs in primary producers at the base of the food web; and $\triangle_{\mathrm{TAA} / \mathrm{SAA}}$ is the difference in the $T D F$ of the TAAs and SAAs during each trophic transfer $\left(\Delta_{\mathrm{TAA} / \mathrm{SAA}}=T D F_{\mathrm{TAA}}-T D F_{\mathrm{SAA}}\right)$. Trophic amino acids (TAAs) (e.g., Ala, Asp, Glu, Ile, Leu, Pro, and Val) tend to show large ${ }^{15} \mathrm{~N}$ enrichment (by $\sim 3-8 \%$ ) relative to diet during trophic transfer, which likely reflects isotopic fractionation associated with deamination (a first step in transamination, Macko et al., 1986; Miura and Goto, 2012) as a dominant metabolic pathway for these AAs in consumers (Fig. 5a). Source amino acids (SAAs) (e.g., Met, Lys, and Phe) show little 
290

291

292

293

294

295

296

297

298

299

300

301

302

303

304

305

306

307

308

309

310

311

312

313

314

315

316

317

318

319

320

321

322

323

324

325

the initial steps in their metabolism are generally dominated by reactions that neither form nor cleave C-N bonds (Fig. 5a) and thus directly provide an estimate of the $\delta^{15} \mathrm{~N}_{\mathrm{SAA}}$ value of the base of the food web. Therefore, CSIA-AA derived TP values are independent of temporal or spatial changes in the $\delta^{15} N$ value at the base of the food web (Fig. 4b).

Chikaraishi et al. $(2009,2010)$ first suggested the utility of Glu and Phe as a TAA and a SAA, respectively, with $\beta_{\text {Glu/Phe }}$ values of $-3.4 \%$ for aquatic and $+8.4 \%$ for terrestrial C3 plant-based food webs, and with $\Delta_{\text {Glu/Phe }}$ values of $7.6 \%$ for both ecosystems. Later, it was found that the $\beta$ value in vascular plants is increased by the deamination of Phe for lignin biosynthesis, a process specific to vascular plants (Fig. 5b; Ohkouchi and Takano, 2014; Naito et al., 2016a). Therefore, algal $v s$. vascular grouping is a better classification than aquatic $v s$. terrestrial (Chikaraishi et al., 2009, 2010). Indeed, the observed $\beta$ values in seagrasses (vascular plants from coastal marine environments) are similar to those of terrestrial vascular plants (e.g., Vander Zanden et al., 2013; Choi et al., 2017). However, for simplified nomenclature we use the terms aquatic and terrestrial throughout this paper.

$$
\begin{aligned}
& {\left[T P_{\mathrm{Glu} / \mathrm{Ph}}\right]_{\mathrm{aqua}}=\left[\left(\delta^{15} \mathrm{~N}_{\mathrm{Glu}}-\delta^{15} \mathrm{~N}_{\mathrm{Phe}}-3.4\right) / 7.6\right]+1} \\
& {\left[T P_{\mathrm{Glu} / \mathrm{Phe}}\right]_{\mathrm{terr}}=\left[\left(\delta^{15} \mathrm{~N}_{\mathrm{Glu}}-\delta^{15} \mathrm{~N}_{\mathrm{Phe}}+8.4\right) / 7.6\right]+1}
\end{aligned}
$$

Because of the large differences in $\beta_{\mathrm{TAA} / \mathrm{SAA}}$ values between aquatic and terrestrial producers, mixing models must be constructed so as to consider two potential food webs where both aquatic and terrestrial primary producers may serve as basal food resources. These environments include rivers (Ishikawa et al., 2014) and coastal marine ecosystems (Vander Zanden et al., 2013; Choi et al., 2017). In this paper, and many others, there has been a focus on glutamic acid and phenylalanine as the canonical trophic and source amino acids, However, in principle, any combination of trophic and source amino acids can be used in equation 2 (e.g., Decima et al., 2013; Nielsen et al., 2015; Bradley et al., 2015) as long as $\beta_{\mathrm{TAA} / \mathrm{SAA}}$ and $\Delta_{\mathrm{TAA} / \mathrm{SAA}}$ values appropriate for the combination of trophic and source amino acids are used.

\subsection{Uncertainties and errors in the $T P$ assessment}

3.2.1. Variability in trophic discrimination factors

Constant $\Delta_{\mathrm{Glu} / \mathrm{Phe}}\left(=T D F_{\mathrm{Glu}}-T D F_{\mathrm{Phe}}\right)$ or $\Delta_{\mathrm{TAA} / \mathrm{SAA}}$ values throughout the food web is prerequisite for estimating $T P$ precisely. However, the stability of $\Delta_{\mathrm{Glu} / \mathrm{Phe}}$ has recently come under increasing scrutiny based on new laboratory and field studies (e.g., Dale et al., 2011; Matthews and Ferguson, 2014; Chikaraishi et al., 2015; McMahon et al., 2015a). Comprehensive meta-analyses of CSIA-AA from wild animals with known TP values (Nielsen et al., 2015; Bradley et al., 2015) 
and controlled feeding experiments (McMahon and McCarthy, 2016) that examine individual $T D F_{\mathrm{AA}}$ values have addressed the following primary questions: i) what are the magnitude and variability in $\Delta_{\mathrm{TAA} / \mathrm{SAA}}$ values across a wide range of consumer-resource relationships, and ii) are there systematic underlying mechanisms driving this variability in predictable ways that could be used to improve CSIA-AA-based estimates of consumer trophic dynamics.

These meta-analyses found large variability in $\Delta_{\mathrm{TAA} / \mathrm{SAA}}$ values. For example, McMahon and McCarthy (2016) found the overall mean $\Delta_{\mathrm{Glu} / \text { Phe }}$ value was $6.2 \pm 2.5 \%$ across a wide range of taxa, diet types, and modes of nitrogen excretion, consistent with other recent large scale analyses of field-collected data for wild-caught marine consumers (6.6 $\pm 1.7 \%$; Nielsen et al., 2015; $5.7 \pm$ $0.3 \%$; Bradley et al. 2015). However, within this distribution there were also some very significant excursions, with $\Delta_{\text {Glu/Phe }}$ values from 0 to $>10 \%$ across 70 species ( 317 individuals) and 88 distinct species-diet combinations. Some of the reported $\Delta_{\mathrm{Gl} / \mathrm{Phe}}$ values, particularly for animals with $T P$ values of less than 3 , were within a small range ( 6 to $8 \%$ ) that overlapped with the original $\Delta_{\mathrm{Glu} / \text { Phe }}$ values of 7.0\% (McClelland and Montoya, 2002) and 7.6\% (Chikaraishi et al., 2007). However, simply focusing on the mean can inherently obscure large variation underlying that mean. The meta-analysis of controlled feeding studies by McMahon and McCarthy (2016) is also consistent with large scale studies of wild consumers by Nielsen et al. (2015) and Bradley et al. (2015), which together strongly suggest that the observed variability in $\Delta_{\mathrm{Glu} / \mathrm{Phe}}$ and $\Delta_{\mathrm{TAA} / \mathrm{SAA}}$ values is not simply noise, but rather is predictably linked to consumer biochemistry. Below, we discuss two possible underlying biochemical and physiological processes that influence $\Delta_{\mathrm{TAA} / \mathrm{SAA}}$ : diet quality and metabolic flux (e.g., mode of nitrogen excretion).

Diet quality: In the aquatic environment, there is a trend between $T P$ and $\Delta_{\mathrm{Glu} / \mathrm{Phe}}$ across a wide range of (although not all) consumers (Bradley et al., 2015; Nielsen et al. 2015; McMahon and McCarthy, 2016). However, this trend was not observed in insects kept in ecologically realistic pure cultures, representing three distinct communities from the terrestrial environment (Steffan et al., 2013). Further, low variability in the $T D F$ was observed among 15 consumer species, representing a phylogenetically diverse group of consumers, from freshwater crustaceans and fish, to terrestrial mammals, fungi, and bacteria (Steffan et al., 2015) Most primary consumers examined in the marine environment (e.g., grazing teleost fishes, zooplankton, etc.) had $\Delta_{\mathrm{Glu} / \mathrm{Phe}}$ values between $6 \%$ and $8 \%$, often not substantially different from the value of $\sim 7-8 \%$ originally reported by McClelland and Montoya (2002), and substantiated by Chikaraishi et al. (2007). In contrast, most marine consumers with $T P$ higher than 3 showed lower $\Delta_{\text {Glu/Phe }}$ values (Bradley et al., 2015; Nielsen et al. 2015; McMahon and McCarthy, 2016). One hypothesis for the pattern of decreasing $\Delta_{\text {Glu/Phe }}$ value with increasing $T P$ is the effect of diet quality (defined here as the relative AA composition of a food source relative to the needs of a consumer) on consumer $\delta^{15} \mathrm{~N}_{\mathrm{AA}}$ values, 
and thus on $\Delta_{\mathrm{Glu} / \mathrm{Phe}}$ values.

The diet quality hypothesis suggests that nitrogen isotope discrimination decreases as dietary protein quality (degree of AA similarity between diet and consumer) increases (Hobson and Clark, 1992; Roth and Hobson, 2000; Robbins et al., 2005, 2010; Mill et al., 2007; Florin et al., 2011). McMahon et al. (2015a) showed that diet quality had a large and systematic effect on the isotopic fractionation of individual AAs in an estuarine fish (Fundulus heteroclitus) fed compositionally distinct diets. This study found a strong relationship between the TDF value of most TAAs and protein quality between diet and consumer, and no change in $T D F_{\text {Phe }}$ across diet types. Furthermore, Chikaraishi et al. (2015) recently showed that with extreme manipulation of dietary composition (i.e., the relative composition of protein/fat/carbohydrates), vastly different $\Delta_{\text {Glu/Phe }}$ values can be obtained in a single consumer. However, these two studies found opposite trends in the $\Delta_{\mathrm{Glu} / \mathrm{Phe}} v s$. diet quality relationship, defined as relative AA composition of a food source relative to the needs of a consumer. McMahon et al. (2015a), showed that as the diet AA composition converged on that of the consumers, the $\Delta_{\mathrm{Glu} / \mathrm{Phe}}$ values tended to decrease. In contrast, Chikaraishi et al. (2015) indicated that the $\Delta_{\text {Glu/Phe }}$ values decreased as diet quality declined. While both of these studies indicate that diet composition strongly affects individual AA isotopic fractionation, more work is necessary to resolve the full relationship between diet quality and $\Delta_{\mathrm{Glu} / \mathrm{Phe}}$ value.

The reason why $\Delta_{\mathrm{Glu} / \mathrm{Phe}}$ often varies with $T P$ might reflect differences in diet quality across different consumer-resource relationships within a food web. Generally, lower TP consumers often feed on diets that are more compositionally distinct relative to their own tissues (e.g., zooplankton feeding on phytoplankton) than higher $T P$ consumers (e.g., fish feeding on other fish). When feeding on low-quality diets, defined as having highly imbalanced AA composition compared with consumer requirements, the consumer synthesizes scarce AAs de novo from surplus AAs. Because TAAs enriched in ${ }^{15} \mathrm{~N}$ relative to SAAs tend to be abundant in the organisms, synthesis leads to the apparent increase in $\delta^{15} \mathrm{~N}_{\mathrm{AA}}$ (Krueger and Sullivan, 1984; Roth and Hobson, 2000; Clements et al., 2009). Conversely, carnivores feeding on high-quality diets can meet more of their AA requirements via direct isotopic routing of dietary AAs, which should reduce ${ }^{15} \mathrm{~N}$ enrichment of heavily transaminating AAs (e.g., Glu) compared with consumers feeding on low-quality diets (Schwarcz, 1991; Ambrose and Norr, 1993). It should be noted that Ishikawa et al. (2017) recently showed that satiated and starved dobsonfly (Protohermes grandis) larvae had similar $\Delta_{\mathrm{Glu} / \mathrm{Phe}}$ values (7.1\%o and $7.3 \%$, respectively), suggesting that the $\Delta_{\mathrm{Glu} / \mathrm{Phe}}$ value was independent from starvation.

Mode of nitrogen excretion: There is also a clear pattern of lower $\Delta_{\mathrm{Glu} / \mathrm{Phe}}$ values for some urea/uric acid-producing organisms relative to ammonia-producing organisms, largely driven by differences 
398

399

400

401

402

403

404

405

406

407

408

409

410

411

412

413

414

415

416

417

418

419

420

421

422

423

424

425

426

427

428

429

430

431

432

433

in $T D F_{\text {Glu }}$ but not $T D F_{\text {Phe }}$ (Dale et al., 2011; Germain et al., 2013; Nielsen et al., 2015; McMahon and McCarthy, 2016). The typically low $\Delta_{\mathrm{Glu} / \mathrm{Phe}}$ values for urea/uric acid producers may be explained by the nitrogen storage and cycling capabilities of animals (Wilkie, 2002), or by the way urea is produced in the liver (Dale et al., 2011). Key nitrogen-transferring enzymes preferentially remove ${ }^{14} \mathrm{~N}$-amines during metabolism, resulting in the subsequent ${ }^{15} \mathrm{~N}$ enrichment of residual animal tissue and the excretion of ${ }^{15} \mathrm{~N}$-depleted nitrogenous waste (DeNiro and Epstein, 1981). The final isotope value of a biochemical reaction depends not only on the number of steps and associated $\varepsilon$ values (i.e., the maximal potential isotopic fractionation), but also on the relative nitrogen fluxes through branch points in the reaction chain (e.g., reviewed by Hayes et al., 2001; Koch et al., 2007). Germain et al. (2013) proposed that this concept of variable nitrogen flux through additional branch points in the ornithine-to-urea pathway probably underlies the offset in $\Delta_{\mathrm{Glu} / \mathrm{Phe}}$ values for urea $v s$. ammonia-excreting organisms. In elasmobranchs, which have reduced hepatic glutamate catabolism relative to ureotelic organisms, a lower $\varepsilon$ value may be related to their unique glutamate-glutamine-urea pathway (Dale et al., 2011). In addition, the recycling of ${ }^{15} \mathrm{~N}$-depleted urea by gut microbes for subsequent AA synthesis is another possible explanation for low $\Delta_{\text {Glu/Phe }}$ values in urea/uric acid-producing consumers (Davidson et al., 2003; Fouillet et al., 2008).

Summary: Independent meta-analyses of controlled feeding studies (McMahon and McCarthy, 2016) and wild consumers (Bradley et al. 2015; Nielsen et al. (2015) have shown that both diet quality and metabolic flux (e.g., mode of nitrogen excretion) affect $\Delta_{\mathrm{Glu} / \text { Phe }}$ values considerably. These processes are not mutually exclusive, and both appear to impact $T D F_{\mathrm{Glu}}$ by affecting the flux of nitrogen through transamination and deamination isotopic branch points. There are many systems that appear to be well characterized by a single $\Delta_{\mathrm{Glu} / \mathrm{Phe}}$ value, where there are minimal changes in diet quality and/or mode of nitrogen excretion within a food web (e.g., Chikaraishi et al., 2009, 2011; Ishikawa et al., 2014; Kruse et al., 2015; Miyachi et al., 2015). However, the accuracy of $T P_{\mathrm{Glu} / \mathrm{Phe}}$ estimates may be improved by directly incorporating $\Delta_{\mathrm{Glu} / \mathrm{Phe}}$ variability into $T P_{\mathrm{Glu} / \mathrm{Phe}}$ estimates in systems where such changes do occur (e.g., Lorrain et al., 2009; Dale et al., 2011; Choy et al., 2012; Germain et al., 2013; Ruiz-Cooley et al., 2013, 2014; Matthews and Ferguson, 2014; McMahon et al., 2015b). This probably requires moving toward multi- $\Delta$ equations (e.g., Hoen et al., 2014), potentially averaging across multiple AAs (e.g., Decima et al., 2013; Nielsen et al., 2015; Bradley et al., 2014), although averaging across multiple AAs has been shown to profoundly increase variability surrounding the TDF in terrestrial and freshwater systems (e.g., Table 1 in Steffan et al., 2015). While accounting for key transitions in diet quality and mode of nitrogen excretion with multi- $\Delta$ equations improves $T P$ estimates in many cases (e.g., McMahon et al., 2015a,b), diet quality and metabolic flux are likely not the only drivers of variability in 
434

435

436

437

438

439

440

441

442

443

444

445

446

447

448

449

450

451

452

453

454

455

456

457

458

459

460

461

462

463

464

465

466

467

468

469

$\Delta_{\text {TAA/SAA }}$ values. Continued exploration of the underlying mechanisms controlling AA $\delta^{15} \mathrm{~N}$ fractionation is critical to improve our ability to accurately estimate consumer $T P$ with the CSIA-AA approach.

\subsubsection{Propagation of error calculations for trophic position determination}

For both ecological and geochemical / paleoceanographic applications, interpreting CSIA-AA based $T P$ data requires a rigorous estimation of uncertainty in values being compared. However, uncertainty in $T P$ based on nitrogen isotopic composition of AAs is more complex than standard uncertainties in measured isotopic values, because it must take into account analytical uncertainty in source and trophic AA isotopic measurements, as well as environmental uncertainty in $\beta$ and $\Delta$ values. The combination of these uncertainties can be calculated using propagation of errors. The variability in the parameters used for $T P$ determination can be modeled using Monte Carlo simulations, however it is also straightforward to propagate errors using a first-order Taylor series expansion (Ku, 1966), resulting in a formula easily solved in a spreadsheet or programmed into an algorithmic language (e.g., Matlab, R).

In general, for any result $w$ that is a function of two or more experimentally determined independent variables, variance in $w$ can be calculated by Taylor series expansion if the variance in the variables is known (e.g., Gelwicks and Hayes, 1990; Phillips and Gregg, 2001). In the case where $w=f(x, y, z)$, variance in $w$ can be determined using the analytical solution of

$$
\sigma_{w}^{2}=(\partial w / \partial x)^{2} \sigma_{x}^{2}+(\partial w / \partial y)^{2} \sigma_{y}^{2}+(\partial w / \partial z)^{2} \sigma_{z}^{2}
$$

The measured values of $\delta^{15} \mathrm{~N}_{\mathrm{TAA}}$ and $\delta^{15} \mathrm{~N}_{\mathrm{SAA}}$ have inherent analytical uncertainty and there is uncertainty in the values of $\beta$ and $\Delta$ compiled in the literature. If we assume a general formulation of the equation used for calculation of $T P$ as equation 2, uncertainty in $T P$ can be determined by propagation of errors (e.g., Blum et al., 2013; Bradley et al., 2015) using the analytical solution of

$$
\begin{aligned}
\left.\left.\sigma_{T P}^{2}=\left(\partial T P / \partial \delta^{15} \mathrm{~N}_{\mathrm{TAA}}\right)^{2} \sigma_{\delta 15 \mathrm{~N}(\mathrm{TAA})}\right)^{2}+\left(\partial T P / \partial \delta^{15} \mathrm{~N}_{\mathrm{SAA}}\right)^{2} \sigma_{\delta 15 \mathrm{~N}(\mathrm{SAA})}\right)^{2} \\
\left.+\left(\partial T P / \partial \beta_{\mathrm{TAA} / \mathrm{SAA}}\right)^{2} \sigma_{\beta(\mathrm{TAA} / \mathrm{SAA})}\right)^{2}+\left(\partial T P / \partial \Delta_{\mathrm{TAA} / \mathrm{SAA}}\right)^{2} \sigma_{\Delta(\mathrm{TAA} / \mathrm{SAA})^{2}}
\end{aligned}
$$

The exact solution to equation 6 has been published elsewhere (Bradley et al., 2015) and an equation for calculating the propagated variance in $T P$ is summarized in equation 7.

$$
\begin{aligned}
& \sigma_{T P}{ }^{2}=\left(1 / \Delta_{\mathrm{TAA} / \mathrm{SAA}}\right)^{2}\left.\left.\left.\sigma_{\delta 15 \mathrm{~N}(\mathrm{TAA})}\right)^{2}+\left(-1 / \Delta_{\mathrm{TAA} / \mathrm{SAA}}\right)^{2} \sigma_{\delta 15 \mathrm{~N}(\mathrm{SAA})}\right)^{2}+\left(1 / \Delta_{\mathrm{TAA} / \mathrm{SAA}}\right)^{2} \sigma_{\beta(\mathrm{TAA} / \mathrm{SAA})}\right)^{2} \\
&+\left\{-1 / \Delta_{\mathrm{TAA} / \mathrm{SAA}}{ }^{2}\left(\delta^{15} \mathrm{~N}_{\mathrm{TAA}}-\delta^{15} \mathrm{~N}_{\mathrm{SAA}}+\beta\right)\right\}^{2} \sigma_{\Delta(\mathrm{TAA} / \mathrm{SAA})}
\end{aligned}
$$


The analytical uncertainty in isotopic measurements of trophic and source AAs in samples must be determined. Because the AA distribution in samples is more complex than that of artificial mixtures of AAs, we suggest replicate analysis of each sample following the recommendations of Hayes et al. (1990).

It has been suggested (Hoen et al., 2014) that the $T P$ of a carnivore might best be determined using separate $\Delta$-values for herbivores and carnivores:

477

$T P=\left\{\left(\delta^{15} \mathrm{~N}_{\mathrm{TAA}}-\delta^{15} \mathrm{~N}_{\mathrm{SAA}}+\beta_{\mathrm{TAA} / \mathrm{SAA}}-\Delta_{\text {herbivore }}\right) / \Delta_{\text {carnivore }}\right\}+2$

479

where $\Delta_{\text {herbivore }}$ is the ${ }^{15} \mathrm{~N}$ enrichment in a TAAs relative to a SAA of a grazing herbivore and 481 $\Delta_{\text {carnivore }}$ is the ${ }^{15} \mathrm{~N}$ enrichment in a TAAs relative to a SAA associated with each trophic transfer 482 for an omnivore or carnivore (Hoen et al., 2014). An expression for the variance in TP based on two different $\Delta$ values is

484

$\left.\left.\sigma_{T P}^{2}=\left(1 / \Delta_{\text {carnivore }}\right)^{2} \sigma_{\delta 15 \mathrm{~N}(\mathrm{TAA})^{2}}+\left(-1 / \Delta_{\text {carnivore }}\right)^{2} \sigma_{\delta 15 \mathrm{~N}(\mathrm{SAA})}\right)^{2}+\left(1 / \Delta_{\text {carnivore }}\right)^{2} \sigma_{\beta(\mathrm{TAA} / \mathrm{SAA})}\right)^{2}$ nitrogen isotopic composition of AAs if the fraction of one of the binary components is independently determined (e.g., Jarman et al., 2017):

492

$T P=\left\{\left(\delta^{15} \mathrm{~N}_{\mathrm{TAA}}-\delta^{15} \mathrm{~N}_{\mathrm{SAA}}+f_{1} \beta_{1}+\left(1-f_{1}\right) \beta_{2}\right) / \Delta_{\mathrm{TAA} / \mathrm{SAA}}\right\}+1$ measured in the sample, and $f_{1}$ is the fractional contribution of one of those plant types. The propagated variance in $T P$ when there is a binary mixture of feeding is given by

498

$$
\begin{aligned}
\sigma_{T P}^{2}= & \left(1 / \Delta_{\mathrm{TAA} / \mathrm{SAA}}\right)^{2} \sigma_{\delta 15 \mathrm{~N}(\mathrm{TAA})}{ }^{2}+\left(-1 / \Delta_{\mathrm{TAA} / \mathrm{SAA}}\right)^{2} \sigma_{\delta 15 \mathrm{~N}(\mathrm{SAA})}{ }^{2}+\left\{\left(\beta_{1}-\beta_{2}\right) / \Delta_{\mathrm{TAA} / \mathrm{SAA}}\right\}^{2} \sigma_{f 1}{ }^{2} \\
& +\left\{\left(1-f_{1}\right) / \Delta_{\mathrm{TAA} / \mathrm{SAA}}\right\}^{2} \sigma_{\beta 2}{ }^{2}+\left(f_{1} / \Delta_{\mathrm{TAA} / \mathrm{SAA}}\right)^{2} \sigma_{\beta 1}{ }^{2} \\
& +\left\{-1 / \Delta_{\mathrm{TAA} / \mathrm{SAA}}{ }^{2}\left(\delta^{15} \mathrm{~N}_{\mathrm{TAA}}-\delta^{15} \mathrm{~N}_{\mathrm{SAA}}+\left(1-f_{1}\right) \beta_{2}+f_{1} \beta_{1}\right)\right\}^{2} \sigma_{\Delta(\mathrm{TAA} / \mathrm{SAA})}{ }^{2}
\end{aligned}
$$




\section{Applications of the CSIA-AA approach to ecological and biogeochemical studies}

\subsection{Food web analyses in aquatic ecosystems}

Several recent studies have used $\delta^{15} \mathrm{~N}_{\mathrm{SAA}}$ variation to understand the baseline of food webs in the North Pacific Subtropical Gyre ecosystem. Hannides et al. (2013) used differences in $\delta^{15} \mathrm{~N}_{\mathrm{SAA}}$ between zooplankton and suspended particles to demonstrate that deep water zooplankton in the subtropical gyre probably depend on surface rather than in situ particulate food, either

514 through sinking of surface particles or vertical migrations. Choy et al. (2015) further showed that surface productivity also fuels higher-order consumers in the North Pacific Subtropical Gyre food web. A large range of $\delta^{15} \mathrm{~N}_{\text {Phe }}$ values in the tissues of both large and small pelagic micronekton suggested that some components of the food web instead are fueled by slowly settling particles that are highly modified by microbes. In contrast, there was no relationship between depth and $\delta^{15} \mathrm{~N}_{\mathrm{SAA}}$ for large predatory fish (Choy et al., 2015), demonstrating how CSIA-AA may also be used to infer species movement and foraging across large depth gradients in oceanic ecosystems, and thus the dependence on a range of nutrient sources.

The $T P$ of consumers can be estimated based only on consumer tissue $\delta^{15} \mathrm{~N}_{\mathrm{AA}}$ (dashed trophoclines in Fig. 6), with food chain length inferred from the TP of apex predators. Chikaraishi et al. (2014) used these trophoclines to describe the food web of a coastal rocky shoreline community in Japan. Based on 39 species $(n=100)$ covering macroalgae, gastropods, echinoderms, bivalves, crustaceans, fish, and a cephalopod to document the food web structure, the study documented a food web covering 4.5 trophic levels (Fig. 7a). Probably supported by macroalgae at $T P 1$, the top predator in the system was the Kidako moray eel (Gymnothorax kidako) with an average $T P$ of 4.6. Despite a large variation in baseline $\delta^{15} \mathrm{~N}$ values, demonstrated by $\delta^{15} \mathrm{~N}_{\text {Phe }}$ values varying between $3.5 \%$ and $8.7 \%$, all algal samples had $T P$ close to 1 with known herbivores all close to $T P 2$, demonstrating the importance in knowing the baseline $\delta^{15} \mathrm{~N}$ value across appropriate time and space scales. In Lake Baikal, Ohkouchi et al. (2015) reported analytical results for seven species $(n=53)$ covering diatoms, amphipods, sculpins, and seals (Fig. $7 \mathrm{~b}$ ). The $T P$ of seals, a top predator in the lake, was as high as 5.1, suggesting that the trophic length of the lake was one unit longer than that calculated based on the $\delta^{15} \mathrm{~N}_{\text {bulk }}$ record. Furthermore, the potential for baseline variation to confound analysis of spatial changes in $T P$ based on bulk $\delta^{15} \mathrm{~N}$ values has recently been highlighted by a study on Lake Superior food webs by Kruger et al. (2016). $T P_{\text {bulk }}$ suggested that the top predator (lake trout) spatially varied by up to $T P$ of 1; however, the $\delta^{15} \mathrm{~N}_{\mathrm{AA}}$ values confirmed a common $T P$ and the likelihood that baseline $\delta^{15} \mathrm{~N}$ variation confounded $T P_{\text {bulk }}$ estimates. A recent study by Papastamatiou et al. (2015) is one of the few to demonstrate variation in bulk isotopic composition due to trophic differences rather than 

trophic flexibility in giant trevally from deep water reefs on a Pacific atoll. Individuals showed variability in their diel migration and feeding behavior that was mirrored in the wide range of $T P$ determined by CSIA-AA (TP 3.5 to 4.6).

In addition to demonstrating the utility of the $\delta^{15} \mathrm{~N}_{\mathrm{AA}}$ approach, these studies highlight the potential variability in food webs, such that higher-order consumers do not occupy a single $T P$. Indeed, the capacity for intraspecific variation in $T P$ has long been known based on theory and empirical work (Polis, 1991; Polis and Strong, 1996). Conceptual examples of trophic omnivory associated with ontogeny are provided in Fig. 6 . Adults and juveniles of an anchovy prey species are shown with varying $T P$ of around 2, whereas the increase in the size classes of an apex consumer (tuna) leads to increased $T P$, likely reaching a $T P$ close to 4.5-5.0 at their maximum size (Choy et al., 2015; Estrada et al., 2005). The degree of trophic omnivory within a food web could be quantified based on the deviation of consumers from integer values (e.g., 2 for strict herbivores, 3 and 4 for strict carnivores) for $T P$ derived from $\delta^{15} \mathrm{~N}_{\mathrm{AA}}$. Recognition of intra-individual variability in $T P$, as observed by Papastamatiou et al. (2015) in deep reef giant trevally, will be an important outcome of future $\delta^{15} \mathrm{~N}_{\mathrm{AA}}$ studies.

The trophic role of apex consumers will probably ultimately be elucidated by applying CSIA-AA to TP estimates in aquatic systems. Several recent studies have highlighted the importance of accurate $T P$ estimates for apex consumers, and raised questions about the trophic role of sharks as apex predators in coral reef ecosystems. Hussey et al. (2014) highlighted the dependence of $T P_{\text {bulk }}$ estimates on $T D F_{\text {bulk }}$ values and suggested that the $T P$ of apex shark species may have been underestimated using $\delta^{15} \mathrm{~N}_{\text {bulk. }}$. Hussey et al. (2015) later demonstrated an expanded trophic complexity among large sharks using CSIA-AA. Hilting et al. (2013) used bulk stable isotope analysis to suggest that apex predators in central Pacific reefs might be predominately supported by benthic productivity and $\mathrm{N}_{2}$-fixation. However, strong conclusions could not be drawn because of spatial variability in primary producer bulk isotopes (see also the CSIA-AA findings of O'Malley et al. (2012) on two species of lobster in the Northwest Hawaiian Islands). Conversely, based on limited bulk isotope analyses, Frisch et al. (2016) assigned Great Barrier Reef tiger sharks (Galeocerdo cuvier) to pelagic productivity, whereas whitetip and blacktip reef sharks were assigned to predominately benthic sources (65\% and $72 \%$, respectively). Coupling $\delta^{15} \mathrm{~N}_{\text {bulk }}$ values with stomach contents analyses suggested these reef sharks occupy similar trophic positions to large predatory fish, such as snapper, rather than acting as apex predators (Frisch et al., 2016). CSIA-AA tools to understand the habitat of cryptic species. One example is Miller et al. (2012), 
578

579

580

581

582

583

584

585

586

587

588

589

590

591

592

593

594

595

596

597

598

599

600

601

602

603

604

605

606

607

608

609

610

611

612

613

japonica), whose food source is unknown. The estimated mean TP of the eel larvae was 2.4, which in that ecosystem was most consistent with a diet based on particulate organic matter (POM) composed of detritus from multiple sources. Ohkouchi et al. (2013) reported the TP of deep-water ram's horn squid (Spirula spirula), one of the most enigmatic cephalopods found commonly all over the world. Such information is useful for conserving endangered species through developing artificial diets for aquafarming.

Finally, it is important to note that CSIA-AA is also applicable to laboratory and museum specimens. A laboratory experiment conducted over the period of one year indicated that formalin-fixation does not affect $\delta^{15} \mathrm{~N}_{\mathrm{AA}}$ values derived from an aquatic consumer (Ogawa et al., 2013). Ogawa et al. (2013) used formalin-fixed samples to reconstruct historical variation (1916 to 1992 CE) in TP of isaza (Gymnogobius isaza), a pelagic gobiid fish from the eutrophic Lake Biwa, Japan. The $\delta^{15} \mathrm{~N}_{\text {bulk }}$ value of isaza has increased greatly during the $20^{\text {th }}$ century (Ogawa et al., 2001; Nakazawa et al., 2010), which can be explained either by an increase in $T P$ with the reorganization of bio-communities because of eutrophication, or by the increase of $\delta^{15} \mathrm{~N}$ in the nitrogen pool owing to denitrification. The CSIA-AA results strongly suggested that eutrophication did not affect the $T P$ of the fish in the lake, and that the $\delta^{15} \mathrm{~N}_{\mathrm{AA}}$ value of the formalin-fixed fish reflected the $\delta^{15} \mathrm{~N}$ of the nitrogen pool of the lake accurately (Fig. 8). A large global archive of formalin-fixed samples would offer a tool for reconstructing paleo-limnological changes, and for constraining the ecological consequences of environmental change with CSIA-AA.

\subsection{Food web analyses in terrestrial ecosystems}

CSIA-AA has provided new insights into the trophic roles of terrestrial organisms and, as in aquatic ecosystems, distinguished itself from traditional bulk isotopic approaches (Chikaraishi et al., 2011; Steffan et al., 2013). Chikaraishi et al. (2011) showed that equation 2 is equally valid for terrestrial systems and Steffan et al. (2013) demonstrated that accurate and precise TP could be derived for higher-order carnivores, using the CSIA-AA method to measure TP across four trophic levels in terrestrial insect communities. Recent work in regards to carbon CSIA-AA shows great promise in filling gaps currently left open by nitrogen CSIA-AA approaches because carbon isotopic composition among essential AAs, also called $\delta^{13} \mathrm{C}_{\mathrm{EAA}}$ fingerprints, can provide information about trophic pathways from plant sources and gut/soil microbes to consumers in terrestrial ecosystems (Larsen et al., 2016a, 2016b). Carbon and nitrogen CSIA-AA has also revealed novel aspects of animal and microbial biology, proving CSIA-AA to be a powerful new tool for examining modern and ancient biological communities (O'Brien et al., 2002, 2004;

Chikaraishi et al., 2014; Steffan et al., 2015a).

\subsubsection{Trophic position estimation}



organisms was obtained by using the $\delta^{15} \mathrm{~N}$ values of Glu and Phe of primarily herbivorous

616 organisms and their plant host material collected from a farm in Japan (Chikaraishi et al., 2011).

617 Because aphids are strict herbivores, they were ideal subjects for testing the accuracy of this tool,

618 and the estimated $T P$ of the aphids was shown to be the expected value of $\sim 2.0$. Carnivorous insect

619 specimens (e.g., lady beetles, wasps, and hornets) were also analyzed via CSIA to estimate their TP

620 values. The data provided interesting insights into the trophic ecology of these animals; however,

621 because most carnivores are free-roaming generalists, their actual TP values were not known and

622 they were not suitable for testing the accuracy of this tool. These early studies revealed that insect

$623 T P$ remained constant through major ontogenetic shifts, including insect pupation (Chikaraishi et

624 al., 2011). During such metamorphoses, there is much synthesis of new tissues and organs, so it

625 was expected that there would be significant fractionation or routing of ${ }^{15} \mathrm{~N}$ within the pupating

626 insect. The finding that arthropod metamorphosis left the $\delta^{15} \mathrm{~N}$ values largely unchanged was critical to further applications of $\delta^{15} \mathrm{~N}_{\mathrm{AA}}$ to insect food web ecology (Chikaraishi et al., 2011).

Steffan et al. (2013) used terrestrial insect populations in axenic culture to test whether top carnivore $T P$ could be reliably determined using $\delta^{15} \mathrm{~N}_{\mathrm{AA}}$. In this study, two different insect communities were maintained, each spanning four trophic levels, and each consuming an ecologically realistic component of their diet. Steffan et al. (2013) showed that the $T P_{\mathrm{Glu} / \mathrm{Phe}}$ of

632 higher-order consumers (carnivorous insects) could be measured with high accuracy, and that the

$633 \Delta_{\text {Glu/Phe }}$ value was consistent between herbivores and tertiary carnivores. The $\Delta_{\mathrm{Glu} / \mathrm{Phe}}$ value for 634 herbivorous and carnivorous arthropods was similar to that found by Chikaraishi et al. (2009) for marine fish and gastropods, showing that the $T P$ formula using a $\Delta_{\mathrm{Glu} / \mathrm{Phe}}$ value $\sim 7.6 \%$ and a $\beta_{\mathrm{Glu} / \mathrm{Phe}}$ value appropriate for each environment in equation 2 was applicable to a wide variety of ecosystems. The consistency in the CSIA-AA findings across animal taxa and ecosystem types observed on land (Chikaraishi et al., 2010; Steffan et al., 2013) provided a foundation to begin 639 investigating consumer $T P$ in the field, at larger spatial scales and in more diverse communities. 640 Further CSIA-AA of directly sampled terrestrial organisms in the wild revealed a high degree of 641 trophic omnivory among 38 consumer species, providing some of the strongest empirical evidence of the predominance of omnivory in food webs (Chikaraishi et al., 2014).

644 microbiome and mainly the inclusion of microbes in trophic hierarchies. Studies involving multiple 645 phyla of fungi and bacteria, plus vertebrate and invertebrate animals, showed that the CSIA-AA 646 approach provides a new way to probe trophic ecology of the three domains of life (Steffan et al., 647 2015a). Fungi are particularly important consumers and symbionts in many terrestrial systems 648 (Bardgett and Cook, 1998; Moore and de Ruiter, 2012). Showing that these organisms can be 649 integrated into food-chains has allowed more refined interpretations of animal trophic identity. 
However, this also raises questions of how to interpret the $T P$ values of detritivores. Recent work has shown that microbes increase the $T P$ values of detrital complexes, and when animals eat such microbe-colonized complexes, the consumer TP values increase to the same degree (Steffan et al., 2017). Given that detritivory is the dominant trophic paradigm on land (Coleman, 1996; Hagen et al., 2012) and that microbes are the dominant consumers among the detritivores (Peterson and Luxton, 1982; van der Heijden et al., 2008; Moore and de Ruiter, 2012), the ability to explicitly integrate microbes into trophic hierarchies represents a major advance in trophic ecology. Common detritivorous animals, such as earthworms, fruit flies, and springtails, exhibit $T P$ values (2.4-2.8), providing evidence of the degree to which they mix microbivory with herbivory (Steffan et al., 2017). Detritivores form an immense prey base for predators in terrestrial systems (Haraguchi et al.,

660 2013; Hyodo et al., 2015), and this prey base tends to shape the trophic identity of most carnivores

661 (Coleman, 1996; Bardgett and Cook, 1998).

662

\subsubsection{Recent discoveries in terrestrial biology and ecology}

$\delta^{15} \mathrm{~N}_{\mathrm{AA}}$ was used to reveal that leafcutter ants (Acromyrmex) in Neotropical rainforests are trophically carnivorous (Steffan et al., 2015a). The ants feed almost exclusively on the fruiting bodies of their fungal symbiont, Leucoagaricus. Since this fungus feeds solely on plant material, the fungus is a strict herbivore, and the ants are strict carnivores. This finding implies that fungi, not ants, are the dominant herbivores of the Neotropics. Interestingly, there is a third symbiont, a bacterium, in the leafcutter ant fungus gardens that gathers in powdery white masses on the ant exoskeleton (Currie et al., 2006). It was unclear whether this bacterium fed on the ants or some other resource. CSIA-AA showed that the bacteria were feeding on ant tissues; thus, a bacterium was the apex carnivore within the fungus-garden community (Fig. 9, Steffan et al., 2015a). Fungi can also be predators, and $\delta^{15} \mathrm{~N}_{\mathrm{AA}}$ values were used to demonstrate that an entomopathogenic fungus, Beauveria bassiana, registered a $T P$ of 3.0 after killing and consuming its prey, a herbivorous caterpillar. At the other end of the trophic spectrum, Asiatic black bears (Ursus thibetanus) were shown to feed remarkably low in the food-chain, registering near TP 2.0. Thus, there are now multiple examples in the literature where the trophic tendencies of terrestrial mammals (e.g., mice, bears) have been measured using $\delta^{15} \mathrm{~N}_{\mathrm{AA}}$ (Nakashita et al., 2011; Steffan et al., 2015a).

In agricultural contexts, CSIA-AA has been used to characterize the trophic roles of organisms thought to be beneficial to crop protection (Steffan et al., 2015b). Carnivorous arthropods are generally assumed to be helpful in suppressing herbivorous pest species, but

683 CSIA-AA has shown that only certain predator species contribute substantially to pest control.

684 Some carnivores are beneficial for crop protection, and some are neutral, and other species may 685 undermine crop protection efforts by feeding on the beneficial carnivores (Fig. 10). Knowledge of 
686

687

688

689

690

691

692

693

694

695

696

697

698

699

700

701

702

703

704

705

706

707

708

709

710

711

712

713

714

715

716

717

718

719

720

721

which predator communities are likely to help or harm crop protection is useful for the ecological management of crop fields.

\subsection{Applications to ancient humans and extinct mammals}

CSIA-AA has been used to study tissues, like bone collagen and scalp hair, from archaeological and contemporary humans, and ancient soils in archaeological and anthropological studies. These studies span various fields, including paleodiet, nutrition, paleopathology, and ancient land use (e.g., Hare et al., 1991; Fogel, 1997; Petzke et al., 2005). Studies of paleodiet mainly revolve around investigating i) marine protein consumption (Naito et al., 2010a, 2010b; Styring et al., 2010), ii) the importance of animal proteins relative to plant proteins in terrestrial ecosystems (Naito et al., 2013b, 2016b), and iii) the importance of proteins from freshwater resources relative to proteins from terrestrial resources (Naito et al., 2013a). Goal iii) is challenging because distinguishing terrestrial and freshwater food consumption is difficult since these two environments may share the same nitrogen sources (e.g., contributions of terrestrial primary production to a stream ecosystem, Naito et al., 2016a).

$\delta^{15} \mathrm{~N}_{\text {Phe }}$ values in some archaeological contexts in animals mirrors their nitrogen source owing to little trophic ${ }^{15} \mathrm{~N}$ enrichment. For example, Naito et al. $(2010,2013 b)$ examined coastal and inland archaeological sites from the Jomon period in Japan ( $c a$. 15,000 to 2,300 years BP). The $\delta^{15} \mathrm{~N}_{\text {Phe }}$ values of animals in these contrasting ecosystems, including humans, were consistent within each ecosystem, although there were differences between ecosystems (Fig. 11). The coastal population showed $\delta^{15} \mathrm{~N}_{\text {Phe }}$ values between those of marine and terrestrial ecosystems, with values closer to marine ecosystems, indicating heavier reliance of the humans on marine food resources. However, the inland population had $\delta^{15} \mathrm{~N}_{\text {Phe }}$ values in the terrestrial ecosystem indicating purely terrestrial food habits. In both cases, tracing the nitrogen source for humans was facile because each ecosystem showed marked differences in $\delta^{15} \mathrm{~N}_{\text {Phe }}$ values. However, this is not the case in other archaeological contexts where $\delta^{15} \mathrm{~N}_{\text {Phe }}$ values vary substantially within each ecosystem. $\delta^{15} \mathrm{~N}_{\text {Phe }}$ values in terrestrial prey animals can vary widely $(>6 \%)$, even for a single species from a single site, which makes it difficult to trace the nitrogen source (Fig. 12). Nevertheless, this technique is still useful for examining $T P$ values of animals. Neanderthals from this site exhibited $T P$ values of 2.7 to 2.8 , similar to those of wolves (TP 2.9), suggesting that the Neanderthals ate meat-based diets, with the possible addition of plant foods (Fig. 11).

CSIA-AA can also be used to investigate diets of extinct mammals, including wooly mammoths (Mammuthus primigenius) (Naito et al., 2016b; Schwartz-Narbonne et al., 2015), cave bears (Ursus spelaeus) (Naito et al., 2016c), scimitar-toothed cats (Homotherium serum), and short-faced bears (Arctodus spp.) (Schwartz-Narbonne et al., 2015). Based on the high $\delta^{15} \mathrm{~N}_{\text {Phe }}$ value of mammoths, it has been hypothesized that the mammoth occupied a distinct foraging niche 
or habitat compared with other coeval herbivores, owing to the high $\delta^{15} \mathrm{~N}$ values of bulk collagen arising from ${ }^{15} \mathrm{~N}$-enriched food sources (Naito et al., 2016b). This finding demonstrates the separation of mixtures of environmental signals (e.g., aridity may elevate the $\delta^{15} \mathrm{~N}$ values of animal body tissues: Heaton et al., 1986; Schwarcz et al., 1999) and dietary signals in $\delta^{15} \mathrm{~N}$ values of collagen. However, the $\delta^{15} \mathrm{~N}$ values of body tissues, and probably the $\delta^{15} \mathrm{~N}_{\mathrm{AA}}$ values, may also encode physiological states, illness, and quality of diet (Fogel et al., 1989; Fuller et al., 2004, 2006; Reitsema and Muir, 2015; Reitsema, 2013; Chikaraishi et al., 2015). In combination with studies on contemporary humans and archaeological human remains, the number of study fields for CSIA-AA, such as paleopathology, may expand (Fogel, 1997; Metges and Petzke, 1997; Petzke et al., 2006, 2010; Romek et al., 2013).

Lastly, CSIA-AA has also been used to investigate past land use by humans. Preliminary results suggest that the $\delta^{15} \mathrm{~N}$ values of Phe and Thr in the soil may be useful for distinguishing the soil under grassland from that under cereal (Bol et al., 1998; Simpson et al., 1997, 1999). Although the underlying mechanisms controlling the $\delta^{15} \mathrm{~N}$ dynamics of soil AAs are not well understood, some AAs may provide clues for understanding past human activities like cultivation (Styring et al., 2013), which is important because cultivars are rarely preserved in the archaeological record.

\subsection{CSIA-AA and isoscapes: application to ecogeochemistry and the detection of animal migration}

Ecogeochemistry is the application of geochemical techniques to fundamental questions in population and community ecology, and is inherently spatial (e.g., Bowen, 2010; Graham et al., 2009; Ramos and Gonzalez-Solis, 2012; McMahon et al., 2013a). Consequently, accurate interpretation of stable isotopic compositions in ecological or environmental studies requires knowledge of the geospatial and temporal variability in isotope values at the base of the food web, often referred to as isotope baselines (Post, 2002; McMahon et al., 2013b). Spatiotemporally explicit maps of isotopic variability, termed isoscapes, have emerged as important tools for addressing interrelated ecological questions about animal movement, habitat use, biogeochemical cycling, and forensic science (e.g., West et al., 2010).

Effective application of isoscapes to ecological questions requires specific information (Hobson et al., 2010). First, an isoscape must be established that characterizes systematic geospatial variability in isotopic compositions across environmental gradients. Second, tissue turnover rates that determine the period of spatial integration of isotopic composition for a particular animal tissue must be constrained. Finally, the isotope fractionation factors between the consumer and diet, or between animals and the ambient environment that offset geochemical values in animal tissues from baseline isoscape values, must be estimated or quantified.

Bulk tissue or whole animal isotope analyses have been the primary tools in applications 
of terrestrial and marine ecosystem isoscapes (Bowen et al., 2009; Jaeger et al., 2010; MacKenzie et al., 2011; Hobson et al., 2012; Trueman et al., 2012; Clementz et al., 2014). However, in addition to

760

761

762

763

764

765

766

767

768

769

770

771

772

773

774

775

776

777

778

779

780

781

782

783

784

785

786

787

788

789

790

791

792

793

characterizing the geospatial structure of isotope data within a system, we also must account accurately for how baseline isotope values are modified as they propagate through food webs to upper trophic level consumers (Hobson et al., 2010). Thus, a major obstacle to interpreting bulk tissue isotope values of consumers accurately is separating the relative effects of variability at the base of the food web from trophic dynamics within the food web that links consumers to those baselines (Post, 2002).

CSIA-AA can disentangle the relative effects of geographic and trophic dynamics on consumer isotopic compositions (Chikaraishi et al., 2007, 2009; Popp et al., 2007; Lorrain et al., 2009, 2015; Olson et al., 2010). The differential isotopic fractionation of individual AAs provides direct access to information about integrated ecosystem isotopic baselines without the confounding issue of trophic fractionation, and without the need to analyze and characterize all the trophic linkages between the baseline isoscapes and upper trophic level consumers a priori. Below we highlight several unique but complementary examples of how CSIA-AA, in the context of geospatial isotopic variations, provides unprecedented links between animal ecology and biogeochemistry in complex ecosystems.

\subsubsection{Case study 1: Mussel isoscapes of the California coast}

One promising CSIA-AA isoscape application for monitoring coastal biogeochemical change is the creation of detailed maps of coastal isotopic baselines, based on CSIA-AA measurements in filter feeding mollusks. Coastal system isoscapes are inherently challenging owing to high temporal and spatial variability in primary production and biogeochemical cycles. Many coastal regions are characterized by large seasonal swings in temperature, salinity, nutrient availability, and terrestrial inputs, while high spatial variability in oceanographic conditions is driven by coupled local winds, upwelling, and current patterns (e.g., Walker and McCarthy, 2012; Walker et al., 2014). The isotopic compositions of consumers can often integrate this environmental variation. However, on the spatial scales of coastal processes, assigning mobile consumers to specific locations can be difficult. Tissues of sessile filter-feeders, such as mussels, offer a solution to this problem: they do not move, and specific tissues/organism sizes can be chosen to provide additional control over the integrated time scales represented by the samples. Early work coupling CSIA-AA proxies for isotopic baseline (i.e., $\delta^{15} \mathrm{~N}_{\text {Phe }}$ ), coupled with high resolution sampling of filter feeding consumers, has allowed the creation of isoscapes of baseline coastal primary production, based on precisely known and replicable sampling locations (Vokhshoori et al., 2014; Vokhshoori and McCarthy, 2014).

However, the reconstruction of baseline isoscapes based on $\delta^{15} \mathrm{~N}_{\mathrm{AA}}$ also poses a number of 
794

795

796

797

798

799

800

801

802

803

804

805

806

807

808

809

810

811

812

813

814

815

816

817

818

819

820

821

822

823

824

825

826

827

828

829

challenges, primarily with the interpretation of $\delta^{15} \mathrm{~N}_{\text {Phe }}$ values in mollusk bioarchives. The challenges include clarifying the mix of littoral food sources using CSIA-AA proxy records, understanding temporal/seasonal effects in this signal, and the requirement to understand the influence of bulk algal $\delta^{15} \mathrm{~N}$ isoscapes on mollusk AA isotopic values. In two recent papers, Vokhshoori and coauthors explored these problems using littoral Mytilus californianus collected from 28 sites on the California coast, spanning $\sim 10$ degrees of latitude $\left(32^{\circ}\right.$ to $\left.42^{\circ} \mathrm{N}\right)$ within the California current system (Vokhshoori et al., 2014; Vokhshoori and McCarthy, 2014). CSIA-AA values of adductor muscle tissue from individuals of a similar size class were selected to represent approximately annual integration timescales.

$\delta^{15} \mathrm{~N}_{\text {bulk }}$ values in mussels showed a strong linear trend with latitude (Fig. 13). Although there were clear site-specific and region-specific offsets in $\delta^{15} \mathrm{~N}$ values, the overall data indicated a strongly linear progressive change in $\delta^{15} \mathrm{~N}$ values, averaging $0.4 \%$ per degree of latitude, across the coastal California current system. This change reflects the relative geographical influence of water upwelled from the California undercurrent, which transports ${ }^{15} \mathrm{~N}$-rich nitrate poleward (e.g., Altabet et al., 1999). The $\delta^{15} \mathrm{~N}_{\text {Phe }}$ values also tracked the $\delta^{15} \mathrm{~N}_{\text {bulk }}$ values, confirming the nutrient baseline as the underlying driver for changes in bulk mussel tissue. Prior studies had indicated generally lower $\delta^{15} \mathrm{~N}_{\text {nitrate }}$ values in more northern regions of this system (Altabet et al., 1999; Kienast et al., 2002; Sigman et al., 2009), however the strength of the linear trend revealed by high resolution mussel sampling was surprising. This result suggests that such mollusk-derived isoscapes can be used to precisely define changes in the effects of coastal oceanography on baseline Isoscapes, as well as to identify local regions of variation linked for example to upwelling patterns (Walker and McCarthy, 2012).

However, $\delta^{15} \mathrm{~N}_{\text {bulk }}$ records are inherently unable to reconstruct baseline $\delta^{15} \mathrm{~N}$ values directly. $\delta^{15} \mathrm{~N}_{\text {bulk }}$ values were 2 to $4 \%$ higher than the expected range of $\delta^{15} \mathrm{~N}_{\text {nitrate }}$ values in this system, probably because of a combination of trophic transfer and tissue-specific offsets.

Vokhshoori and McCarthy (2014) found that $\delta^{15} \mathrm{~N}_{\text {Phe values corresponded most closely to the range }}$ of previously measured $\delta^{15} \mathrm{~N}_{\text {nitrate, }}$, suggesting that $\delta^{15} \mathrm{~N}_{\text {Phe }}$ in mussels is a direct proxy for annual average $\delta^{15} \mathrm{~N}_{\text {nitrate. }}$. Finally, a constant $\delta^{15} \mathrm{~N}_{\text {bulk }} v s . \delta^{15} \mathrm{~N}_{\text {Phe }}$ offset observed for all samples allowed the construction of predicted "coastal nitrate" $\delta^{15} \mathrm{~N}$ values. The resulting isoscape was grounded in high-resolution bulk sampling, but then calibrated to baseline $\delta^{15} \mathrm{~N}$ values based on CSIA-AA data (Fig. 12). It is unclear how far isoscapes based on littoral species can be extrapolated. However, for Monterey Bay, a direct comparison of mussel $\delta^{15} \mathrm{~N}$ data with a greater variety of more offshore sample types (e.g., sinking POM, plankton tows, and surface sediments) suggested that, at least on the timescales sampled, mussel $\delta^{15} \mathrm{~N}_{\text {Phe }}$ values reflect baseline $\delta^{15} \mathrm{~N}$ values in local coastal waters.

These results demonstrate the potential of CSIA-AA in sessile filter feeders to create the first true baseline isoscapes of coastal production, with the potential for an extraordinary degree of 
830 geographic and temporal resolution. Although bulk tissue analysis can indicate geographic trends, 831 coupling $\delta^{13} \mathrm{C}_{\mathrm{EAA}}$ fingerprinting with $\delta^{15} \mathrm{~N}_{\mathrm{AA}}$ allows the fundamental ambiguity of organic matter 832 sources to be addressed, and can quantify the relative balance of sources underlying CSIA-AA 833 signals. $\delta^{15} \mathrm{~N}_{\text {Phe }}$ values can track baseline $\delta^{15} \mathrm{~N}$ values, and in systems with full nitrate utilization this 834 should also allow direct assembly of $\delta^{15} \mathrm{~N}_{\text {nitrate }}$ isoscapes. Therefore, it may be possible to monitor 835 fine-scale shifts in coastal nitrogen biogeochemical cycles linked to short- or longer-term 836 fluctuations in climate and physical forcing. However, several challenges remain, including 837 understanding in more detail the calibrations required to link measured $\delta^{15} \mathrm{~N}_{\mathrm{AA}}$ values to average 838 primary production (or nitrate) isotope values, and investigating integration timescales, such as 839 potential seasonal bias and the effects of tissue type, organism size, and growth stage.

\subsubsection{Case study 2: Detecting animal migration}

Systematic variations in nitrogen isotopic compositions in the ocean, such as the mussel isoscapes in Section 4.4.1 or those in the eastern tropical North Pacific (Olson et al., 2010), create ecoregions with distinctive isotope ratios in baseline organisms (e.g., phytoplankton). These regional differences allow the results of CSIA-AA to be used to recognize animal migrations. This approach principally relies on certain AA isotopic compositions in animals having reached a steady state with the $\delta^{15} \mathrm{~N}$ value at the base of the food web.

Marine animal migrations can be identified with CSIA-AA by two approaches. The first is a chronological reconstruction of isotopic compositions of AAs in an archival tissue (e.g., otoliths, fin spines) that represent the animal's environment at different stages of ontogeny. Older tissues can represent an isotopic steady state with an environment different from an animal's current location, which can then be compared with recently synthesized tissue that has AA isotopic compositions in a steady state with the current location. The second approach is to compare isotopic compositions of AAs in a non-archival tissue (e.g., muscle) across individuals that are a suspected mix of residents and recent migrants to a particular environment. With this approach, the timeframe for distinguishing residents from migrants is defined by the turnover time of nitrogen in the tissue analyzed. The $\delta^{15} \mathrm{~N}_{\mathrm{SAA}}$ values in animals record the isotopic composition at the base of the food web. In addition, the difference in $\delta^{15} \mathrm{~N}_{\mathrm{SAA}}$ and $\delta^{15} \mathrm{~N}_{\mathrm{TAA}}$ values constrains potential TP variations between residents and suspected migrants (e.g., Madigan et al., 2012b; Seminoff et al., 2012).

For example, $\delta^{15} \mathrm{~N}_{\mathrm{AA}}$ values were used to study the foraging ecology and habitat use of the brown stingray (Dasyatis lata) near Kaneohe Bay, Oahu, Hawaii (Dale et al., 2011). Although quantitative stomach content analysis of $D$. lata indicated an ontogenetic shift to a higher $T P$ in larger, older specimens, the largest stingrays had the lowest $\delta^{15} \mathrm{~N}_{\text {bulk }}$ values. Lower $\delta^{15} \mathrm{~N}_{\text {bulk }}$ values would indicate a decreased TP in the largest stingrays, contradicting stomach content analyses, if all 
et al. (2011) used differences in $\delta^{15} \mathrm{~N}_{\mathrm{Glu}}$ and $\delta^{15} \mathrm{~N}_{\text {Phe }}$ to show that $T P$ of $D$. lata increased with size and that $\delta^{15} \mathrm{~N}_{\text {bulk }}$ values were independent of TP. These findings clearly indicated that the largest $D$. lata were feeding in habitats that had distinctly lower $\delta^{15} \mathrm{~N}$ values at the base of the food web than the environments where smaller stingrays foraged. One implication of this finding was that stingray $\delta^{13} \mathrm{C}_{\text {bulk }}$ and $\delta^{15} \mathrm{~N}_{\text {bulk }}$ values reflected migration patterns better than $T P$. Both $\delta^{15} \mathrm{~N}$ and $\delta^{13} \mathrm{C}$ values, examined as a function of size and stingray sex, revealed that changes in bulk isotopic compositions closely coincided with the onset of sexual maturity, confirming Kaneohe Bay as a nursery habitat for D. lata (Dale et al. 2011).

$\delta^{15} \mathrm{~N}_{\mathrm{AA}}$ values have been used to recognize marine fish undergoing trans-Pacific migrations (Madigan et al., 2014, 2016). Pacific bluefin tuna (Thunnus orientalis) inhabit the western and eastern Pacific Ocean. All bluefin tuna spawn in the western Pacific and an unknown proportion of these tuna migrate to the eastern Pacific early in their life. Once in the eastern Pacific, these bluefin tuna migrants reside in the California Current ecosystem for several years and then return to the western Pacific to spawn. Tracking these transoceanic migrations has been challenging; however, large differences in baseline $\delta^{15} \mathrm{~N}$ values between the eastern and western Pacific Ocean (e.g., Navarro et al., 2013) can be used to understand the timing and numbers of individuals undergoing trans-Pacific migration better.

Recently, Madigan et al. (2012a, 2013) showed that the short-lived Fukushima-derived radiocesium $\left({ }^{134} \mathrm{Cs}\right)$ content of bluefin tuna caught in the eastern Pacific unequivocally identified bluefin tuna that had fed off the coast of Japan and migrated from the western Pacific. Madigan et al. (2014) combined nitrogen isotope analyses of AAs with bluefin tuna containing Fukushima-derived ${ }^{134} \mathrm{Cs}$ to evaluate the migration history of different year class bluefin tuna caught in the eastern Pacific. Bluefin tuna in the eastern Pacific had a bimodal distribution of $\delta^{15} \mathrm{~N}_{\text {bulk }}$, with lower values consistently found in bluefin tuna specimens with Fukushima-derived ${ }^{134} \mathrm{Cs}$. Bluefin tuna with Fukushima-derived ${ }^{134} \mathrm{Cs}$ had $\delta{ }^{15} \mathrm{~N}$ values even lower than baseline organisms (krill, copepods) found in the eastern Pacific Ocean. Madigan et al. (2014) also found that the $\delta^{15} \mathrm{~N}_{\mathrm{SAA}}$ in eastern Pacific bluefin tuna with Fukushima-derived ${ }^{134} \mathrm{Cs}$ were 7.7 to $8.7 \%$ lower than in fish that lacked This indicated that $\delta^{15} \mathrm{~N}_{\mathrm{SAA}}$ values were robust markers for distinguishing resident bluefin tuna from recent migrants. In addition, the results of CSIA-AA indicated that differences in $\delta^{15} \mathrm{~N}_{\text {bulk }}$ values were not due to trophic variability among bluefin tuna. Recently, Madigan et al. (2016) used the CSIA-AA results for giant bluefin tuna caught in the western Pacific Ocean to validate the westward trans-Pacific migration of sexually mature individuals from the eastern Pacific Ocean to spawning grounds off the coast of Taiwan. 
indicated that the eastern Pacific bluefin tuna population was subsidized by a substantial number of older individuals (i.e., year class 2 to 3 ) from the western Pacific, which was not previously recognized. In addition, knowledge of muscle turnover time in bluefin tuna (Madigan et al., 2012b) sets limits on how quickly a migrant bluefin tuna would reach a nitrogen isotope steady state with the new environment (and thus be classified as a resident based on CSIA-AA), and allows the date of migrant arrival to be estimated. Madigan et al. (2014) found that the proportion of recent migrants to residents decreased with increasing age, which is critical information for effectively managing this heavily fished species. Unlike a radiogenic isotopic tracer that has finite utility for studying animal migration in the ocean, CSIA-AA can be used ad infinitum and in other species. For example, the same isotopic differences in the North Pacific Ocean were used to distinguish apparent eastern and western Pacific migratory groups of endangered leatherback sea turtles (Dermochelys coriacea), which provided unique evidence for foraging area philopatry among turtles nesting in Indonesia (Seminoff et al., 2012). These CSIA-AA results clarify the interpretation of bulk tissue isotopic variability in populations, and can be used to recognize and trace movements of many highly

917 migratory pelagic species.

\subsubsection{Case study 3: Deep-sea coral}

As Earth's climate changes, there is a growing need to put these changes and their subsequent effects on ecosystem structure and function into a greater historical context (Corno et al., 2007; Hoegh-Guldberg and Bruno, 2010). One of the most exciting new applications for CSIA-AA is in paleoceanography, where parameters originally developed for ecology are being adapted as new paleo-proxies in novel protein-rich archives. Biogenic skeletons of proteinaceous deep-sea corals provide a remarkable geochemical archive of information about the structure and function of past ocean ecosystems (Druffel, 1997; Robinson et al., 2014). These globally distributed corals represent "living sediment traps", recording geochemical information about recently exported organic materials in their exquisitely preserved accretionary protein skeletons (Roark et al., 2009; Guilderson et al., 2013). Much of the recent work with proteinaceous deep-sea corals has focused on isotope analysis of total skeletal material as a proxy for changes in surface ocean conditions (e.g., Sherwood et al., 2005; Williams et al., 2007; Hill et al., 2014). However, CSIA-AA results can provide unprecedented reconstruction of past ocean conditions (Sherwood et al., 2011, 2014; Schiff et al., 2014; Strzepek et al., 2014; McMahon et al., 2015c; Williams et al., 2017). The $\delta^{15} \mathrm{~N}_{\mathrm{SAA}}$ values of these consumers provide particularly faithful records of baseline nitrogen sources and cycling that are otherwise seldom preserved in paleorecords.

Sherwood et al. (2011) first applied CSIA-AA to deep-sea corals to distinguish between temporal (decadal to centennial) changes in nitrogen sources, while constraining changes in the trophic structure of proteinaceous deep-sea corals in the Scotia-Maine region of the Northwest 
938 Atlantic Ocean. They used the $\delta^{15} \mathrm{~N}_{\mathrm{SAA}}$ values of Primnoa resedaeformis coral as a proxy for 939 increasing nitrate levels in the region, associated with externally driven shifts in slope water source partitioning over the last 100 years. Given that slope water circulation in the Scotia-Maine region is

941 linked with broader scale climate variability associated with the North Atlantic Oscillation (Loder et

942 al., 2001; Pershing et al., 2001), these authors concluded that changes in nitrate source partitioning 943 may be tied to recent, human-caused changes in global climate.

More recently, Sherwood et al. (2015) determined $\delta^{15} \mathrm{~N}_{\text {bulk }}$ and $\delta^{15} \mathrm{~N}_{\mathrm{AA}}$ values recorded in

945 the skeletons of the very long-lived (>1,000 years) deep-sea proteinaceous corals Kulamanamana

946 haumeaae collected from the Hawaiian Archipelago. After nearly a millennium of minor oscillations,

947 coral $\delta^{15} \mathrm{~N}_{\text {bulk }}$ values decreased dramatically in the last 150 years. Using $\delta^{15} \mathrm{~N}_{\text {Phe }}$ as a proxy for

948 baseline isotopic composition, Sherwood et al. (2015) calculated the relative contribution of

$949 \mathrm{~N}_{2}$-fixation to export production in the North Pacific Subtropical Gyre. They found that increasing

$950 \mathrm{~N}_{2}$-fixation in the subtropical gyre recently observed in the modern instrumental record (Karl et al.,

9511997,2001 ) is a continuation of a much longer centennial-scale trend, resulting in a $17 \%$ to $27 \%$

952 increase in $\mathrm{N}_{2}$-fixation since the end of the Little Ice Age and the onset of the Industrial Era. These

953 authors suggested that this increase in $\mathrm{N}_{2}$-fixation might be attributed to Northern Hemisphere

954 climate change since the end of the Little Ice Age (Wilson et al., 2006; Mann et al., 2008).

955 In a complementary study of K. haumeaae in the North Pacific Subtropical Gyre,

956 McMahon et al. (2015c) reconstructed the first high-resolution records of changing plankton

957 community composition over the past millennium, using the AA carbon isotope fingerprinting

958 approach of Larsen et al. $(2009,2013)$. This study revealed three major plankton regimes

959 corresponding to Northern Hemisphere climatic periods over the past 1,000 years. The most recent

960 regime, which began during the warming and stratification period following the end of the Little Ice

961 Age (1850 CE; Corno et al., 2007; Dore et al., 2008), was characterized by an increase of

962 approximately $47 \%$ in the contribution of exported POM from $\mathrm{N}_{2}$-fixing cyanobacteria. These data

963 support the growing body of evidence that the last 150 years in the North Pacific Subtropical Gyre

964 have seen a major, and likely unique shift in plankton community dynamics and nitrogen cycling

965 associated with the end of the Little Ice Age. These studies illustrate the power of CSIA-AA

966 approaches to reconstructing past ocean ecosystem dynamics and biogeochemical cycling.

967

968 4.5. CSIA-AA as an indicator of organic matter source and degradation state

969

970

4.5.1. Patterns in microbial $\delta^{15} \mathrm{~N}_{\mathrm{AA}}$ variability

971 The majority of OM in natural environments is not in living organisms, but exists as

972 detrital OM (e.g., Hedges, 1992; Eglinton and Repeta, 2004). Thus, production, alteration, and

973 degradation of detrital OM are key components in biogeochemical cycles, especially for carbon 
and nitrogen, and they also play important roles in ecosystems. AAs represent a major fraction of nitrogenous detritus, and are vital in biogeochemical cycles of OM in various environments such as ocean water columns (Cowie and Hedges, 1994; McCarthy et al., 1996), marine sediments (Keil et al., 2000), and soils (Schulten and Schnitzer, 1997). Therefore, $\delta^{15} \mathrm{~N}_{\mathrm{AA}}$ values and patterns also represent novel indicators for the sources and degradation state of detrital OM, especially for organic nitrogen. In contrast to CSIA-AA in animal ecology (Section 4), however, CSIA-AA studies of detrital OM must consider not only food chain processes, but also the subsequent effects of metabolism of chemotrophic microbes (both heterotrophs and chemoautotrophs) on $\delta^{15} \mathrm{~N}_{\mathrm{AA}}$ values and patterns. This remains a frontier area of CSIA-AA applications, and exactly how $\delta^{15} \mathrm{~N}_{\mathrm{AA}}$ patterns are altered by microbial processes remains an area of active research. Importantly, in contrast to metazoans, the metabolic plasticity of microbes allows for multiple means of AA acquisition, including de novo synthesis, salvage incorporation (i.e., uptake and incorporation of existing AAs into bacterial biomass), as well as selected resynthesis (i.e., heterotrophic synthesis). This metabolic diversity is likely the reason that observed microbial $\delta^{15} \mathrm{~N}_{\mathrm{AA}}$ fractionation patterns are substantially more complex than metazoans. Based on the literature results, we propose that $\delta^{15} \mathrm{~N}_{\mathrm{AA}}$ patterns resulting from microbial heterotrophy can be classified into four main categories, and that these patterns can be used as a conceptual framework for interpreting $\delta^{15} \mathrm{~N}_{\mathrm{AA}}$ values in detrital OM. Patterns indicating different microbial metabolisms may include changes in $T P$, $\delta^{15} \mathrm{~N}_{\mathrm{SAA}}$ values, and an additional parameter, $\Sigma V$. Here, $\Sigma V$ is a proxy for total heterotrophic resynthesis, and is defined as $\Sigma V=1 / n \sum \operatorname{Abs}\left(\chi_{\mathrm{AA}}\right)$, where deviation of each TAA is $\chi=\delta^{15} \mathrm{~N}_{\mathrm{AA}}$ $\delta^{15} \mathrm{~N}$ of average Ala, Asp, Glu, Ile, Leu, and Pro, and $n$ is the total number of TAAs used in the calculation (McCarthy et al., 2007, Fig. 14).

996

997 Pattern 1: Algae-like $\delta^{15} \mathrm{~N}_{\text {AA }}$ patterns from de novo AA synthesis: Pure culture experiments with microbes have shown that when chemotrophic microbes (i.e., both heterotrophs and chemoautotrophs, including Eukarya, Bacteria, and Archaea) synthesize AAs de novo from inorganic nitrogen, the relative $\delta^{15} \mathrm{~N}_{\mathrm{AA}}$ pattern normalized to $\delta^{15} \mathrm{~N}_{\mathrm{Glu}}$ is very similar to that of algae (Fig. 14a, Yamaguchi, 2013). Applying standard formulas discussed above on such material indicates low $T P$ values and low $\Sigma V$ values, just as in fresh algal biosynthetic (Yamaguchi, 2013). Just as for algal production, the absolute $\delta^{15} \mathrm{~N}$ values depend on that of the nitrogen source and isotopic fractionation during uptake and synthesis of Glu (e.g., Hoch et al., 1992; Fogel and Cifuentes, 1993; Chikaraishi et al., 2007; Ohkouchi and Takano, 2014), which is the sole source of most nitrogen in the other AAs (Bender, 2012). contribute greatly to detrital OM in some environments. For example, in environments with carbon-rich $\mathrm{OM}$ and abundant inorganic nitrogen, such as forest litter, some heterotrophic microbes 
use inorganic nitrogen as the main nitrogen source for AA synthesis. Another example is

1011 environments where chemoautotrophic microbes are the dominant primary producers, such as 1012 submarine hydrothermal vents. The algae-like de novo $\delta^{15} \mathrm{~N}_{\mathrm{AA}}$ pattern of chemotrophic microbes 1013 could be useful for explaining $\delta^{15} \mathrm{~N}_{\mathrm{AA}}$ values and patterns of detrital OM in such environments, 1014 although the effect of microbial heterotrophy must also be considered (see pattern 2-4).

These results show that most algae and chemotrophic microbes covering the three domains of life generally show similar $\delta^{15} \mathrm{~N}_{\mathrm{AA}}$ patterns for de novo AA synthesis. However, some differences in specific AAs may exist between domains or between microbial species (McCarthy et al., 2013; Yamaguchi, 2013; Maki et al., 2014). To use $\delta^{15} \mathrm{~N}_{\mathrm{AA}}$ patterns as indicators for specific microbial groups, further microbial culture experiments are needed to verify interspecies differences and to understand the variation of microbial $\delta^{15} \mathrm{~N}_{\mathrm{AA}}$ values mechanistically in terms of AA metabolic pathways.

Pattern 2: Animal-like changes in $\delta^{15} \mathrm{~N}_{\mathrm{AA}}$ values (increases in $T P$ value): Heterotrophic microbes can use existing AAs in environments (sometimes specific AAs) by metabolizing AAs as carbon and nitrogen sources for resynthesis, or by salvage incorporation. The enzymatic degradation processes of AAs, such as deamination or transamination, cause nitrogen isotopic fractionation (e.g., Macko and Estep, 1984; Macko et al. 1986). Experiments using axenic cultures of heterotrophic microbes across the three domains (Eukarya, Bacteria, and Archaea) have shown that the pattern of $T D F_{\mathrm{AA}}$ between microbial biomass and substrates (free AAs or complex media containing proteins) can be similar to that of animals, as evidenced by large positive $T D F_{\mathrm{TAA}}(e . g .,+6$ to $+8 \%$ in Glu) and the small $T D F_{\text {Phe }}(\sim 0 \%$ ) (Steffan et al., 2015a; Yamaguchi, 2013, Fig. 14b). These results suggest that when microbes incorporate AAs from the environment, the AAs in the microbial biomass and the microbially produced $\mathrm{OM}$ show higher $T P$ values, which would be distinct from the algae-like de novo $\delta^{15} \mathrm{~N}_{\mathrm{AA}}$ pattern (pattern 1$)$.

However, the mechanisms behind the apparently similar TDF patterns may differ between animals and heterotrophic microbes, because these organisms often use different metabolic AA pathways. For example, the proposed mechanism for the small, stable $T D F_{\text {Phe }}$ in animals via the phenylalanine hydroxylase pathway (Chikaraishi et al., 2007) would not apply to many microbes, which can synthesize Phe, and do not have this pathway (Yamaguchi, 2013). Alternatively, the small $T D F_{\text {Phe }}$ in heterotrophic microbes may arise from the high energetic cost of Phe biosynthesis, which would strongly suppress Phe synthesis and degradation and result in the salvage incorporation of Phe from the culture media (Yamaguchi, 2013; Akashi and Gojobori, 2002). To better understand the mechanisms of the heterotrophic changes in microbial $\delta^{15} \mathrm{~N}_{\mathrm{AA}}$ values, we propose that it is important to examine the AAs that were not analyzed in these first culture experiments (e.g., Met, Thr, Tyr, etc.), and to directly compare $\delta^{15} \mathrm{~N}_{\mathrm{AA}}$ patterns in microbes that have different metabolic AA 
pathways, as has been done for $\delta^{13} \mathrm{C}_{\mathrm{AA}}$ (Scott et al., 2006).

Pattern 3: Scattered changes in $\delta^{15} \mathrm{~N}_{\mathrm{AA}}$ values (large increase in $\Sigma V$ value): Although pure culture experiments have demonstrated that the heterotrophic microbes can show $\delta^{15} \mathrm{~N}_{\mathrm{AA}}$ changes similar to those of animals, the microbial $\delta^{15} \mathrm{~N}_{\mathrm{AA}}$ changes in natural environments may also show patterns that are more scattered (Fig. 14c). For example, incubation experiments of natural marine microbes with algal DOM showed that microbial DOM reworking caused $\delta^{15} \mathrm{~N}_{\mathrm{AA}}$ changes that were more scattered than those observed in pure culture experiments and in animals (Calleja et al., 2013). Large ${ }^{15} \mathrm{~N}$ enrichment was observed for some AAs, such as Gly $(>10 \%)$, and small ${ }^{15} \mathrm{~N}$ enrichment was observed for some TAAs such as Ile $(\sim 0 \%)$. Similarly, incubation of plant materials in salt marsh sediments also showed highly scattered $\delta^{15} \mathrm{~N}_{\mathrm{AA}}$ changes caused by microbial OM reworking and replacement, but little change in Phe (Fogel and Tuross, 1999). Microcosm experiments of an alga and a phagotrophic protist showed a scattered TDF pattern in the protist (e.g., $+8 \%$ for Ala and $\sim 0 \%$ o for Glu, Gutierrez-Rodriguez et al., 2014).

These "scattered" $\delta^{15} \mathrm{~N}_{\mathrm{AA}}$ changes caused by heterotrophic microbial resynthesis of only selected AAs can be quantified by relative $\Sigma V$ values, (as defined above by the average deviation in the $\delta^{15} \mathrm{~N}$ values of the trophic AAs, Ala, Asp, Glu, Ile, Leu, and Pro; McCarthy et al., 2007). Changes in $\Sigma V$ values caused by microbial OM reworking may also be decoupled from changes in

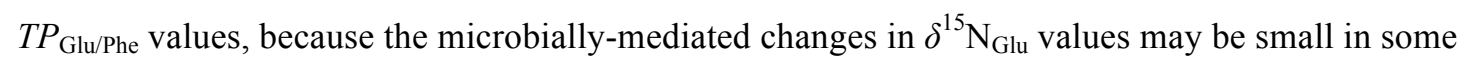
settings, relative to changes in other source AA (e.g., Gutierrez-Rodriguez et al., 2014). Thus, large increase of $\Sigma V$ values decoupled with $T P_{\text {Glu/Phe }}$ values has been hypothesized as a characteristic marker of microbial reworking (McCarthy et al., 2007). In contrast, while $\Sigma V$ values also increase in animal trophic steps to some extent, the increase of $\Sigma V$ values in animals are relatively small and usually coupled with increase of $T P_{\text {Glu/Phe }}$ values (McCarthy et al., 2007). The AAs used to calculate $\Sigma V$ values may also vary, because some AAs often cannot be measured depending on analytical protocols and the status of samples. Therefore, relative inter-sample trends in $\Sigma V$ values would be typically interpreted as diagnostic for relative degradation, whereas exact values are only generally comparable among studies.

Mechanisms for selected AA $\delta^{15} \mathrm{~N}$ changes, leading to "scattered" $\delta^{15} \mathrm{~N}_{\mathrm{AA}}$ changes linked to microbial reworking of $\mathrm{OM}$ in natural settings are still poorly understood, but we suggest several hypotheses. First, the quality of OM substrates, particularly AA content and AA imbalances between substrates and microbial biomass, may be an important factor controlling the $\delta^{15} \mathrm{~N}_{\mathrm{AA}}$ changes by heterotrophic microbes, as has been suggested for animals (Chikaraishi et al., 2015; McMahon et al., 2015a, see Section 3.2.1). For example, substantial effects of the C:N ratio (i.e., AA content) of substrates on the microbial $\delta^{15} \mathrm{~N}_{\mathrm{AA}}$ patterns were reported in microbial culture experiments using a single AA as the nitrogen source (Maki et al., 2014). Second, a mixture of de novo AA synthesis 
1082

1083

1084

1085

1086

1087

1088

1089

1090

1091

1092

1093

1094

1095

1096

1097

1098

1099

1100

1101

1102

1103

1104

1105

1106

1107

1108

1109

1110

1111

1112

1113

1114

1115

1116

1117

from inorganic nitrogen, coupled with direct AA incorporation from the environment (i.e., combination of patterns 1 and 2) could also cause scattered $\delta^{15} \mathrm{~N}_{\mathrm{AA}}$ values, due to selective microbial resynthesis of specific AAs. This mixed metabolism may be particularly important in settings with abundant available inorganic nitrogen. Third, the diversity of microbial AA metabolic pathways itself could also be a cause of the variation in $\delta^{15} \mathrm{~N}_{\mathrm{AA}}$ patterns. Finally, while only internal processes within microbial cells are considered in the above three hypothesis, mixing between microbially-produced $\mathrm{OM}$ and residue of original substrate also needs to be considered for reworking of detrital OM. Because the patterns of $\delta^{15} \mathrm{~N}_{\mathrm{AA}}$ fractionation may be different between intercellular and extracellular processes (see pattern 4), mixing of the two different OM pools could complicate $\delta^{15} \mathrm{~N}_{\mathrm{AA}}$ patterns. To use the $\Sigma V$ value properly as an indicator of heterotrophic microbial OM reworking, it is important to reproduce the scattered $\delta^{15} \mathrm{~N}_{\mathrm{AA}}$ changes in highly controlled culture experiments with heterotrophic microbes whose AA metabolic pathways are well characterized. Such future controlled experiments should particular address if $\Sigma V$ changes can be linked to specific AA, whose $\delta^{15} \mathrm{~N}$ values change under specific conditions. In addition, for assessing the factors controlling $\Sigma V$ changes, it is important to culture microbes with substrates containing varying AA contents and compositions, or with substrates containing both inorganic nitrogen and AAs.

Pattern 4: Similar $\delta^{15} \mathrm{~N}_{\mathrm{TAA}}$ and $\delta^{15} \mathrm{~N}_{\underline{\mathrm{SAA}}}$ increases, possibly by extracellular protein hydrolysis: The last $\delta^{15} \mathrm{~N}_{\mathrm{AA}}$ pattern that has been observed is very different from any others discussed: linked increases in $\delta^{15} \mathrm{~N}$ values for both TAAs and SAAs (including Phe), with similar amplitudes for all AA, possibly due to isotopic fractionation associated with extracellular protein hydrolysis to oligomers (Fig. 14d) (Hannides et al., 2013). To assimilate AAs in natural environments, heterotrophic microbes usually need to conduct extracellular hydrolysis to degrade proteins into small molecules such as free AAs or small peptides (Hoppe et al., 2002). If preferential cleavage of ${ }^{14} \mathrm{~N}-\mathrm{C}$ peptide bonds in proteins occurs during microbial extracellular hydrolysis, the residual AAs in the proteins should show ${ }^{15} \mathrm{~N}$ enrichment (Silfer et al., 1992). Furthermore, if nitrogen isotopic fractionation during peptide bond hydrolysis is similar among peptide bonds between various AAs, there should be similar increases in $\delta^{15} \mathrm{~N}$ values for TAAs and SAAs. Hannides et al. (2013) proposed this mechanism to explain the $\delta^{15} \mathrm{~N}_{\mathrm{AA}}$ values of suspended POM observed in the mesopelagic ocean (Section 4.5.2), noting that $\delta^{15} \mathrm{~N}_{\mathrm{AA}}$ changes across all AAs were consistent with a simple Raleigh distillation mechanism, suggesting an external (as opposed to metabolic) fractionation process. It has been suggested that extracellular protein hydrolysis by heterotrophic microbes plays an important role in the biogeochemical cycles in many environments (e.g., Arnosti, 2011); thus, the effect of this mechanism on the $\delta^{15} \mathrm{~N}_{\mathrm{AA}}$ values of detrital OM might be critical in various environments.

However, nitrogen isotope fractionation of AAs during peptide bond hydrolysis has been 
1118 experimentally investigated only for the abiotic hydrolysis of glycylglycine (Silfer et al., 1992), and

1119 there has been no experimental study of changes in $\delta^{15} \mathrm{~N}_{\mathrm{AA}}$ during peptide bond hydrolysis by

1120 microbes. Future experimental studies using various microbes or enzymes are needed to verify this

1121 hypothesized $\delta^{15} \mathrm{~N}_{\mathrm{AA}}$ pattern resulting from extracellular protein hydrolysis. Such studies must

1122 carefully separate measurement of microbial biomass from partially-hydrolyzed substrate in order to

1123 isolate the origins of the patterns described above.

\subsubsection{Case studies: Suspended particles in the ocean}

As discussed above Section 4.5.1, $\delta^{15} \mathrm{~N}_{\mathrm{AA}}$ analysis of detrital $\mathrm{OM}$ can provide a direct molecular-level view of $\delta^{15} \mathrm{~N}_{\text {bulk }}$ values of OM. In the ocean, early studies documented large increases in $\delta^{15} \mathrm{~N}_{\text {bulk }}$ values of POM from the mesopelagic surface ocean (e.g., Saino and Hattori, 1980; Altabet et al., 1991). Hannides et al. (2013) evaluated the mechanisms of a $\delta^{15} \mathrm{~N}_{\text {bulk }}$ increase by applying CSIA-AA to POM in the North Pacific Subtropical Gyre. Their key observation was one of large similar increases in $\delta^{15} \mathrm{~N}$ values of SAAs and TAAs between the surface and mesopelagic POM. This resulted in constant $T P$ values of POM with depth. The $\Sigma V$ values also remained low and stable with depth. Thus, they concluded that the inclusion of high-TP material or heterotrophic microbial biomass in the POM pool (i.e., patterns 2 and 3) is unlikely to be the mechanism of ${ }^{15} \mathrm{~N}$ enrichment for mesopelagic POM in the North Pacific Subtropical Gyre. They also suggested that microbial utilization of ${ }^{15} \mathrm{~N}$-enriched nitrate in the midwater as a nitrogen source for de novo AA synthesis (i.e., contribution of pattern 1) is not likely to be a major contributor to the $\delta^{15} \mathrm{~N}$ depth trends of POM.

Hannides et al. (2013) also proposed that isotopic fractionation associated with heterotrophic degradation, probably driven by extracellular hydrolysis of protein (pattern 4), controls the $\delta^{15} \mathrm{~N}_{\mathrm{AA}}$ values of midwater POM. The smaller magnitude of ${ }^{15} \mathrm{~N}$ enrichment in Lys, which is around half that of most AAs, is consistent with the proposed hydrolytic mechanism, because Lys was the only measured AA with both an amide and an amino nitrogen (Hannides et al., 2013).

1144 However, the values for $\mathrm{Thr}$ do not appear consistent with the extracellular protein hydrolysis 1145 hypothesis. The depth changes in $\delta^{15} \mathrm{~N}_{\text {Thr }}$ values were very small in the POM measured by Hannides 1146 et al. (2013). In contrast to Lys, there is no obvious explanation for the $\delta^{15} \mathrm{~N}_{\text {Thr }}$ values. There is no 1147 experimental data on the nitrogen isotopic effect on Thr during microbial heterotrophic processes; 1148 thus, future studies on $\delta^{15} \mathrm{~N}_{\text {Thr }}$ during microbial degradation, including extracellular protein 1149 hydrolysis and heterotrophic resynthesis, will be important to explain the anomalous $\delta^{15} \mathrm{~N}_{\text {Thr }}$ signature in POM and to clarify POM transformation processes in the ocean. 
1154 proteinaceous $\delta^{15} \mathrm{~N}$ values, estimated as the molar-weighted average of individual $\delta^{15} \mathrm{~N}_{\text {AA }}$ values 1155 (McCarthy et al., 2013; Calleja et al., 2013; Batista et al., 2014). When concentrations of AAs and 1156 bulk nitrogen are known, $\delta^{15} \mathrm{~N}$ values of the nitrogen fraction other than THAA (non-THAA) can be 1157 calculated by $\delta^{15} \mathrm{~N}$ mass balance. Accurate quantification of AAs and bulk nitrogen is, however, 1158 essential for these mass-balance calculations, but has been absent from many past CSIA-AA studies.

1159 We suggest that the concentration of AAs and bulk nitrogen should be routinely reported in future 1160 CSIA-AA studies, to better understand the relationship between $\delta^{15} \mathrm{~N}$ values of THAA and 1161 non-THAA in organisms and detrital OM (e.g., Cowie and Hedges, 1992; Amelung and Zhang, 1162 2001).

1163

\section{Future work and challenges}

1165

We have reviewed the current "state of the art" of using nitrogen isotopic composition of AAs for estimating the $T P$ of organisms, as well as broader applications to terrestrial and marine ecology and biogeochemical cycling. The CSIA-AA method provides information on diet sources that is more precise than classical bulk isotope methods and is now rapidly expanding into a number of fields, such as biomagnification of toxic chemicals (e.g., polychlorinated biphenyls) through the food web (Ohkouchi et al., 2016), and nitrogen exchange between symbionts and host organisms (Maeda et al., 2012). Although the advantages of CSIA-AA for studying a wide range of ecosystems are clear, at the same time the methods remain relatively new, and will benefit greatly from further improvement and development. We suggest the following as being among the main problems which need to be addressed in future studies.

1) A prerequisite for the wider application of this tool for accurately estimating $T P$ is a robust knowledge of the magnitude of $T D F_{\mathrm{AA}}$, especially, but not only, for well documented source and trophic amino acid pairings such as Phe and Glu. As discussed in Section 3.2, the most appropriate $\Delta_{\mathrm{Glu} / \text { Phe }}$ values, for instance, for calculating $T P$ in specific situations is still open to debate. In some cases, the CSIA-AA approach based on current understanding of $T D F_{\mathrm{AA}}$ has not produced ecologically realistic $T P$ values (e.g., penguins in Lorrain et al. (2009), elasmobranchs in Dale et al. (2011), dragonfish in Choy et al. (2012), killer whales in Matthews and Ferguson (2014), sperm whales in Ruiz-Cooley et al. (2014)). The following questions thus need to be addressed regarding the trophic discrimination of amino acids. A) Is the $T D F_{\mathrm{AA}}$ of a given AA value constant or variable across a wide variety of food webs? $\mathrm{B}$ ) Do $T D F_{\mathrm{AA}}$ values decrease with increasing $T P$ (Hetherington et al., 2016)? C) Are $T D F_{\mathrm{AA}}$ value more constant in the terrestrial environment than in the aquatic environment, as suggested by the work of Steffan et al. (2013, 2015a)? And most broadly, it will be critical to determine to what extent $T D F_{\mathrm{AA}}$ variations depend on the specific biochemistry and physiology of organisms and their diet, as suggested may be the case by the feeding experiments of McMahon et al. (2015a) and Chikaraishi et al. (2015). To answer these 
questions, further work focused on understanding the biochemical, physiological, and ecological mechanisms underlying $T D F_{\mathrm{AA}}$ variability is required.

2) In natural environments, microorganisms play critical roles in the food web. Although several studies have examined explicitly aspects of these roles (e.g., Steffan et al. 2017), the effects of microbial activity on the isotopic compositions of AAs require further evaluation. Knowledge of these effects is extremely important, particularly in terms of understanding complex microbially-driven nitrogen cycling in ocean and soil environments using CSIA-AA.

3 ) It is still difficult to estimate precisely the $T P$ of multivorous feeders that integrate aquatic and terrestrial food webs feeders such as humans. In some cases, such as Naito et al. (2010), the $\delta^{15} \mathrm{~N}_{\text {Phe }}$ value can be used to distinguish between aquatic and terrestrial food sources, whereas in other cases it cannot. Development of techniques which will help expand the application of CSIA-AA tools across food webs could open broad new applications in both ecological and archaeological contexts.

4) Although to date most CSIA-AA studies have relied heavily on the isotopic compositions of just two AAs, Glu and Phe, to determine $T P$, we need a more holistic application of the technique, such as by embracing the diversity in $T D F_{\mathrm{AA}}$ in 1) above, to fully exploit the utility of AA data for interpreting the diet and physiology of organisms (e.g., Bradley et al., 2015; Nielsen et al. 2015).

5) Currently, we know very little about how D-AAs affect $\delta^{15} \mathrm{~N}_{\mathrm{AA}}$ values. Because D-AAs are subject to different metabolic pathways, they should have distinct isotopic compositions from L-AAs (Engel and Macko, 1986; Takano et al., 2010; Chan, 2016), which may affect the overall $\delta^{15} \mathrm{~N}_{\mathrm{AA}}$ value, even if they are minor components.

Finally, we note that in addition to nitrogen isotopic composition, carbon isotopic composition of AAs can provide an independent measure of sources and metabolic processes, and has immense potential to help resolve some of the challenges outlined above. Furthermore, recent advances in measuring the radiocarbon of AAs may also provide detailed information on carbon transfer from the environment to consumers. This latter technique may be especially useful for soil ecosystems, where old carbon potentially makes significant contributions to microbial substrates, and should also be helpful for adding chronological information to the food web, as well as for identifying the source of AAs from various pools. While such applications are beyond the scope of the current review, development of appropriate methods is ongoing (e.g., Marom et al., 2014; Takano et al., 2015; Bour et al., 2016). Ultimately, combining CSIA-AA with such new tools offers the promise of extraordinarily high-resolution delineation of food webs in space and time, as well as the potential to quantify food web linkages between and within aquatic and terrestrial 


\section{Acknowledgments}

We dedicate this paper to the memory of John Hayes, who pioneered CSIA through the establishment of GC/IRMS. We thank JST-CREST for financially supporting the workshop. NO, ASJW, and YTY were supported by the Japan Society for the Promotion of Science. TL was supported by the Cluster of Excellence 80 "The Future Ocean" under the Deutsche Forschungsgemeinschaft (DFG).

\section{References}

Akashi, H., Gojobori, T., 2002. Metabolic efficiency and amino acid composition in the proteomes of Escherichia coli and Bacillus subtilis. Proceedings of the National Academy of Sciences of the United States of America 99, 3695-3700.

Altabet, M.A., Francois, R., 1994. Sedimentary nitrogen isotopic ratio as a recorder for surface ocean nitrate utilization. Global Biogeochemical Cycles 8, 103-116.

Altabet, M.A., Deuser, W.G., Honjo, S., Stienen, C., 1991. Seasonal and depth-related changes in the source of sinking particles in the North Atlantic. Nature 354, 136-139.

Altabet, M.A., Pilskaln, C., Thunell, R., Pride, C., Sigman, D., Chavez, F., Francois, R., 1999. The nitrogen isotope biogeochemistry of sinking particles from the margin of the Eastern North Pacific. Deep-Sea Research Part I 46, 655-679.

Ambrose, S.H., Norr, L., 1993. Carbon isotopic evidence for routing of dietary protein to bone collagen, and whole diet to bone apatite carbonate: purified diet growth experiments. In: Lamber, J., G. Grupe, G. (Eds.), Molecular Archaeology of Prehistoric Human Bone. Springer-Verlag, Berlin, Germany, pp. 1-37.

Amelung, W., Zhang X, 2001. Determination of amino acid enantiomers in soils. Soil Biology and Biochemistry 33, 553-562.

Arnosti, C., 2011. Microbial Extracellular Enzymes and the Marine Carbon Cycle. Annual Reviews of Marine Science 3, 401-425.

Bardgett, R., Cook, R., 1998. Functional aspects of soil animal diversity in agricultural grasslands. Applied Soil Ecology 10, 263-276.

Batista, F.C., Ravelo, A.C., Crusius, J., Casso, M.A., McCarthy, M.D., 2014. Compound specific amino acid $\delta^{15} \mathrm{~N}$ in marine sediments: A new approach for studies of the marine nitrogen cycle. Geochimica et Cosmochimica Acta 142, 553-569.

Bender, D.A., 2012. Amino Acid Metabolism, 3rd Edition. Wiley-Blackwell.

Bengtsson, J., Setala, H., Zheng, D., 1996. Food webs and nutrient cycling in soils: Interactions and positive feedbacks. In: Polis, G.A., Winemiller, K.O. (Eds.), Food webs: Integration of Patterns and Dynamics. Chapman \& Hall, New York, pp. 30-38.

Blum, J.D., Popp, B.N., Drazen, J.C., Choy, A.C., Johnson, M.W., 2013. Mercury isotope evidence 
for methylation below the mixed layer in the central North Pacific Ocean. Nature Geoscience 6, 879-884.

Bol, R., Ostle, N.J., Petzke, K.J., Watson, A., Cockburn, J., 1998. Amino acid ${ }^{15} \mathrm{~N} /{ }^{14} \mathrm{~N}$ analysis at natural abundances: A new tool for soil organic matter studies in agricultural systems. Isotopes in Environtal and Health Studies 34, 87-93.

Bour, A.L., Walker, B.D., Broek, T.A., McCarthy, M.D., 2016. Radiocarbon analysis of individual amino acids: Carbon blank quantification for a small-sample high-pressure liquid chromatography purification method. Analytical Chemistry 88, 3521-3528.

Bowen, G.J., 2010. Isoscapes: spatial pattern in isotopic biogeochemistry. Annual Review of Earth and Planetary Science 38, 161-187.

Bowen, G.J., West, J.B., Vaughn, B.H., Dawson, T.E., Ehleringer, J.R., Fogel, M.L., Hobson, K., Hoogewerff, J., Kendall, C., Lai, C.T., Miller, C.C., 2009. Isoscapes to address large-scale earth science challenges. EOS, Transactions American Geophysical Union 90, 109-110.

Bradley, C.J., Wallsgrove, N.J., Choy, C.A., Drazen, J.C., Hoen, D.K., Hetherington, E.D., Popp, B.N., 2015. Trophic position estimates of marine teleosts using amino acid compound specific isotopic analysis. Limnology and Oceanography: Methods 13, 476-493.

Broek, T.A.B., McCarthy, M.D., 2014. A new approach to $\delta^{15} \mathrm{~N}$ compound-specific amino acid trophic position measurements: preparative high pressure liquid chromatography technique for purifying underivatized amino acids for stable isotope analysis. Limnology and Oceanography, Methods 12, 840-852.

Broek, T.A., Walker, B.D., Andersen, D.H., McCarthy, M.D., 2013. High-precision measurement of phenylalanine $\delta^{15} \mathrm{~N}$ values for environmental samples: A new approach coupling high-pressure liquid chromatography purification and elemental analyzer isotope ratio mass spectrometry. Rapid Communications in Mass Spectrometry 27, 2327-2337.

Calleja, M.L., Batista, F., Peacock, M., Kudela, R., McCarthy, M.D., 2013. Changes in compound specific $\delta^{15} \mathrm{~N}$ amino acid signatures and $\mathrm{D} / \mathrm{L}$ ratios in marine dissolved organic matter induced by heterotrophic bacterial reworking. Marine Chemistry 149, 32-44.

Chan, H.S., Ohkouchi, N., Takano, Y., Chikaraishi, Y., 2016. Nitrogen isotope analysis of amino acid contents in carbonaceous chondrites Yamato 980115 and Allan Hills A77003. Earth, Planet, and Space 68:7 DOI 10.1186/s-40623-016-0382-8

Cheng, H.H., Bremner, J.M., 1964. Variations of nitrogen-15 abundance in soils. Science 146, 1574-1575.

Chikaraishi, Y., Kashiyama, Y., Ogawa, N.O., Kitazato, H., Ohkouchi, N., 2007. Metabolic control of nitrogen isotope composition of amino acids in macroalgae and gastropods: implications for aquatic food web studies. Marine Ecology Progress Series 342, 85-90.

Chikaraishi, Y., Ogawa, N.O., Kashiyama, Y., Takano, Y., Suga, H., Tomitani, A., Miyashita, H., 
Kitazato, H., Ohkouchi, N., 2009. Determination of aquatic food-web structure based on compound-specific nitrogen isotopic composition of amino acids. Limnology and Oceanography Method 7, 740-750.

Chikaraishi, Y., Ogawa, N.O., Ohkouchi, N., 2010. Further evaluation of the trophic level estimation based on nitrogen isotopic composition of amino acids. In: Ohkouchi, N. Tayasu, I., Koba, K. (Eds.), Earth, Life, and Isotopes. Kyoto University Press, Kyoto, pp. 37-51.

Chikaraishi, Y., Ogawa, N.O., Doi, H., Ohkouchi, N., 2011. ${ }^{15} \mathrm{~N} /{ }^{14} \mathrm{~N}$ ratios of amino acids as a tool for studying terrestrial food webs: a case study of terrestrial insects (bees, wasps, and hornets). Ecological Research 26, 835-844.

Chikaraishi, Y., Steffan, S.A, Ogawa, N.O, Ishikawa, N.F., Sasaki, Y., Tsuchiya, M., Ohkouchi, N., 2014. High-resolution food webs based on nitrogen isotopic composition of amino acids. Ecology and Evolution 4, 2423-2449.

Chikaraishi, Y., Steffan, S.A., Takano, Y., Ohkouchi, N., 2015. Diet quality influences isotopic discrimination among amino acids in an aquatic vertebrate. Ecology and Evolution 5, 2048-2059.

Choi, B., Ha, S., Lee, J., Chikaraishi, Y., Ohkouchi, N., Shin, K-H., 2017. Trophic interaction among organisms in a seagrass meadow ecosystem as revealed by bulk $\delta^{13} \mathrm{C}$ and amino acid $\delta^{15} \mathrm{~N}$ analyses. Limnology and Oceanography Method, in press.

Choy, C.A., Davison, P.C., Drazen, J.C., Flynn, A., Gier, E.J., Hoffman, J.C., McClain-Counts, J.P., Miller, T.W., Popp, B.N., Ross, S.W., 2012. Global trophic position comparison of two dominant mesopelagic fish families (Myctophidae, Stomiidae) using amino acid nitrogen isotopic analyses. PLoS ONE 7, e50133.

Choy, C.A., Popp, B.N., Hannides, C.C.S., Drazen, J.C., 2015. Trophic structure and food resources of epipelagic and mesopelagic fishes in the North Pacific Subtropical Gyre ecosystem inferred from nitrogen isotopic compositions. Limnology and Oceanography 60, 1156-1171.

Clements, K.D., Raubenheimer, D., Choat, J.H., 2009. Nutritional ecology of marine herbivorous fishes: ten years on. Functional Ecology 23, 79-92.

Clementz, M.T., Fordyce, R.E., Peek, S.L., Fox, D.L., 2014. Ancient marine isoscapes and isotopic evidence of bulk-feeding by Oligocene cetaceans. Palaeogeography Palaeoclimatology Palaeoecology 400, 28-40.

Cline, J.D., Kaplan, I.R., 1975. Isotopic fractionation of dissolved nitrate during denitrification in the eastern tropical North Pacific Ocean. Marine Chemistry 3, 271-299.

Coleman, D.C., 1996. Energetics of Detritivory and Microbivory in Soil in Theory and Practice. In: Polis, G.A., Winemiller, K.O. (Eds.), Food webs: Integration of Patterns and Dynamics. Chapman \& Hall, New York, pp. 39-50.

Corno, G., Karl, D.M., Church, M.J., Letelier, R.M., Lukas, R., Bidigare, R.R., Abbott, M.R., 2007. 
Impact of climate forcing on ecosystem processes in the North Pacific Subtropical Gyre. Journal of Geophysical Research Oceans 112, C04021.

Cowie, G.L., Hedges, J.I., 1994. Biochemical indicators of diagenetic alteration in natural organic matter mixtures. Nature 369, 304-307.

Currie, C.R., Poulsen, M., Mendenhall, J., Boomsma, J.J., Billen, J., 2006. Coevolved crypts and exocrine glands support mutualistic bacteria in fungus-growing ants. Science 311, 81-83.

Dale, J.J., Wallsgrove, N.J., Popp, B.N., Holland, K., 2011. Foraging ecology and nursery habitat use of a benthic stingray from stomach content, bulk and amino acid stable isotope analysis. Marine Ecology Progress Series 433, 221-236.

Davidson, D.W., Cook, S.C., Snelling, R.R., Chua, T.H., 2003. Explaining the abundance of ants in lowland tropical rainforest canopies. Science 300, 969-972.

Decima, M., Landry, M. R., Popp, B.N., 2013. Environmental perturbation effects on baseline $\delta^{15} \mathrm{~N}$ values and zooplankton trophic flexibility in the southern California Current Ecosystem. Limnology and Oceanography 58, 624-634.

DeNiro, M.J., Epstein, S., 1981. Influence of diet on the distribution of nitrogen isotopes in animals. Geochimica et Cosmochimica Acta 45, 341-351.

Dore, J.E., Brum, J.R., Tupas, L.M., Karl, D.M., 2002. Seasonal and interannual variability in sources of nitrogen supporting export in the oligotrophic subtropical North Pacific Ocean. Limnology and Oceanography 47, 1595-1607.

Dore, J.E., Letelier, R.M., Church, M.J., Lucas, R., Karl, D.M., 2008. Summer phytoplankton blooms in the oligotrophic North Pacific Subtropical Gyre: Historical perspective and recent observations. Progress in Oceanography 76, 2-38.

Druffel, E.R.,1997. Geochemistry of corals: Proxies of past ocean chemistry, ocean circulation, and climate. Proceedings of the National Academy of Science USA 94, 8354-8361.

Eglinton, T.I., Repeta, D.J., 2004. Organic matter in the contemporary ocean. In Treatise on Geochemistry, 2nd edition. Elsevier. pp. 151-189.

Engel, M.H., Macko, S.A., 1986. Stable isotope evaluation of the origins of amino acids in fossils. Nature 323, 531-533.

Estrada, J.A., Lutcavage, M., Thorrold, S.R., 2005. Diet and trophic position of Atlantic bluefin tuna (Thunnus thynnus) inferred from stable carbon and nitrogen isotope analysis. Marine Biology $147,37-45$.

Federherr, E., Kupka, H.J., Cerli, C., Kalbitz, K., Dunsbach, R., Loos, A., de Reus, M. Lange, L., Panetta, R.J., Schmidt, T.C. (2016) A novel tool for stable nitrogen isotope analysis in aqueous samples. Rapid Communications in Mass Spectrometry 30, 2537-2544.

Florin, S.T., Felicetti, L.A., Robbins, C.T., 2011. The biological basis for understanding and predicting dietary-induced variation in nitrogen and sulphur isotope ratio discrimination. 
Fogel, M.L., 1997. Biogeochemical record of ancient humans. Organic Geochemistry 27, 275-287.

Fogel, M.L., Cifuentes, L.A., 1993. Isotope fractionation during primary production. In: Engel, M.H., Macko, M.A. (Eds.) Organic Geochemistry: Principles and Applications. Plenum, New York, pp. 73-98.

Fogel, M.L., Tuross, N., 1999. Transformation of plant biochemicals to geological macromolecules during early diagenesis. Oecologia 120, 336-346.

Fogel, M.L., Tuross, N., Owsley, D.W., 1989. Nitrogen isotope tracers of human lactation in modern and archeological populations. Carnegie Institution of Washington Yearbook 88, 111-117.

Fouillet, H., Juillet, B., Bos, C., Mariotti, F., Gaudichon, C., Benamouzig, R., Tomé, D., 2008. Urea-nitrogen production and salvage are modulated by protein intake in fed humans: results of an oral stable-isotope-tracer protocol and compartmental modeling. The American Journal of Clinical Nutrition 87, 1702-1714.

Frisch, A.J., Ireland, M., Rizzari, J.R., Lönnstedt, O.M., Magnenat, K.A., Mirbach, C.E., Hobbs, J-P.A., 2016. Reassessing the trophic role of reef sharks as apex predators on coral reefs. Coral Reefs 35, 459-472.

Fry, B., 2006. Stable Isotope Ecology. Springer, New York, 308 pp.

Fuller, B.T., Fuller, J.L., Sage, N.E., Harris, D.A., O’Connell, T.C., Hedges, R.E.M., 2004. Nitrogen balance and $\delta^{15} \mathrm{~N}$ : why you're not what you eat during pregnancy. Rapid Communications in Mass Spectrometry 18, 2889-2896.

Fuller, B.T., Fuller, J.L., Harris, D., Hedges, R.E.M., 2006. Detection of breastfeeding and weaning in modern human infants with carbon and nitrogen stable isotope ratios. American Journal of Physical Anthropology 129, 279-293.

Gaebler, O.H., Choitz, H.C., Vitti, T.G., Vukmirovich, R., 1963. Significance of $\mathrm{N}^{15}$ excess in nitrogenous compounds of biological origin. Canadian Journal of Biochemistry and Physiology 41, 1089-1097.

Gaebler, O.H., Vitti, T.G., Vukmirovich, R., 1966. Isotope effects in metabolism of ${ }^{14} \mathrm{~N}$ and ${ }^{15} \mathrm{~N}$ from unlabeled dietary proteins. Canadian Journal of Biochemistry 44, 1249-1257.

Gelwicks, J.T., Hayes, J.M., 1990. Carbon-isotopic analysis of dissolved acetate. Analytical Chemistry 62, 535-539.

Germain, L.R., Koch, P.L., Harvey, J., McCarthy, M.D., 2013. Nitrogen isotope fractionation in amino acids from harbor seals: implications for compound-specific trophic position calculations. Marine Ecology Progress Series 482, 265-277.

Graham, B.S., Koch, P.L., Newsome, S.D., McMahon, K.W., Aurioles, D., 2009. Using isoscapes to trace the movements and foraging behavior of top predators in oceanic ecosystems. In: West, J., Bowen, G.J., Dawson, T.E., Tu, K.P. (Eds.), Isoscapes: Understanding Movement, Pattern and 
Process on Earth Through Isotope Mapping. Springer, New York, pp. 299-318.

Guilderson, T.P., McCarthy, M.D., Dunbar, R.B., Englebrecht, A., Roark, E.B., 2013. Late Holocene variations in Pacific surface circulation and biogeochemistry inferred from proteinaceous deep-sea corals. Biogeosciences 10, 6019-6028.

Gutiérrez-Rodríguez, A., Décima, M., Popp, B.N., Landry, M.R., 2014. Isotopic invisibility of protozoan trophic steps in marine food webs. Limnology and Oceanography 59, 1590-1598.

Hagen, E.M., Mccluney, K.E., Wyant, K.A., Soykan, C.U., Keller, A.C., Luttermoser, K.C., Holmes, E.J., Moore, J.C., Sabo, J.L., 2012. A meta-analysis of the effects of detritus on primary producers and consumers in marine, freshwater, and terrestrial ecosystems. Oikos 121, 1507-1515.

Hannides, C.C., Popp, B.N., Landry, M.R., Graham, B.S., 2009. Quantification of zooplankton trophic position in the North Pacific Subtropical Gyre using stable nitrogen isotopes. Limnology and Oceanography 54, 50-61.

Hannides, C.C.S., Popp, B.N., Choy, C.A., Drazen, J.C., 2013. Midwater zooplankton and suspended particle dynamics in the North Pacific Subtropical Gyre: A stable isotope perspective. Limnology and Oceanography 58, 1931-1946.

Haraguchi, T.F., Uchida, M., Shibata, Y., Tayasu, I., 2013. Contributions of detrital subsidies to aboveground spiders during secondary succession, revealed by radiocarbon and stable isotope signatures. Oecologia 171, 935-944.

Hare, P.E., Fogel, M.L., Stafford, T.W.Jr., Mitchell, A.D., Hoering, T.C., 1991. The isotopic composition of carbon and nitrogen in individual amino acids isolated from modern and fossil proteins. Journal of Archaeological Science 18, 277-292.

Hayes, J.M., Freeman, K.H., Hoham, C.H., Popp, B.N., 1990. Compound-specific isotopic analyses, a novel tool for reconstruction of ancient biogeochemical processes. Organic Geochemistry 16, $1115-1128$.

Hayes, J.M., 2001. Fractionation of carbon and hydrogen isotopes in biosynthetic processes. Reviews in Mineralogy and Geochemistry 43, 225-277.

Heaton, T.H.E., Vogel, J.C., Chevallerie, G. von la, Collett, G., 1986. Climatic influence on the isotopic composition of bone nitrogen. Nature 322, 822-823.

Hedges, J.I., 1992. Global biogeochemical cycles: progress and problems. Marine Chemistry 39, 67-93.

Hetherington, E.D., Olson, R.J., Drazen, J.C., Lennert-Cody, C.E., Balance, L.T., Kaufmann, R.S., Popp, B.N., 2017. Spatial food-web structure in the eastern tropical Pacific Ocean based on compound-specific nitrogen isotope analysis of amino acids. Limnology and Oceanography, in press.

Hill, T.M., Myrvold, C.R., Spero, H.J., Guilderson, T.P., 2014. Evidence for benthic-pelagic food 
web coupling and carbon export from California margin bamboo coral archives. Biogeosciences 11, 3845-3854.

Hilting, A.K., Currin, C.A., Kosaki, R.K., 2013. Evidence for benthic primary production support of an apex predator-dominated coral reef food web. Marine Biology 160, 1681-1695.

Hobson, K.A., Clark, R.G., 1992. Assessing Avian Diets Using Stable Isotopes II: Factors Influencing Diet-Tissue Fractionation. The Condor 94, 189-197.

Hobson, K.A., Barnett-Johnson, R., Cerling, T., 2010. Using isoscapes to track animal migration. In: West, J., Bowen, G.J., Dawson, T.E., Tu, K.P. (Eds.), Isoscapes: Understanding Movement, Pattern and Process on Earth Through Isotope Mapping. Springer, New York, pp. 273-298. Hobson, K.A., Van Wilgenburg, S.L., Wassenaar, L.I., Larson, K., 2012. Linking hydrogen $\left(\delta^{2} H\right)$ isotopes in feathers and precipitation: sources of variance and consequences for assignment to isoscapes. PLoS ONE 7, e35137.

Hoch, M.P., Fogel M.L., Kirchman D.L., 1992. Isotope fractionation associated with ammonium uptake by a marine bacterium. Limnology and Oceanography 37, 1447-1459.

Hoegh-Guldberg, O., Bruno, J.F., 2010. The impact of climate change on the world's marine ecosystems. Science 328, 1523-1528.

Hoen, D.K., Kim, S.L., Hussey, N.E., Wallsgrove, N.J., Drazen, J.C., Popp, B.N., 2014. Amino acid ${ }^{15} \mathrm{~N}$ trophic enrichment factors of four large carnivorous fishes. Journal of Experimental Marine Biology and Ecology 453, 76-83.

Hoering, T.C., Ford, H.T., 1960. The isotope effect in the fixation of nitrogen by Azotobacter. Journal of American Chemical Society 82, 376-378.

Hoppe, H.-G., Arnosti, C., Herndl, G.J., 2002. Ecological significance of bacterial enzymes in the marine environment. In: Burns, R.G.,, Dick, R.P. (Eds.), Enzymes in the Environment: Activity, Ecology, and Applications. Marcel Dekker, New York, pp. 73-108.

Hussey, N.E., MacNeil, M.A., Siple, M.C., Popp, B.N., Dudley, S.F.J., Fisk, A.T., 2015. Expanded Trophic complexity among large sharks. Food Webs 4, 1-7.

Hyodo, F., Matsumoto, T., Takematsu, Y. Itioka, T., 2015. Dependence of diverse consumers on detritus in a tropical rain forest food web as revealed by radiocarbon analysis. Functional Ecology 29, 423-429.

Ishikawa, N.F., Kato, Y., Togashi, H., Yoshimura, M., Yoshimizu, C., Okuda, N., Tayasu, I., 2014. Stable nitrogen isotopic composition of amino acids reveals food web structure in stream ecosystems. Oecologia 175, 911-922.

Ishikawa, N.F., Hayashi, F., Sasaki, Y., Chikaraishi, Y., Ohkouchi, N., 2017. Trophic discrimination factor of nitrogen isotopes within amino acids in the dobsonfly Protohermes grandis (Megaloptera: Corydalidae) larvae in a controlled feeding experiment. Ecology and Evolution, in press. 
Jaeger, A., Lecomte, V.J., Weimerskirch, H., Richard, P., Cherel, Y., 2010. Seabird satellite tracking validates the use of latitudinal isoscapes to depict predators' foraging areas in the Southern Ocean. Rapid Communications in Mass Spectrometry 24, 3456-3460.

Karl, D.M., Letelier, R.M., Tupas, L., Dore, J., Christian, J., Hebel, D., 1997. The role of nitrogen fixation in biogeochemical cycling in the subtropical North Pacific Ocean. Nature 388, 533-538.

Karl, D.M., Bidigare, R.R., Letelier, R.M., 2001. Long-term changes in plankton community structure and productivity in the North Pacific Subtropical Gyre: the domain shift hypothesis. Deep Sea Research Part II 48, 1449-1470.

Keil, R.G., Tsamakis, E., Hedges, J.I., 2000. Early diagenesis of particulate amino acids in marine systems. In: Goodfriend, G.A., Collins, M.J., Fogel, M.L., Macko, S.A., Wehmiller, J.F. (Eds.), Perspectives in Amino Acid and Protein Geochemistry. Oxford University Press, New York. pp. 69-82.

Kienast, S.S., Calvert, S.E., Pedersen, T.F., 2002. Nitrogen isotope and productivity variations along the northeast Pacific margin over the last 120 kyr: Surface and subsurface paleoceanography. Paleoceanography 17, 1055, doi:10.1029/2001PA000650

Koch, P.L., 2007. Isotopic study of the biology of modern and fossil vertebrates. Stable isotopes in Ecology and Environmental Science 2, 99-154.

Krueger, H.W., Sullivan, C.H., 1984. Models for carbon isotope fractionation between diet and bone. In: Turnland, J.F., Johnson, P.E. (Eds.), Stable Isotopes in Nutrition ACS Symposium Series, 258. American Chemical Society, Washington D.C., pp. 205-222.

Kruger, B.R., Werne, J.P., Branstrator, D.K., Hrabik, T.R., Chikaraishi, Y., Ohkouchi, N., Minor, E.C., 2016. Organic matter transfer in Lake Superior's food web: Insights from bulk and molecular stable isotope and radiocarbon analyses. Limnology and Oceanography 61, 149-164.

Kruse, S., Pakhomov, E.A., Hunt, B., Chikaraishi, Y., Ogawa, N.O., Bathmann, U., 2015. Uncovering the trophic relationship between Themisto gaudichaudii and Salpa thompsoni in the Antarctic Polar Frontal Zone. Marine Ecology Progress Series 529, 63-74.

Ku, H.H., 1966. Notes on the use of propagation of error formulas. Journal of Research of the National Bureau of Standards 70, 263-273.

Larsen, T., Taylor, D.L., Leigh, M.B., O'Brien, D.M., 2009. Stable isotope fingerprinting: a novel method for identifying plant, fungal, or bacterial origins of amino acids. Ecology 90, 3526-3535.

Larsen, T., Ventura, M., Andersen, N., O’Brien, D.M., Piatkowski, U., McCarthy, M.D., 2013. Tracing carbon sources through aquatic and terrestrial food webs using amino acid stable isotope fingerprinting. PloS ONE 8, e73441.

Larsen, T., Pollierer, M.M., Holmstrup, M., D'Annibale, A., Maraldo, K., Andersen, N., Eriksen, J., 
2016a. Substantial nutritional contribution of bacterial amino acids to earthworms and enchytraeids: A case study from organic grasslands. Soil Biology and Biochemistry 99, 21-27.

Larsen, T., Ventura, M., Maraldo, K., Triadó-Margarit, X., Casamayor, E.O., Wang, Y.V., Andersen, N., O'Brien, D.M., 2016b. The dominant detritus-feeding invertebrate in Arctic peat soils derives its essential amino acids from gut symbionts. Journal of Animal Ecology 85, $1275-1285$.

Loder, J.W., Shore, J.A., Hannah, C.G., Petrie, B.D., 2001. Decadal-scale hydrographic and circulation variability in the Scotia-Maine region. Deep-Sea Research Part II 48, 3-35.

Lorrain, A., Graham, B., Menard, F., Popp, B.N., Bouillon, S., Van Breugel, P., Cherel, Y., 2009. Nitrogen and carbon isotope values of individual amino acids: a tool to study foraging ecology of penguins in the Southern Ocean. Marine Ecology Progress Series 391, 293-306.

Lorrain, A., Graham, B., Popp, B.N., Allain, V., Olson, R.J., Hunt, B.P.V., Potier, M., Fry, B., Galvan-Magna, F., Menkes, C.E.R., Kaehler, S., Menard, F., 2015. Nitrogen isotopic baselines and implications for estimating foraging habitat and trophic position of yellowfin tuna in the Indian and Pacific Oceans. Deep-Sea Research II 113, 188-198.

MacKenzie, K.M., Palmer, M.R., Moore, A., Ibbotson, A.T., Beaumont, W.R., Poulter, D.J., Trueman, C.N., 2011. Locations of marine animals revealed by carbon isotopes. Scientific Reports 1:21 doi:10.1038/srep00021.

Macko, S., Estep, M., 1984. Microbial alteration of stable nitrogen and carbon isotopic compositions of organic matter. Organic Geochemistry 6, 787-790.

Macko, S.A., Fogel Estep, M.L., Engel, M.H., Hare, P.E., 1986. Kinetic fractionation of nitrogen isotopes during amino acid transamination. Geochimica et Cosmochimica Acta 50, 2143-2146.

Macko S.A., Fogel, M.L., Hare, P.E., Hoering, T.C., 1987. Isotopic fractionation of nitrogen and carbon in the synthesis of amino acids by microorganisms. Chemical Geology 65, 79-92.

Madigan, D.J., Baumann, Z., Fisher, N.S., 2012a. Pacific bluefin tuna transport Fukushima-derived radionuclides from Japan to California. Proceedings of the National Academy of Sciences USA 109, 9483-9486.

Madigan, D.J., Litvin, S.Y., Popp, B.N., Carlisle, A.B., Farwell, C.J., Block, B.A., 2012b. Tissue turnover rates and isotopic trophic discrimination factors in the endothermic teleost, Pacific Bluefin tuna (Thunnus orientalis). PLoS ONE 7, e49220.

Madigan, D.J., Baumann, Z., Snodgrass, O.E., Ergul, H.A., Dewar, H., Fisher, N.S., 2013. Radiocesium in Pacific bluefin tuna Thunnus orientalis in 2012 validates new tracer technique. Environmental Science and Technology 2287-2294.

Madigan, D.J., Baumann, Z., Carlisle, A.B., Hoen, D.K., Popp, B.N., Dewar, H., Snodgrass, O.E., Block, B.A., Fisher, N.S., 2014. Reconstructing transoceanic migration patterns of Pacific bluefin tuna using a chemical tracer toolbox. Ecology 95, 1674-1683. 
Madigan D.J., Chiang W-C., Wallsgrove N.J., Popp B.N., Kitagawa T., Choy C.A., Tallmon J., Ahmed N., Fisher N.S., Sun C., 2016. Intrinsic tracers reveal recent foraging ecology of giant Pacific bluefin tuna at their primary spawning grounds. Marine Ecology Progress Series 553, 253-266.

Maeda, T., Hirose, E., Chikaraishi, Y., Kawato, M., Takishita, K., Yoshida, T., Verbruggen, H., Tanaka, J., Shimamura, S., Takai, Y., Tsuchiya, M., Iwai, K., Maruyama, T., 2012. Algivore or phototroph? Plakobranchus ocellatus (Gastropoda) continuously acquires kleptoplasts and nutrition from multiple algal species in nature. PloS ONE 7, e42024.

Maki, K., Ohkouchi, N., Chikaraishi, Y., Fukuda, H., Miyajima, T., Nagata, T., 2014. Influences of nitrogen substrates and substrate $\mathrm{C}: \mathrm{N}$ ratios on the nitrogen isotopic composition of amino acids from the marine bacterium Vibrio harveyi. Geochimica et Cosmochimica Acta 140, 521-530.

Mann, M.E., Zhang, Z., Hughes, M.K., Bradley, R.S., Miller, S.K., Rutherford, S., Ni, F., 2008. Proxy-based reconstructions of hemispheric and global surface temperature variations over the past two millennia. Proceedings of the National Academy of Sciences USA 105, 13252-13257.

Marom, A., McCullagh, S.O., Higham, T.F.G., Sinitsyn, A.A., Hedges, R.E.M., 2012. Single amino acid radiocarbon dating of Upper Paleolithic modern humans. Proceedings of National Academy of Science USA 109, 6878-6881.

Martinez del Rios, C., Wolf, N., Carlton, S.A., Gunnes, L.Z., 2009. Isotopic ecology ten years after a call for more laboratory experiments. Biological Reviews 84, 91-111.

Matthews, C.J.D., Ferguson, S.H., 2014. Spatial segregation and similar trophic-level diet among eastern Canadian Arctic/north-west Atlantic killer whales inferred from bulk and compound specific isotopic analysis. Journal of Marine Biological Association of the United Kingdom 94, 1343-1355.

McCarthy, M., Hedges, J., Benner R., 1996. Major biochemical composition of dissolved high molecular weight organic matter in seawater. Marine Chemistry 55, 281-297.

McCarthy, M.D., Benner, R., Lee, C., Fogel, M.L., 2007. Amino acid nitrogen isotopic fractionation patterns as indicators of heterotrophy in plankton, particulate, and dissolved organic matter. Geochimica et Cosmochimica Acta 71, 4727-2744.

McCarthy, M.D., Lehman, J., Kudela, R., 2013. Compound-specific amino acid $\delta^{15} \mathrm{~N}$ patterns in marine algae: Tracer potential for cyanobacterial vs. eukaryotic organic nitrogen sources in the ocean. Geochimica et Cosmochimica Acta 103, 104-120.

McClelland, J.W., Montoya, J.P., 2002. Trophic relationships and the nitrogen isotopic composition of amino acids in plankton. Ecology 83, 2173-2180.

McCutchan, J.H.Jr, Lewis, W.M., Kendall, C., McGrath, C.C., 2003. Variation in trophic shift for stable isotope ratios of carbon, nitrogen, and sulfur. Oikos 102, 378-390.

McMahon, K.W., McCarthy, M.D., 2016. Embracing variability in amino acid $\delta^{15} \mathrm{~N}$ fractionation: 
McMahon, K.W., Hamady, L., Thorrold, S.R., 2013a. Ocean ecogeochemistry - A review. Oceanography and Marine Biology - an Annual Review 51, 327-374.

McMahon, K.W., Hamady, L., Thorrold, S.R., 2013b. A review of ecogeochemistry approaches to estimating movements of marine animals. Limnology and Oceanography 58, 697-714.

McMahon, K.W., Elsdon, T., Thorrold, S.R., McCarthy, M., 2015a. Trophic discrimination of nitrogen stable isotopes in amino acids varies with diet quality in a marine fish. Limnology and Oceanography 60, 1076-1087.

McMahon, K.W., Polito, M., Abel, S., McCarthy, M.D., Thorrold, S.R., 2015b. Carbon and nitrogen

McMahon, K.W., McCarthy, M.D., Sherwood, O.A., Larsen, T., Guilderson, T.P., 2015c. Millennial-scale plankton regime shifts in the subtropical North Pacific Ocean. Science, 350, $1530-1533$.

Merritt, D.A., Hayes, J.M., 1994. Nitrogen isotopic analyses by isotope-ratio-monitoring gas chromatography/mass spectrometry. Journal of the American Society for Mass Spectrometry 5 , 387-397.

Metges, C.C., Petzke, K.J., 1997. Measurement of ${ }^{15} \mathrm{~N} /{ }^{14} \mathrm{~N}$ isotopic composition in individual plasma free amino acids of human adults at natural abundance by gas chromatography-combustion isotope ratio mass spectrometry. Analytical Biochemistry 247, 158-164.

Metges, C.C., Petzke, K.-J., Henning, U., 1996. Gas chromatography/combustion/isotope ratio mass spectrometric composition of $\mathrm{N}$-acetyl- and $\mathrm{N}$-pivaloyl amino acid esters to measure " $\mathrm{N}$ isotopic abundances in physiological samples: a pilot study on amino acid synthesis in the upper gastro-intestinal tract of minipigs. Journal of Mass Spectrometry 31, 367-376.

Mill, A.C., Pinnegar, J.K., Polunin, N.V.C., 2007. Explaining isotope trophic-step fractionation: why herbivorous fish are different. Functional Ecology 21, 1137-1145.

Miller, M.J., Chikaraishi, Y., Ogawa, N.O., Yamada, Y., Tsukamoto, K., Ohkouchi, N., 2012. A low trophic position of Japanese eel larvae indicates feeding on marine snow. Biology Letters 9 , DOI: $10.1098 /$ rsbl.2012.0826

Minagawa, M., Wada, E., 1984. Stepwise enrichment of ${ }^{15} \mathrm{~N}$ along food chains. Further evidence and the relation between ${ }^{15} \mathrm{~N}$ and animal age. Geochimica et Cosmochimica Acta 48, 1135-1140.

Miura, K., Goto, A.S., 2012. Stable nitrogen isotopic fractionation associated with transamination of glutamic acid to aspartic acid: implications for understanding ${ }^{15} \mathrm{~N}$ trophic enrichment in ecological food webs. Researches in Organic Geochemistry 28, 13-17.

Miyachi, S., Mayahara, T., Tsushima, K., Sasada, K., Kohno, E., Ogawa, N.O., Chikaraishi, Y., Ohkouchi, N., 2015. Approach to determine individual trophic level and the difference in food 
sources of Japanese anchovy Engraulis japonicus in Sagami Bay, based on compound-specific nitrogen stable isotope analysis of amino acids. Fisheries Science, 81, 1053-1062.

Miyake, Y., Wada, E., 1967. The abundance ratio of ${ }^{15} \mathrm{~N} /{ }^{\prime} \mathrm{N}$ in marine environments. Records in Oceanographic Works in Japan 9, 32-53.

Moore, J.C., de Ruiter, P.C., 2012. Energetic Food Webs. Oxford University Press, Oxford, 344 pp. Naito, Y.I., Chikaraishi, Y., Ohkouchi, N., Mukai, H., Shibata, Y., Honch, N. V, Dodo, Y., Ishida, H., Amano, T., Ono, H., Yoneda, M., 2010a. Dietary reconstruction of the Okhotsk Culture of Hokkaido, Japan, based on nitrogen composition of amino acids: implications for correction of 14C marine reservoir effects on human bone. Radiocarbon 52, 671-681.

Naito, Y.I., Honch, N.V., Chikaraishi, Y., Ohkouchi, N., Yoneda, M., 2010b. Quantitative evaluation of marine protein contribution in ancient diets based on nitrogen isotope ratios of individual amino acids in bone collagen: An investigation at the Kitakogane Jomon site. American Journal of Physical Anthropology 143, 31-40.

Naito, Y.I., Chikaraishi, Y., Ohkouchi, N., Drucker, D.G., Bocherens, H., 2013a. Nitrogen isotopic composition of collagen amino acids as an indicator of aquatic resource consumption: insights from Mesolithic and Epipalaeolithic archaeological sites in France. World Archaeology 45, 338-359.

Naito, Y.I., Chikaraishi, Y., Ohkouchi, N., Yoneda, M., 2013b. Evaluation of carnivory in inland Jomon hunter-gatherers based on nitrogen isotopic compositions of individual amino acids in bone collagen. Journal of Archaeological Science 40, 2913-2923.

Naito, Y.I., Bocherensa, H., Chikaraishi, Y., Drucker, D.G., Wißing, C., Yoneda, M., Ohkouchi, N., 2016a. An overview of methods used for the detection of aquatic resource consumption by humans: compound-specific delta N-15 analysis of amino acids in archaeological materials. Journal of Archaeological Science 6, 720-732.

Naito, Y.I., Chikaraishi, Y., Drucker, D.G., Ohkouchi, N., Semal, P., Wißing, C., Bocherens, H., 2016b. Ecological niche of Neanderthals from Spy Cave revealed by nitrogen isotopes of individual amino acids in collagen. Journal of Human Evolution 93, 82-90.

Naito, Y.I., Germonpré, M., Chikaraishi, Y., Ohkouchi, N., Drucker, D.G., Hofreiter, M., Edwards, M.A., Hobson, K.A., Wißing, C., Bocherens, H., 2016. Evidence for herbivorous cave bears (Ursus spelaeus) in Goyet Cave, Belgium: implications for paleodietary reconstruction of fossil bears using amino acid $\delta^{15} \mathrm{~N}$ approaches. Journal of Quaternary Science 31, 598-606.

Nakashita, R., Suzuki, Y., Akamatsu, F., Naito, Y.I., Sato-Hashimoto, M., Tsubota, T., 2011. Ecological application of compound-specific stable nitrogen isotope analysis of amino acids A case study of captive and wild bears. Researches in Organic Geochemistry 27, 73-79.

Nakazawa, T., Sakai, Y., Hsieh, C-H., Koitabashi, T., Tayasu, I., Yamamuro, N., Okuda, N., 2010. Is the relationship between body size and trophic niche position time-invariant in a predatory 
fish? first stable isotope evidence. PLoS ONE 5, e9120.

Nielsen, J.M., Popp, B.N., Winder, M., 2015. Meta-analysis of amino acid stable nitrogen isotope ratios for estimating trophic position in marine organisms. Oecologia 178, 1-12.

O’Brien, D.M., Fogel, M.L., Boggs, C.L., 2002. Renewable and nonrenewable resources: amino acid turnover and allocation to reproduction in Lepidoptera. Proceedings of the National Academy of Sciences of the USA 99, 4413-4418.

O’Brien, D.M.O., Boggs, C.L., Fogel, M.L., 2004. Making eggs from nectar: The role of life history and dietary carbon turnover in butterfly reproductive resource allocation. Oikos 105, 279-291.

Ogawa, N.O., Koitabashi, T., Oda, H., Nakamura, T., Ohkouchi, N., Wada, E., 2001. Fluctuations of nitrogen isotope ratio of gobiid fish specimens and sediments in Lake Biwa during the 20th century. Limnology and Oceanography 46, 1228-1236.

O'Reilly, C.M., Hecky, R.E., CohenA.S., Plisnier, P.-D., 2002. Interpreting stable isotopes in food 
Oceanography 47, 306-309.

Papastamatiou, Y.P., Meyer, C.G., Kosaki, R.K., Wallsgrove, N.J., Popp, B.N., 2015. Movements and foraging of predators associated with mesophotic coral reefs and their potential for linking ecological habitats. Marine Ecology Progress Series 521, 155-170.

Parwel, A., Ryhage, R., Wickman, F. E., 1957. Natural variations in the relative abundances of the nitrogen isotopes. Geochimica et Cosmochimica Acta 11, 165-170.

Pershing, A.J., Greene, C.H., Hannah, C., Sameoto, D., Head, E., Mountain, D.G., Jossi, J.W., Benfield, M.C., Reid, P.C., Durbin, T.G., 2001. Oceanographic responses to climate in the Northwest Atlantic Ocean. Oceanography 14, 76-82.

Peterson, H., Luxton, M., 1982. A comparative analysis of soil fauna populations and their role in decomposition processes. Oikos 39, 287-388.

Petzke, K.J., Boeing, H., Klaus, S., Metges, C.C., 2005. Carbon and nitrogen stable isotopic composition of hair protein and amino acids can be used as biomarkers for animal-derived dietary protein intake in humans. Nutrition Methodology 135, 1515-1520.

Petzke, K.J., Feist, T., Fleig, W.E., Metges, C.C., 2006. Nitrogen isotopic composition in hair protein is different in liver cirrhotic patients. Rapid Communications in Mass Spectrometry 20, 2973-2978.

Petzke, K.J., Fuller, B.T., Metges, C.C., 2010. Advances in natural stable isotope ratio analysis of human hair to determine nutritional and metabolic status. Current Opinion Clinical Nutrition Metabolic Care 13, 532-540.

Phillips, D.L., Gregg, J.W., 2001. Uncertainty in source partitioning using stable isotopes. Oecologia 127, 171-179.

Polis, G.A., 1991. Complex trophic interactions in deserts: an empirical critique of food-web theory. The American Naturalist 138, 123-155.

Polis, G.A., Strong, D.R., 1996. Food web complexity and community dynamics. The American Naturalist 147, 813-846.

Popp, B.N., Graham, B.S., Olson, R.J., Hannides, C.C.S., Lott, M.J., Lopez-Ibarra, G.A., Galvan-Magana, F., Fry, B., 2007. Insight into the trophic ecology of yellowfin tuna, Thunnus albacares, from compound-specific nitrogen isotope analysis of protenaceous amino acids. In: Dawson, T., Siegwolf, R. (Eds.), Stable Isotopes as Indicators of Ecological Change, Elsevier Academic Press, Terrestrial Ecology Series, pp. 173-190.

Post, D.M., 2002. Using stable isotopes to estimate trophic position: models, methods, and assumptions. Ecology 83, 703-718.

Ramos, R., González-Solís, J., 2012. Trace me if you can: the use of intrinsic biogeochemical markers in marine top predators. Frontiers in Ecology and the Environment 10, 258-266.

Reitsema, L.J., 2013. Beyond diet reconstruction: Stable isotope applications to human physiology, 

health, and nutrition. America Journal of Human Biology 25, 445-456.

Reitsema, L.J., Muir, A.B., 2015. Growth velocity and weaning $\delta^{15} \mathrm{~N}$ "Dips" during ontogeny in Macaca mulatta. Americal Journal of Physical Anthropology 157, 347-357.

Roark, E.B., Guilderson, T.P., Dunbar, R.B., Fallon, S.J., Mucciarone, D.A., 2009. Extreme longevity in proteinaceous deep-sea corals. Proceedings of the National Academy of Sciences of the USA 106, 5204-5208.

Robbins, C.T., Felicetti, L.A., Sponheimer, M., 2005. The effect of dietary protein quality on nitrogen isotope discrimination in mammals and birds. Oecologia 144, 534-540.

Robbins, C.T., Felicetti, L.A., Florin, S.T., 2010. The impact of protein quality on stable nitrogen isotope ratio discrimination and assimilated diet estimation. Oecologia 162, 571-579.

Robinson, L.F., Adkins, J.F., Frank, N., Gagnon, A.C., Prouty, N.G., Roark, E.B., Van de Flierdt, T., 2014. The geochemistry of deep-sea coral skeletons: a review of vital effects and applications for palaeoceanography. Deep-Sea Res Part II 99, 184-198.

Rolff, C., 2000. Seasonal variation in $\delta^{13} \mathrm{C}$ and $\delta^{15} \mathrm{~N}$ of size-fractionated plankton at a coastal station in the northern Baltic Proper. Marine Ecology Progress Series 203, 47-65.

Romek, K.M., Julien, M., Frasquet-Darrieux, M., Tea, I., Antheaume, I., Hankard, R., Robins, R.J., 2013. Human baby hair amino acid natural abundance ${ }^{15} \mathrm{~N}$-isotope values are not related to the ${ }^{15} \mathrm{~N}$-isotope values of amino acids in mother's breast milk protein. Amino Acids 45, 1365-1372. Roth, J.D., Hobson, K.A., 2000. Stable carbon and nitrogen isotopic fractionation between diet and tissue of captive red fox: implications for dietary reconstruction. Canadian Journal of Zoology $78,848-852$.

Ruiz-Cooley, R.I., Balance, L.T., McCarthy, M.D., 2013. Range expansion of the jumbo squid in the NE Pacific: $\delta^{15} \mathrm{~N}$ decrypts multiple origins, migration, and habitat use. PLoS ONE 8, e59651.

Ruiz-Cooley, R.I., Koch, P.L., Fiedler, P.C., McCarthy, M.D., 2014. Carbon and nitrogen isotopes from top predator amino acids reveal rapidly shifting ocean biochemistry in the Outer California Current. PLoS ONE 9, e110355.

Sacks, G.L., Brenna, J. T., 2005. ${ }^{15} \mathrm{~N} /{ }^{14} \mathrm{~N}$ position-specific isotopic analyses of polynitrogenous amino acids. Analytical Chemistry 77, 1013-1019.

Saino, T., Hattori A., $1980 .{ }^{15} \mathrm{~N}$ Natural abundance in oceanic suspended particulate matter. Nature 283, 752-754.

Schiff, J.T., Batista, F., Sherwood, O.A., Guilderson, T.P., Hill, T.M., Ravelo, A.C., McMahon, K.W., McCarthy, M.D., 2014. Compound specific amino acid $\delta^{13} \mathrm{C}$ patterns in a deep-sea proteinaceous coral: implications for reconstructing detailed $\delta^{13} \mathrm{C}$ records of exported primary production. Marine Chemistry 166, 82-91.

Schulten, H.R., Schnitzer M., 1997. The chemistry of soil organic nitrogen: a review. Biology and Fertility of Soils 26, 1-15. 
Schwarcz, H.P., 1991. Some theoretical aspects of isotope paleodiet studies. Journal of Archaeological Science 18, 261-275.

Schwarcz, H.P., Dupras, T.L., Fairgrieve, S.I., 1999. ${ }^{15} \mathrm{~N}$ Enrichment in the Sahara: in search of a global relationship. Journal of Archaeological Science 26, 629-636.

Schwartz-Narbonne, R., Longstaffe, F.J., Metcalfe, J.Z., Zazula, G., 2015. Solving the woolly mammoth conundrum: amino acid ${ }^{15} \mathrm{~N}$-enrichment suggests a distinct forage or habitat. Scientific Reports 5, 9791. doi:10.1038/srep09791

Scott, J. H., O'Brien, D.M., Emerson, D., Sun, H., McDonald, G.D., Salgado, A. Fogel, M.L., 2006. Examination of carbon isotopic effects associated with amino acid biosynthesis. Astrobiology 6 , 867-880.

Seminoff, J., Benson, S.R., Arthur, K.E., Tomoharu, E., Dutton, P.H., Tapilatu, R.F., Popp, B.N., 2012. Stable isotope tracking of endangered sea turtles: Validation with satellite telemetry and $\delta^{15} \mathrm{~N}$ analysis of amino acids. PLoS ONE 7, e37403.

Sherwood, O.A., Heikoop, J.M., Scott, D.B., Risk, M.J., Guilderson, T.P., McKinney, R.A., 2005. Stable isotopic composition of deep-sea gorgonian corals Primnoa spp.: a new archive of surface processes. Marine Ecology Progress Series 301, 135-148.

Sherwood, O.A., Lehmann, M.F., Schubert, C.J., Scott, D.B., McCarthy, M.D., 2011. Nutrient regime shift in the western North Atlantic indicated by compound-specific $\delta^{15} \mathrm{~N}$ of deep-sea gorgonian corals. Proceedings of the National Academy of Science USA 108, 1011-1015.

Sherwood, O.A., Guilderson, T.P., Batista, F.C., Schiff, J.T., McCarthy, M.D., 2014. Increasing subtropical North Pacific Ocean nitrogen fixation since the Little Ice Age. Nature 505, 78-81.

Silfer, J.A., Engel, M.H., Macko, S.A., Jumeau, E.J., 1991. Stable carbon isotope analysis of amino acid enantiomers by conventional isotope ratio mass spectrometry and combined gas chromatography/isotope ratio mass spectrometry. Analytical Chemistry 63, 370-374.

Silfer, J.A., Engel, M.H., Macko, S.A., 1992. Kinetic fractionation of stable carbon and nitrogen isotopes during peptide bond hydrolysis: Experimental evidence and geochemical implications. Chemical Geology 101, 211-221.

Simpson, I.A., Bol, R., Dockrill, S.J., Petzke, K.J., Evershed, R.P., 1997. Compound-specific $\delta^{15} \mathrm{~N}$ amino acid signals in palaeosols as indicators of early land use : a preliminary study. Archaeological Prospection 4, 147-152.

Simpson, I., Bol, R., Bull, I., Evershed, R., Petzke, K., Dockrill, S., 1999. Interpreting early land management through compound specific stable isotope analyses of archaeological soils. Rapid Communications in Mass Spectrometry 13, 1315-1319.

Steffan, S., Chikaraishi, Y., Horton, D.R., Ohkouchi, N., Singleton, M.E., Miliczky, E., Hogg, D.B., Jones, V.P., 2013. Trophic hierarchies illuminated via amino acid isotopic analysis. PLoS ONE $8, \mathrm{e} 76152$. 
Steffan, S.A., Chikaraishi, Y., Currie, C.R., Horn, H., Gaines-Day, H.R., Pauli, J.N., Zalapa, J.E., Ohkouchi, N., 2015a. Microbes are trophic analogs of animals. Proceedings of the National Academy of Sciences USA 112, 15119-15124.

Steffan, S.A., Chikaraishi, Y., Dharampal, P.S., Pauli, J.N., Horn, H., Currie, C.R., Guédot, C., Ohkouchi, N., 2017. Unpacking brown foodwebs: Animal trophic identity reflects rampant microbivory. Ecology and Evolution. in revision.

Steffan, S.A., Chikaraishi, Y., Horton, D.R., Miliczky, E., Zalapa, J.E., Jones, V.P., Ohkouchi, N. 2015b. Beneficial or not? Decoding carnivore roles in plant protection. Biological Control 91, 34-41.

Strzepek, K.M., Thresher, R.E., Revill, A.T., Smith, C.I., Komugabe, A.F., Fallon, S.F., 2014 Preservation effects on the isotopic and elemental composition of skeletal structures in the deep-sea bamboo coral Lepidisis spp. (Isididae). Deep Sea Res Part II 99, 199-206.

Styring, A.K., Sealy, J.C., Evershed, R.P., 2010. Resolving the bulk $\delta^{15} \mathrm{~N}$ values of ancient human and animal bone collagen via compound-specific nitrogen isotope analysis of constituent amino acids. Geochimica et Cosmochimica Acta 74, 241-251.

Styring, A.K., Kuhl, A., Knowles, T.D.J., Fraser, R.A., Bogaard, A., Evershed, R.P., 2012. Practical considerations in the determination of compound-specific amino acid $\delta^{15} \mathrm{~N}$ values in animal and plant tissues by gas chromatography-combustion-isotope ratio mass spectrometry, following derivatisation to their $\mathrm{N}$-acetylisopropyl esters. Rapid Communications in Mass Spectrometry 26, 2328-2334.

Styring, A.K., Manning, H., Fraser, R.A., Wallace, M., Jones, G., Charles, M., Heaton, T.H.E., Bogaard, A., Evershed, R.P., 2013. The effect of charring and burial on the biochemical composition of cereal grains: Investigating the integrity of archaeological plant material. Journal of Archaeological Science 40, 4767-4779.

Takano, Y., Kashiyama, Y., Ogawa, N.O., Chikaraishi, Y., Ohkouchi, N., 2010. Isolation and desalting with cation-exchange chromatography for compound-specific nitrogen isotope analysis of amino acids: application to biogeochemical samples. Rapid Communications in Mass Spectrometry 24, 2317-2323.

Takano, Y., Chikaraishi, Y., Ohkouchi, N., 2015. Isolation of underivatized amino acids by ion-pair high performance liquid chromatography for precise measurement of nitrogen isotopic composition of amino acids: development of comprehensive LC x GC/C/IRMS method. International Journal of Mass Spectrometry 379, 16-25.

Trueman, C.N., MacKenzie, K.M., Palmer, M.R., 2012. Identifying migrations in marine fishes through stable-isotope analysis. Journal of Fish Biology 81, 826-847.

Vander Zanden, M.J., Rasmussen, J.B., 2001. Variations in $\delta^{15} \mathrm{~N}$ and $\delta^{13} \mathrm{C}$ trophic fractionation: Implications for aquatic food web studies. Limnology and Oceanography 46, 2061-2066. 
Vander Zanden, H.B., Arthur, K.E., Bolten, A.B., Popp, B.N., Lagueux, C.J., Harrison, E., Campbell, C.L., Bjorndal, K.A., 2013. Trophic ecology of a green turtle breeding population. Marine Ecology Progress Series 476, 237-249.

van der Heijden, M.G.A., Bardgett, R.D., van Straalen, N.M., 2008. The unseen majority: Soil microbes as drivers of plant diversity and productivity in terrestrial ecosystems. Ecology Letters $11,296-310$.

Vokhshoori, N.L., McCarthy, M.D., 2014. Compound-specific $\delta^{15} \mathrm{~N}$ amino acid measurements in littoral mussels in the California upwelling ecosystem: A new approach to generating baseline $\delta^{15} \mathrm{~N}$ isoscapes for coastal ecosystems. PLoS ONE 9, e98087.

Vokhshoori, N.L., Larsen, T., McCarthy, M.D., 2014. $\delta^{13} \mathrm{C}$ of amino acids in littoral mussels: A new approach to constructing isoscapes of primary production in a coastal upwelling system. Marine Ecology Progress Series 504, 59-72.

Wada, E., 1980. Nitrogen isotope fractionation and its significance in biogeochemical processes occurring in marine environments. In, Goldberg, E.D., Horibe, Y., Saruhashi, K. (Eds.) Isotope Marine Chemistry, Uchida Rokkakudo, Tokyo, pp. 375-398.

Wada, E., Kadonaga, T., Matsuo, S., 1975. ${ }^{15} \mathrm{~N}$ abundance in nitrogen of naturally occurring substances and global assessment of denitrification from isotopic viewpoint. Geochemical Journal 9, 139-148.

Walker, B.D., McCarthy, M.D., 2012. Elemental and isotopic characterization of dissolved and particulate organic matter in a unique California upwelling system: Importance of size and composition in the export of labile material. Limnology and Oceanography 57, 1757-1774.

Walker, B.D., Guilderson, T., Okimura, K.M., Peacock, M., McCarthy, M.D., 2014. Radiocarbon signatures and size-age-composition relationships of major organic matter pools within a unique California upwelling system. Geochimica et Cosmochimica Acta 126, 1-17.

Walsh, R.G., He, S., Yarnes, C., 2014, Compound-specific $\delta^{13} \mathrm{C}$ and $\delta^{15} \mathrm{~N}$ analysis of amino acids: a rapid, chloroformate-based method for ecological studies. Rapid Communications in Mass Spectrometry 28, 96-108.

West, J.B., Bowen, G.J., Dawson, T.E., Tu K.P., (Eds.) 2010. Isoscapes: Understanding Movement, Pattern and Process on Earth Through Isotope Mapping. Springer, New York, 487 pp.

Wilkie, M.P., 2002. Ammonia excretion and urea handling by fish gills: present understanding and future research challenges. Journal of Experimental Zoology 293, 284-301.

Williams, B., Risk, M.J., Ross, S.W., Sulak, K.J., 2007. Stable isotope data from deep-water antipatharians: 400-year records from the southeastern coast of the United States of America. Bulletin of Marine Science 81, 437-447.

Williams, B., Thibodeau, B., Chikaraishi, Y., Ohkouchi, N., Walnum, A., Grottoli, A., Colin, P., 2017. Consistency in coral skeletal amino acid composition offshore of Palau in the western 

productivity. Limnology and Oceanography, in press.

Wilson, R., Tudhope, A., Brohan, P., Briffa, K., Osborn, T., Tett, S., 2006. Two-hundred-fifty years of reconstructed and modeled tropical temperatures. Journal of Geophysical Research 111, C10007, doi:10.1029/2005JC003188

Wyatt, A.S.J., Lowe, R.J., Humphries, S., Waite, A.M., 2013. Particulate nutrient fluxes over a fringing coral reef: Source-sink dynamics inferred from carbon to nitrogen ratios and stable isotopes. Limnology and Oceanography 58, 409-427.

Wyatt, A.S.J., Waite, A.M., Humphries, S., 2012. Stable isotope analysis reveals community-level variation in fish trophodynamics across a fringing coral reef. Coral Reefs 31, 1029-1044.

Yamaguchi, Y.T., 2013. Biogeochemical dynamics of amino acids in marine sediments: constraints from compound-specific nitrogen isotopic composition and $\mathrm{D} / \mathrm{L}$ ratio. $\mathrm{PhD}$ thesis, The University of Tokyo, p. 139. on the compound-specific stable isotope analysis of nitrogen in amino acids. Rapid Communication in Mass Spectrometry, in press. 
Table 1. A summary of three types of derivatized amino acids used for the nitrogen isotopic analysis.

Fig. 1. Derivatization of amino acids for the nitrogen isotope analysis by GC/IRMS: Schemes of (a) basic chemical reaction, (b) TFA/AA/iPr ester, (c) Pv/AA/iPr ester, and (d) MOC AA ester.

Fig. 2. Ester exchange between amino acid derivatives and ethyl acetate.

Fig. 3. A representative chromatogram of GC/IRMS analysis of the nitrogen isotope analysis of amino acids as $N$-pivaloyl $O$-isopropyl esters.

Fig. 4. Schematic illustrations of the trophic position $(T P)$ estimates by (a) bulk and (b) CSIA-AA methods. In the bulk method, the $\delta^{15} \mathrm{~N}$ values of consumers at the same $T P$ frequently vary, due to temporal or spatial change in the $\delta^{15} \mathrm{~N}$ value at the basis of food web. In contrast, CSIA-AA method can estimate $T P$ independent of change in the $\delta^{15} \mathrm{~N}$ value at the basis of food web (after Naito et al., 2016).

Fig. 5. (a) Initial steps of the dominant metabolism for glutamic acid and phenylalanine in animals, and (b) schematic illustrations of the relationship between $\delta^{15} \mathrm{~N}$ values of amino acids (Glu and Phe) and trophic position in aquatic and terrestrial food webs (after Chikaraishi et al., 2009, 2010).

Fig. 6. Schematic of two aquatic food webs differentiated based on the $\delta^{15} \mathrm{~N}$ values of Phe and Glu. Changes in baseline nitrogen sources cause each food web to be separated along the source amino acid axis; here an oceanic food web based on phytoplankton production (P) supported by e.g. $\mathrm{N}_{2}$-fixation (low $\delta^{15} \mathrm{~N}_{\text {Phe }}$ ) is separated from a benthic food web based on macroalgae production (M) supported by e.g. upwelling or terrestrial run-off (high $\delta^{15} \mathrm{~N}_{\mathrm{Phe}}$ ). The potential for 'trophic omnivory' can be evident as non-integer $T P$ s; here the oceanic food web depicts potential ontogenetic changes in CSIA-AA-derived TP for fish across two TPs (anchovy and tuna). An example is also provided of a mobile apex predator (the tiger shark, Galeocerdo cuvier; $G a$ ) potentially integrating across oceanic and benthic food webs at a given $T P$, leading to intermediate $\delta^{15} \mathrm{~N}_{\mathrm{SAA}}$ value.

Fig. 7. Two examples of food web analysis by $\delta^{15} \mathrm{~N}_{\mathrm{AA}}$ : a) the coastal marine (a stony shore) ecosystem in Japan (Chikaraishi et al., 2014), and b) Lake Baikal (Ohkouchi et al., 2015). 
Fig. 8. (a) Concentrations of nitrate (black) and phosphate (red) observed in the hypolimetic water in

1928

1929

1930

1931

1932

1933

1934

1935

1936

1937

1938

1939

1940

1941

1942

1943

1944

1945

1946

1947

1948

1949

1950

1951

1952

1953

1954

1955

1956

1957

1958

1959

1960

1961

1962 the north basin of Lake Biwa, Japan. (b) Trophic position of gobiid fish Isaza (Gymnogobius isaza) estimated by the $\delta^{15} \mathrm{~N}_{\mathrm{AA}}$. (c) $\delta^{15} \mathrm{~N}$ values of bulk muscular tissue, Glu, and Phe of formalin-fixed Isaza specimens. $\delta^{15} \mathrm{~N}$ values of bulk sediments were also shown (data from Ogawa et al. 2001). A grey band indicates the major eutrophication period in Lake Biwa (1960-1980, Ogawa et al., 2013)

Fig. 9. Fungi can be carnivorous. Here, the fungus Beauveria bassiana has subdued and killed a caterpillar (larval Spodoptera frugiperda). The trophic position of the fungus is 3.0 (Steffan et al., 2015a), because functionally, this fungus is a strict carnivore.

Fig. 10. Isotopic approaches have been used to decode carnivore impacts on key ecosystem metrics, such as primary productivity (after Steffan et al., 2015b). Heterotrophic feeding induces trophic cascades, which directly and indirectly influence other trophic groups. The trophic tendency of any given species, coupled with its resource capture efficiency (\% consumption of resource base), permits estimation of the consumers' impacts on plant protection.

Fig. 11. Nitrogen isotopic compositions of Phe and Glu of Holocene hunter-gatherers in Japanese archipelago. a) Kitakogane shell midden located near the coastal line of Hokkaido (Early Jomon period, $c a .6000-5300 \mathrm{cal} \mathrm{BP}$ ) and b) Tochibara rockshelter site located at inland Nagano (Initial Jomon period, $c a$. 9100-9700 cal BP). Note that Kitakogane humans exhibit $\delta^{15} \mathrm{~N}_{\text {Phe }}$ closer to marine fauna than terrestrial fauna suggesting their strong reliance on marine foods while Tochibara humans exhibit $\delta^{15} \mathrm{~N}_{\text {Phe }}$ comparable to those of terrestrial fauna suggesting their reliance exclusively on terrestrial foods (Naito et al., 2010b, 2013b).

Fig. 12. Nitrogen isotopic compositions of Phe and Glu for Neanderthal and animal remains from Spy and Scladina caves in Pleistocene Belgium (Naito et al., 2016b).

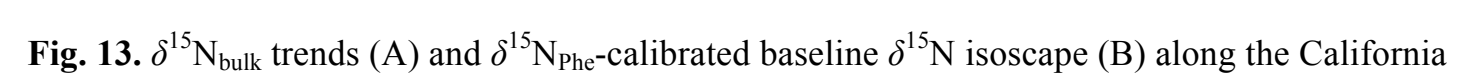
coast, based on selected CSIA-AA within high-density bulk sampling of littoral mussels.

Fig. 14. Conceptual diagrams describing the proposed four patterns of $\delta^{15} \mathrm{~N}_{\mathrm{AA}}$ fractionation of chemotrophic microbes (for details, see Section 4.5.1 in the main text). Eight AAs which have been commonly analyzed are selected for the diagrams. (a) Pattern 1 . The $\delta^{15} \mathrm{~N}_{\mathrm{AA}}$ pattern of $d e$ novo AA synthesis from inorganic nitrogen by chemotrophic microbes (closed circles: microbial biomass), which was observed in the pure culture experiments (Yamaguchi, 2013). The $\delta^{15} \mathrm{~N}_{\mathrm{AA}}$ values are normalized to the $\delta^{15} \mathrm{~N}_{\text {Glu }}$ value. (b) Pattern 2. The $\delta^{15} \mathrm{~N}_{\mathrm{AA}}$ fractionation pattern of 
1963 heterotrophic microbes relative to preformed AA in substrates, which was observed in the pure 1964 culture experiments (red squares: microbial biomass) (Stefan et al., 2015; Yamaguchi, 2013). The $1965 \delta^{15} \mathrm{~N}_{\mathrm{AA}}$ values of the substrates in b, c, and d (open circles) are set as the average pattern of algae 1966 (Chikaraishi et al., 2009; McCarthy et al., 2013), and are normalized to the $\delta^{15} \mathrm{~N}_{\text {Glu }}$ value. (c) 1967 Pattern 3. A possible example of the scattered $\delta^{15} \mathrm{~N}_{\mathrm{AA}}$ fractionation by heterotrophic microbes 1968 relative to substrates in some settings (blue triangles: degraded materials), hypothesized from the 1969 results of incubation or microcosm experiments (Fogel and Tuross, 1999; Calleja et al., 2013;

1970 Gutierrez-Rodriguez et al., 2014). Note that the $\delta^{15} \mathrm{~N}$ fractionation value of each AA in this pattern 1971 is not well constrained and is likely variable. (d) Pattern 4. A hypothesized $\delta^{15} \mathrm{~N}_{\mathrm{AA}}$ fractionation 1972 pattern during extracellular protein hydrolysis by heterotrophic microbes (green squares: residue of 1973 hydrolysis) (Hannides et al., 2013). Note that the magnitude of $\delta^{15} \mathrm{~N}$ fractionation would be 1974 variable, depending on the character of substrates and the degree of degradation. 


\begin{tabular}{lccc}
\hline & TFA/AA/iPr & Pv/AA/iPr & MOC/AA ester \\
\hline Available solvent & DCM & DCM & DCM or MeOH \\
Toxicity & High & Very high & High \\
Stability at $-20^{\circ} \mathrm{C}$ & $1-2$ years & $1-2$ years & $1-2$ weeks \\
Volatility & High & Low & Very high \\
\hline
\end{tabular}


(a) Basic chemical reaction<smiles>[R]C(N)C(=O)O</smiles><smiles>[R]OC1CCCC1</smiles><smiles>[R]OC(=O)C([R])N</smiles><smiles>[R]C(=O)OC([R])=O</smiles><smiles>[R8]OC(=O)C([R])NC([R])=O</smiles>

(b) TFA/AA/iPr<smiles>[R]C(N)C(=O)O</smiles><smiles>CC(C)O</smiles><smiles>[R]C(N)C(=O)OC(C)C</smiles>

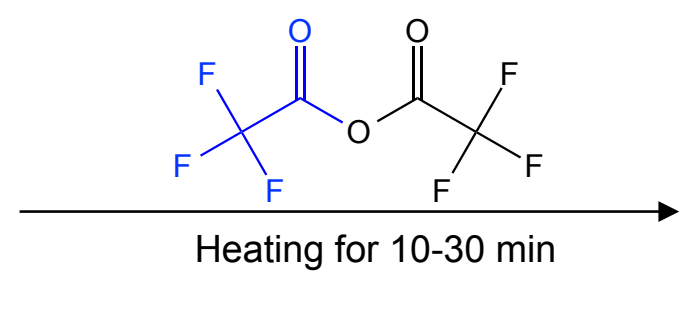<smiles>[R]C(NC(=O)C(F)(F)F)C(=O)OC(C)C</smiles>

(c) Pv/AA/iPr<smiles>[R]C(N)C(=O)O</smiles><smiles>CC(C)O</smiles><smiles>[R]C(N)C(=O)OC(C)C</smiles><smiles>CC(C)(C)C(=O)Cl</smiles><smiles>[R]C(NC(=O)C(C)(C)C)C(=O)OC(C)C</smiles>

(d) MOC AA ester<smiles>[R]C(N)C(=O)O</smiles><smiles>COC(=O)OCCOC(=O)Cl</smiles><smiles>[R]C(NC(=O)OC)C(=O)OC</smiles>

Fig. 1 
(a) Exchange of ester group
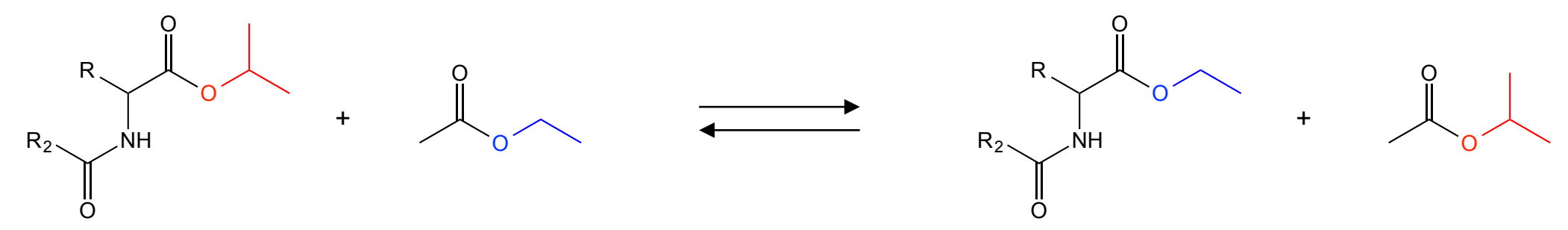

(b) Combustion of TFA/AA/iPr

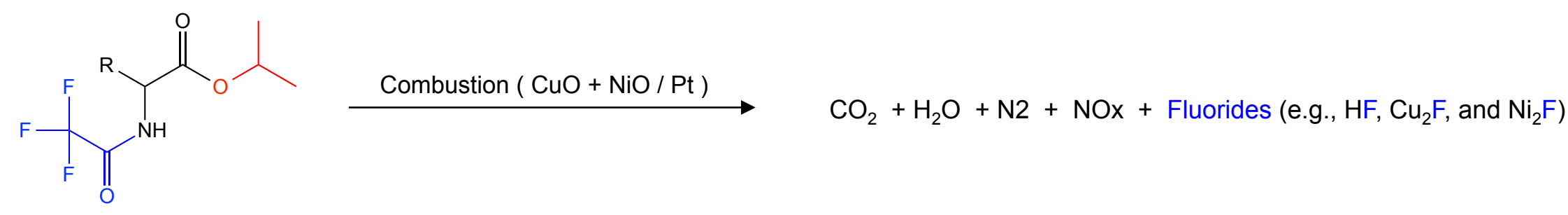

(c) MOC derivatives of glutamic acid<smiles>NC(CCC(=O)O)C(=O)O</smiles>
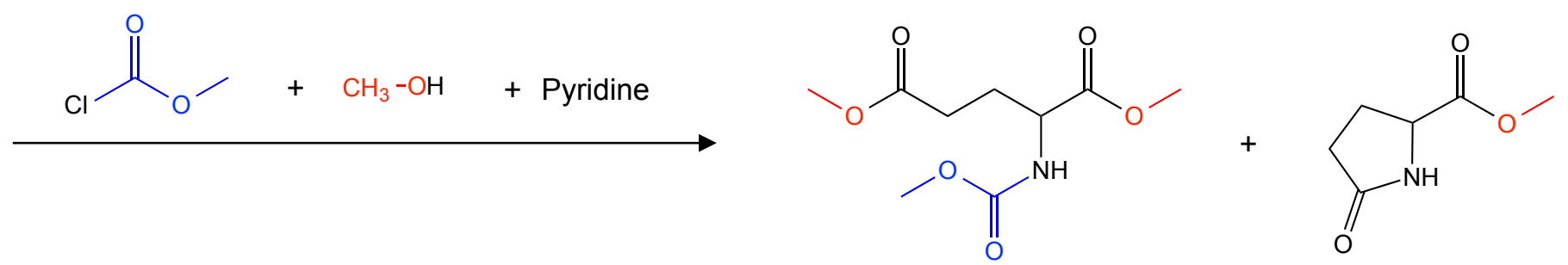

Fig. 2 

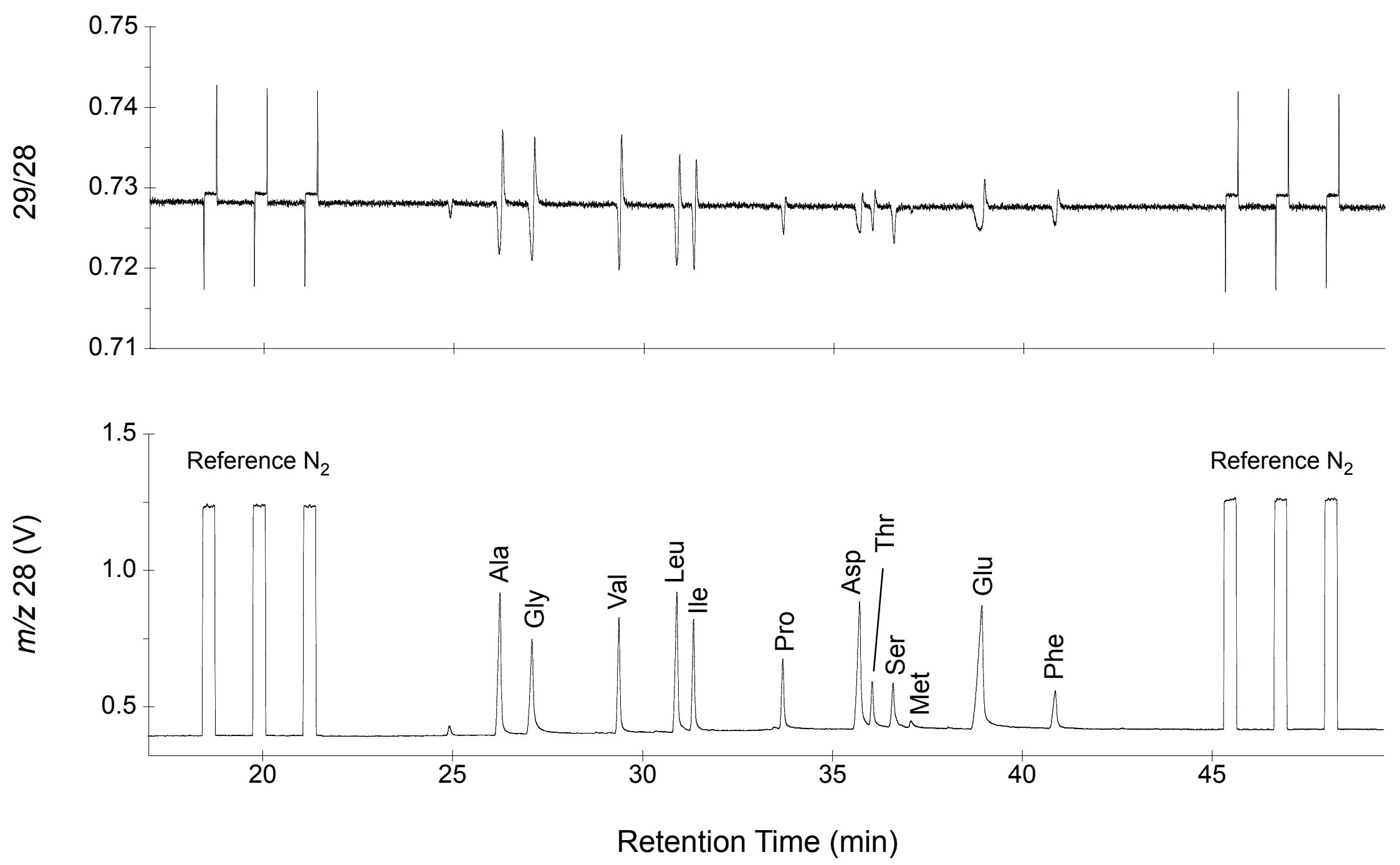

Fig. 3 
(a) Bulk method

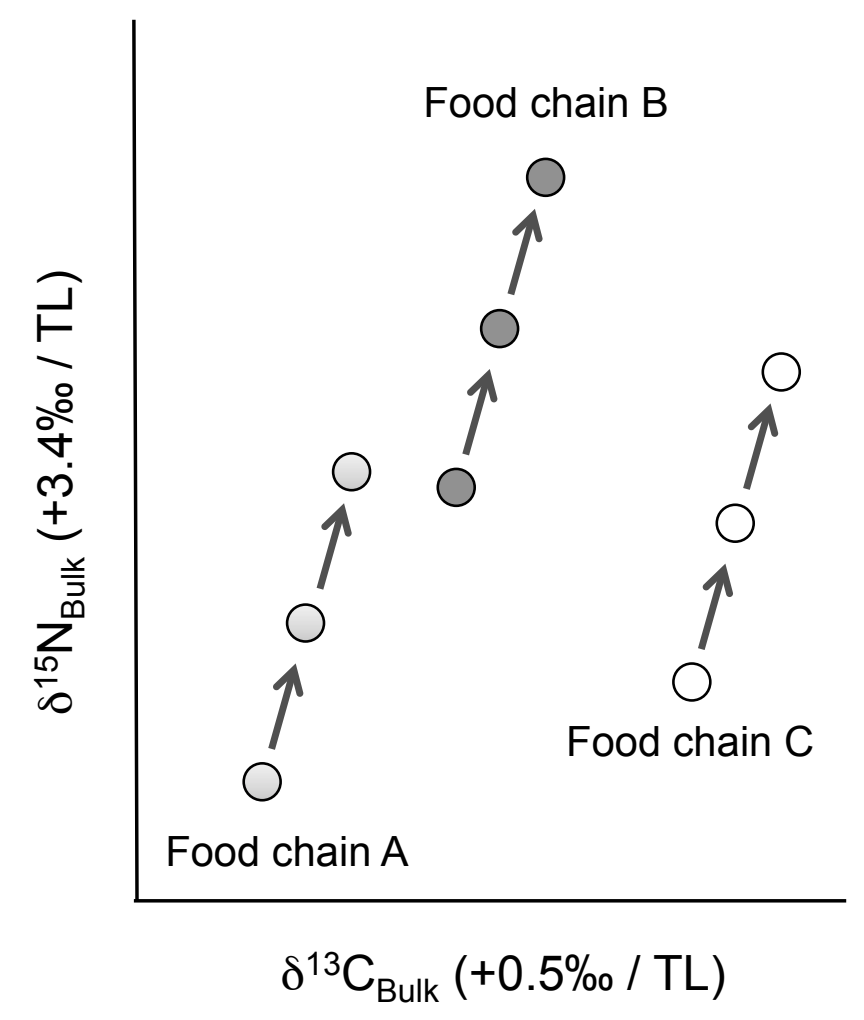

(b) CSIA-AA method

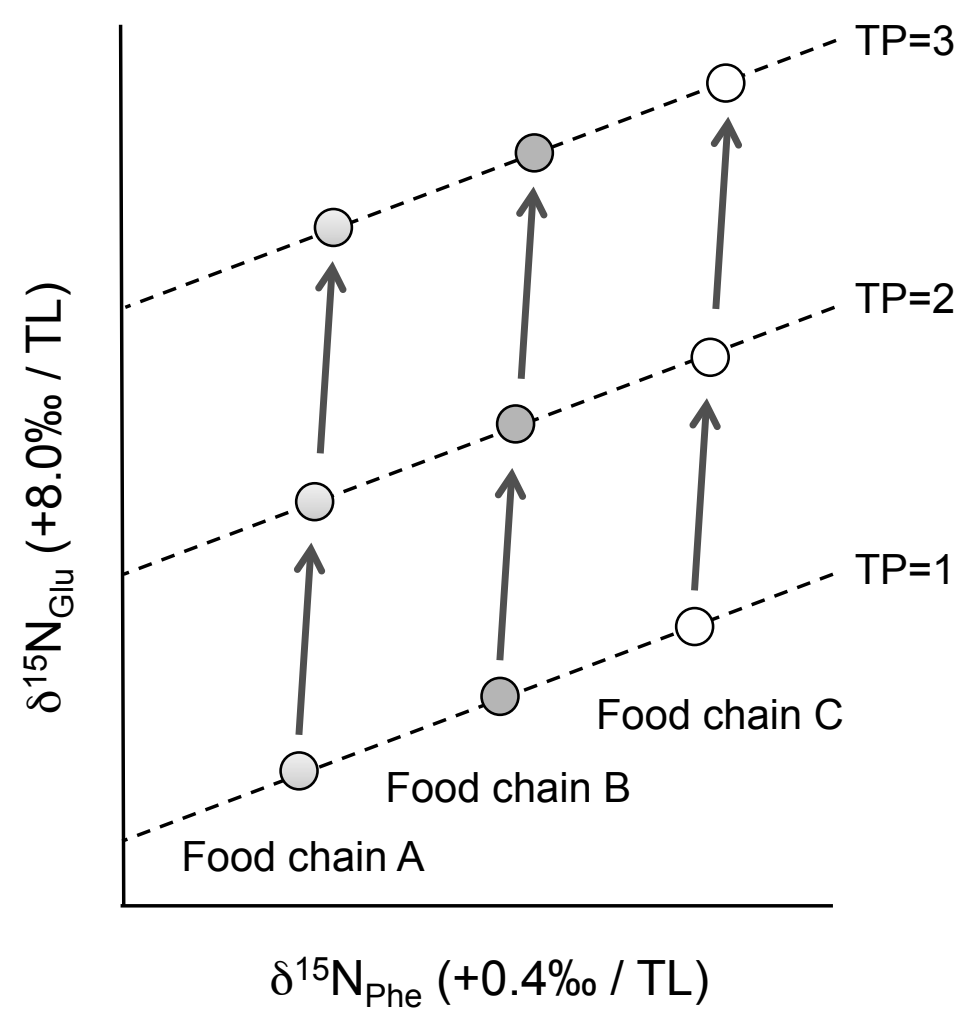

Fig. 4 
(a) First step in metabolism<smiles>[NH3+][C@@H](CCC(=O)O)C(=O)[O-]</smiles>

Glutamic acid<smiles>[NH3+]C(Cc1ccccc1)C(=O)[O-]</smiles>

Phenylalanine
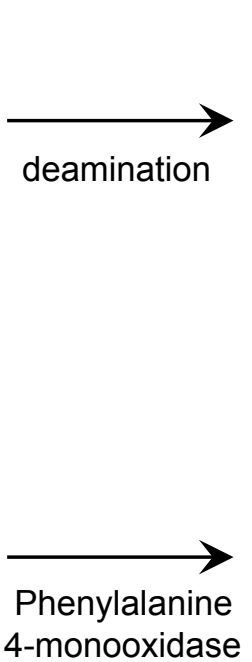

$$
\alpha \text {-Ketoglutamic acid }
$$

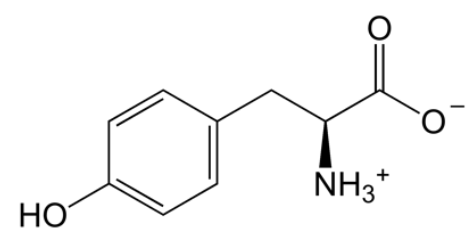

Tyrosine (b) Trophic enrichment in ${ }^{15} \mathrm{~N}$

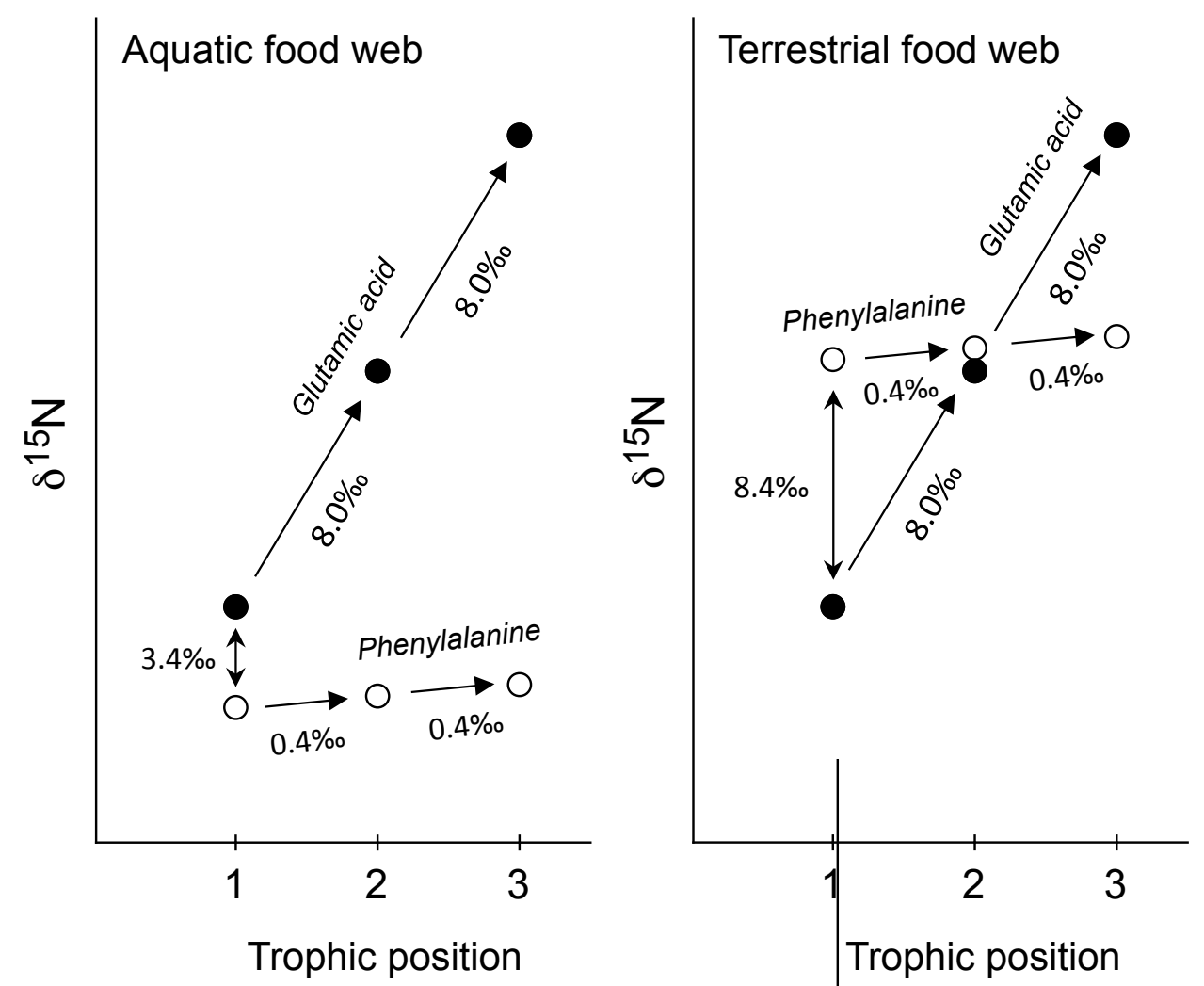

Fig. 5 


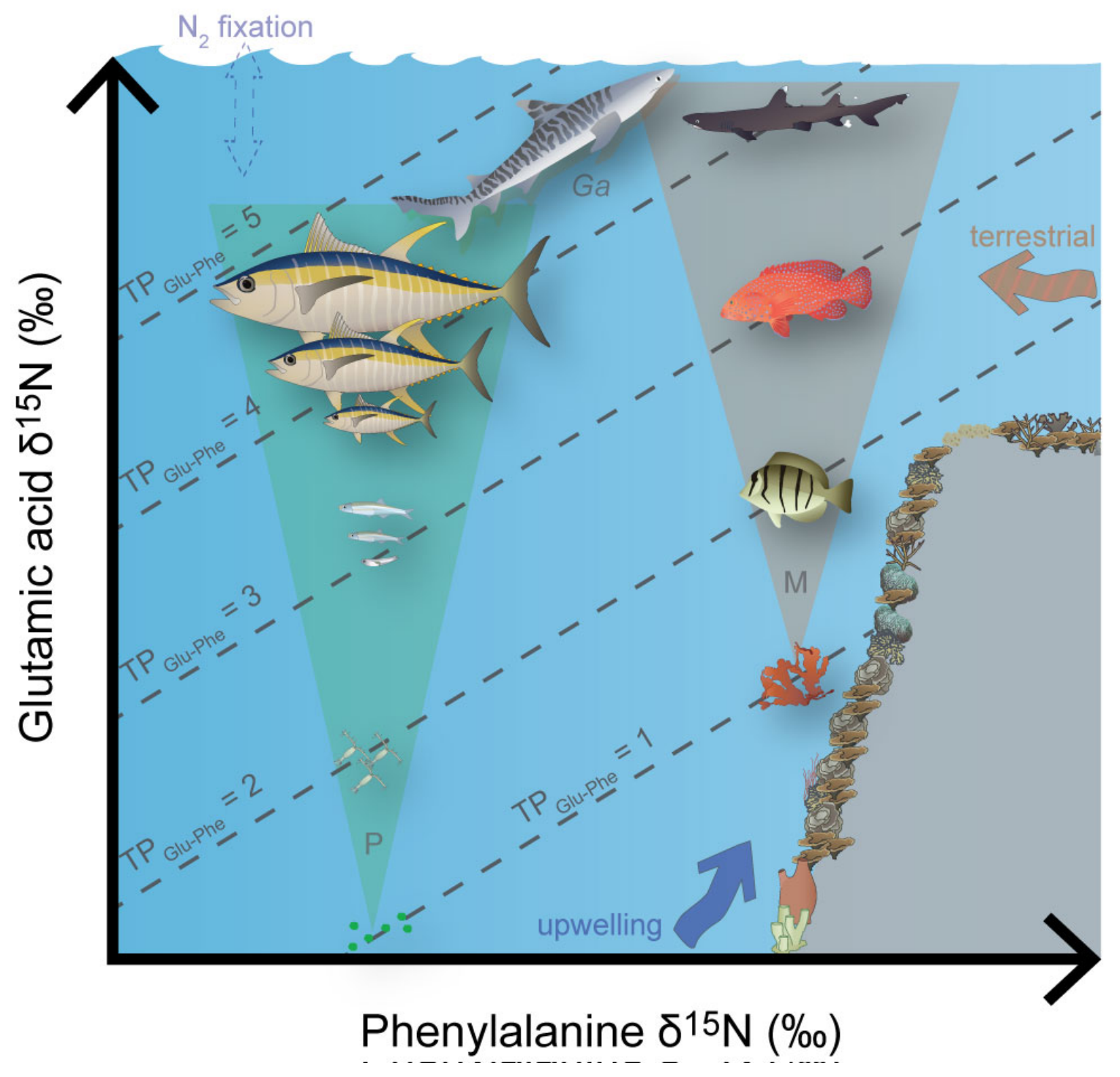

Fig. 6 

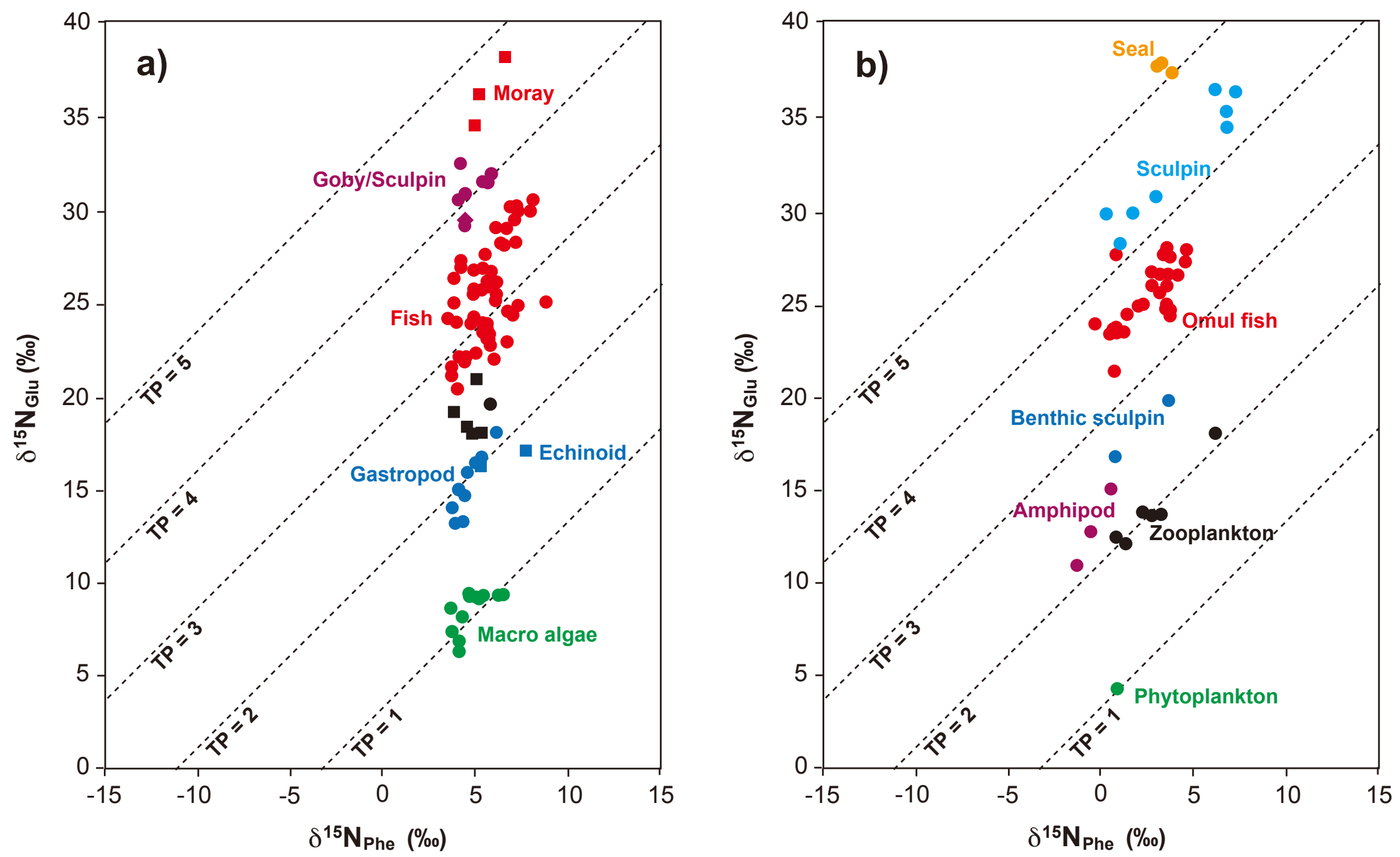

Fig. 7 
Year (AD)
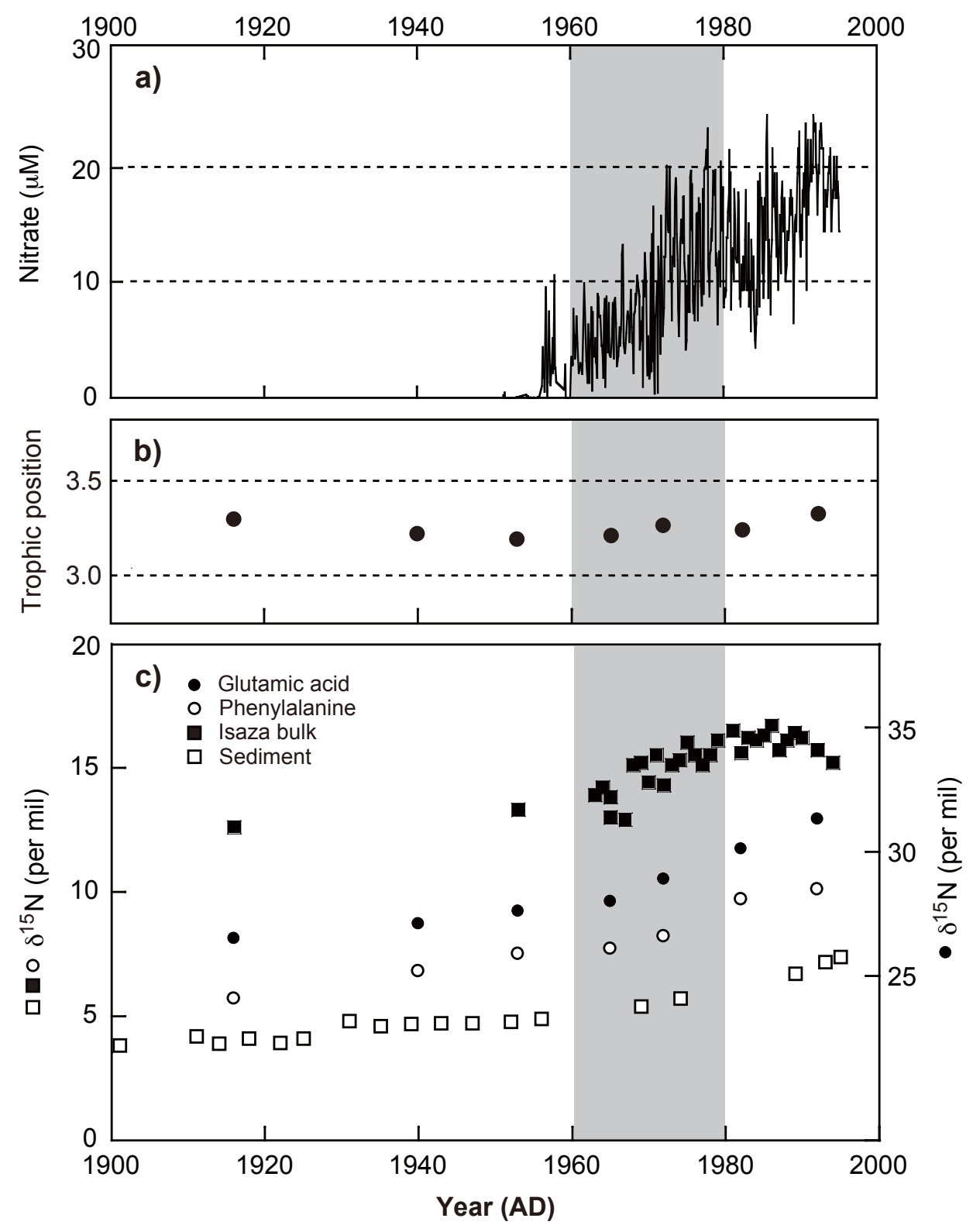

Fig. 8 


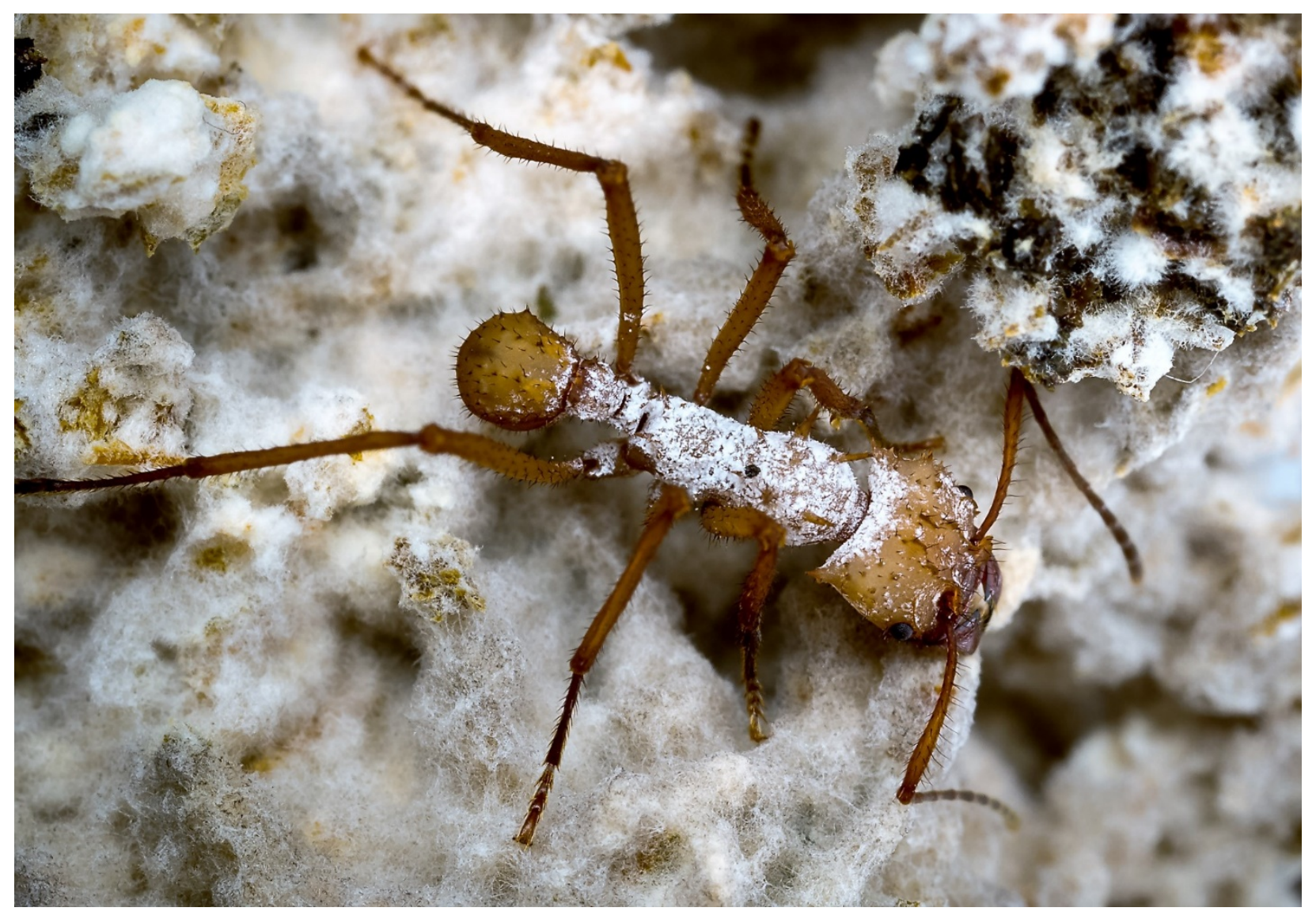

Fig. 9 


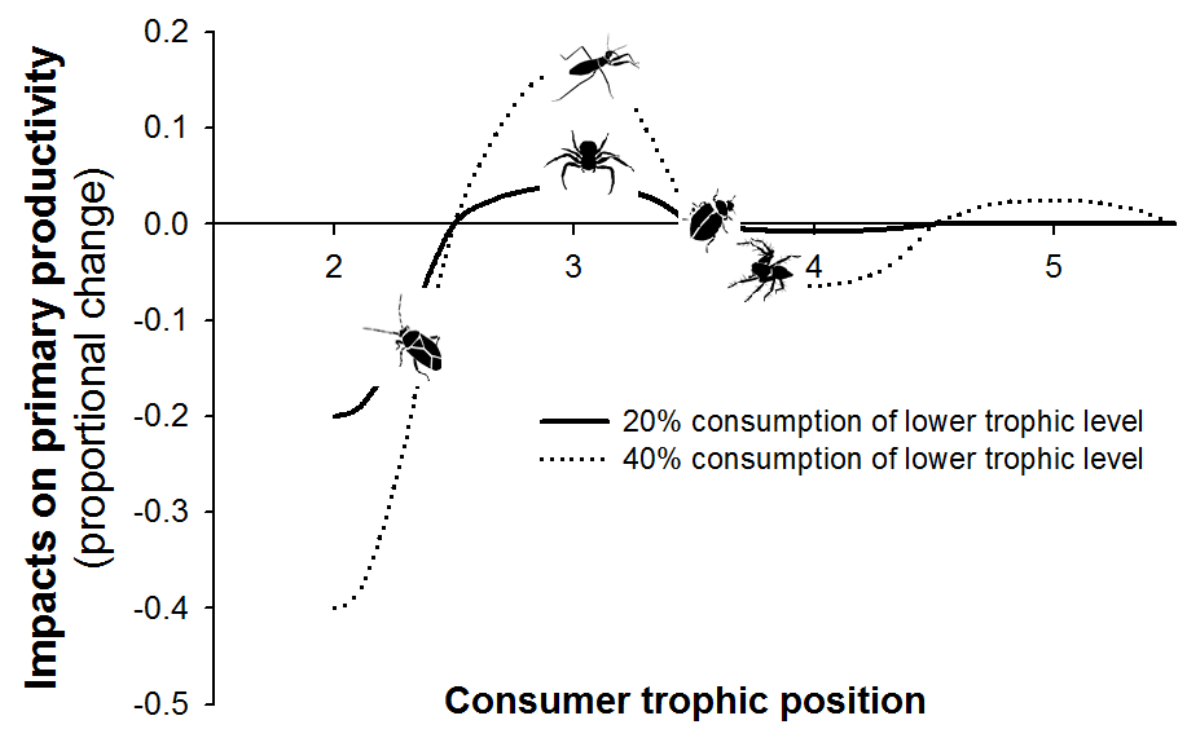

Fig. 10 

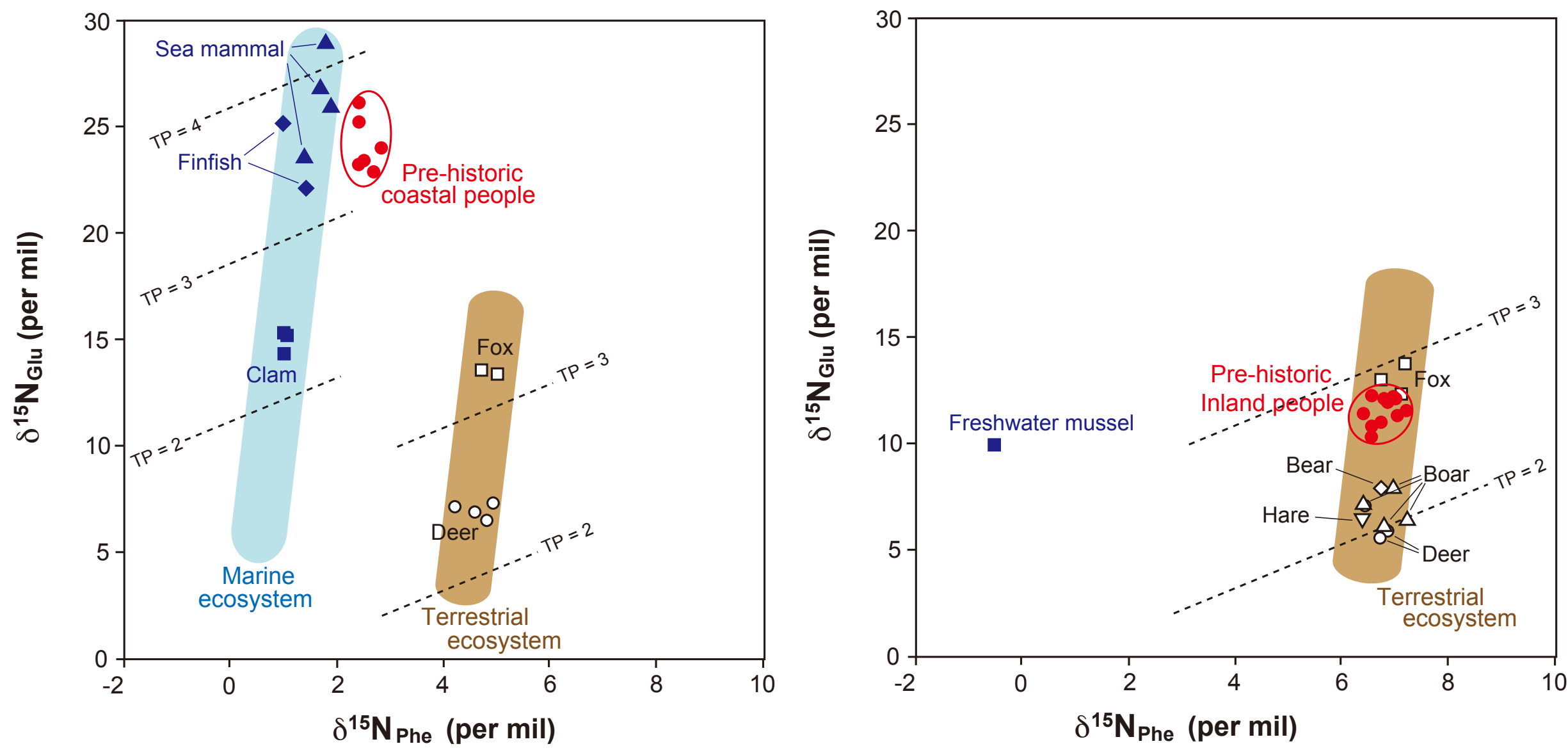

Fig. 11 


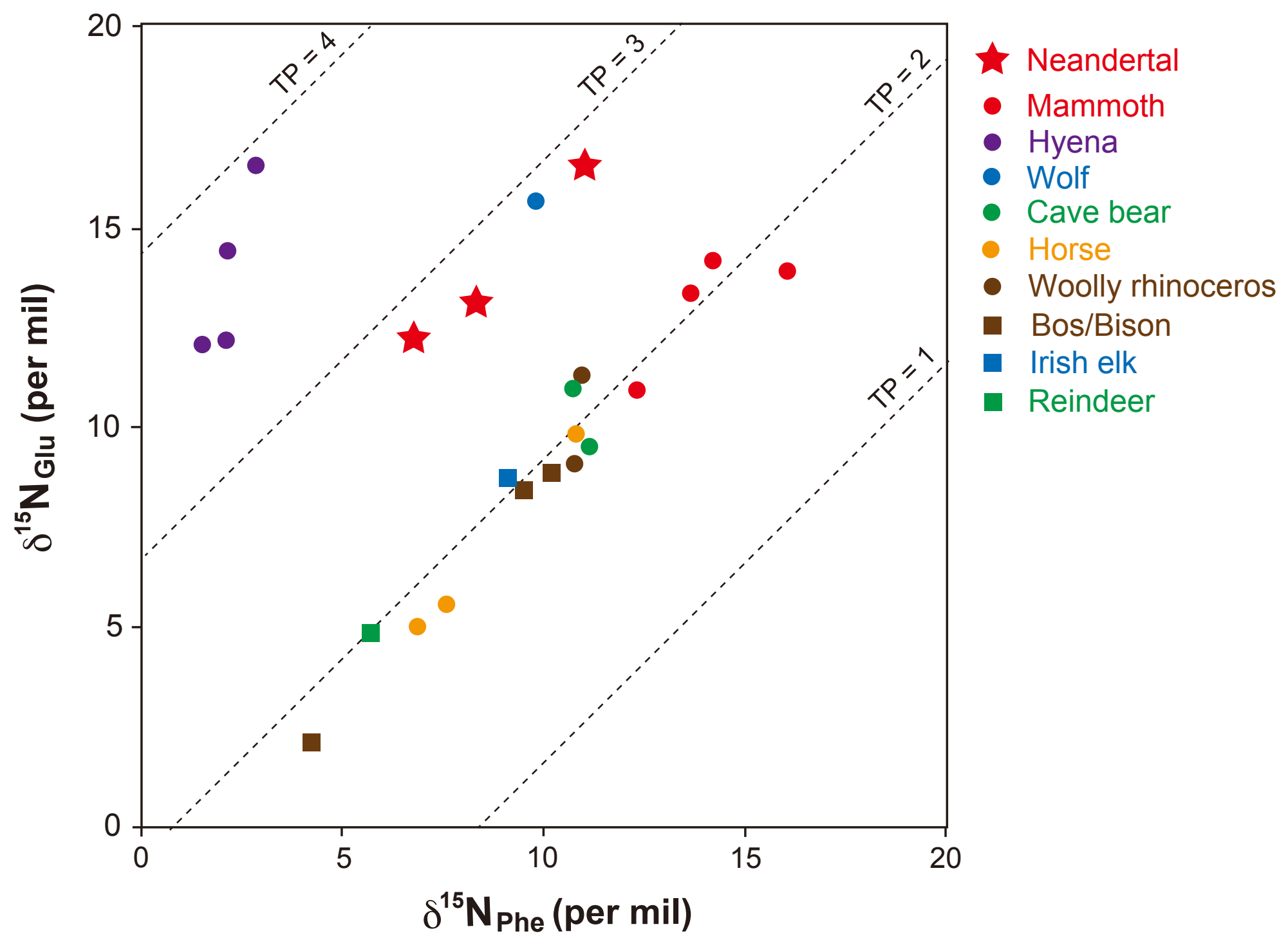

Fig. 12 

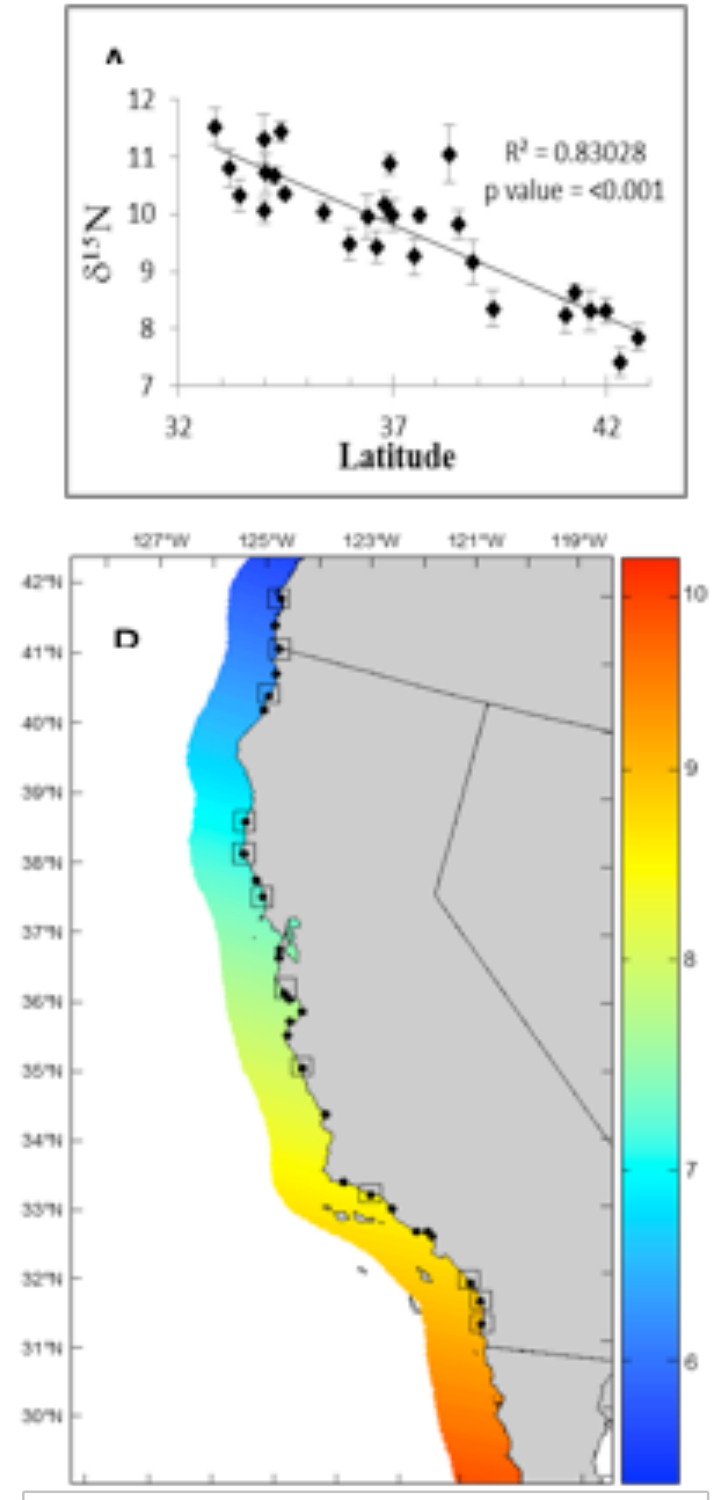

Fig. 1: Bulk $\delta^{15} \mathrm{~N}$ trends [A] and a $\delta^{15} \mathrm{~N}_{\text {Pho }}$ calibrated baseline $\delta^{15} \mathrm{~N}$ isoscape (B) along the CA coast,

Fig. 13 

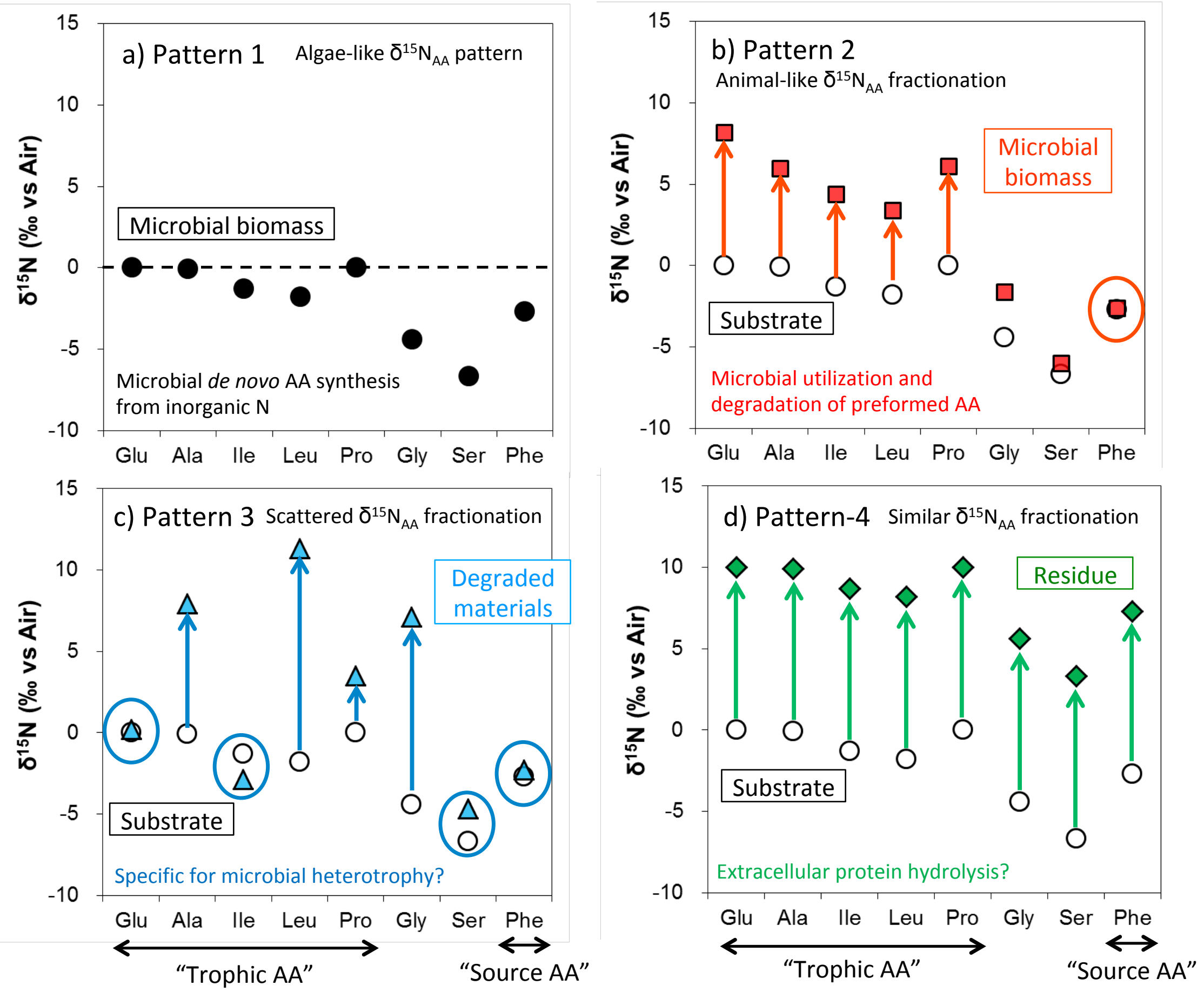

Fig. 14 


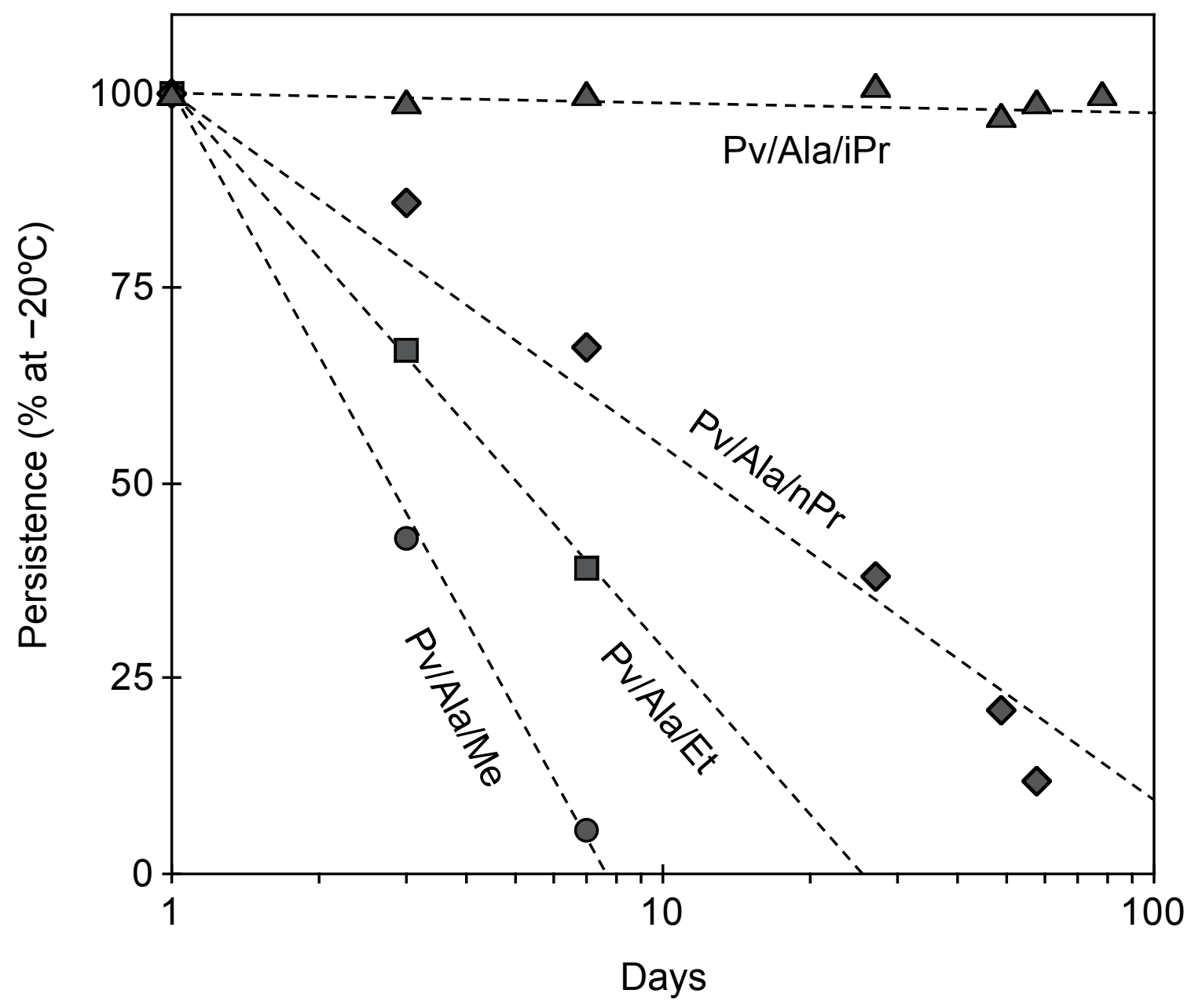

Fig. S1 Comparison of stabilities of various pivaloyl esters of alanine. Triangle: methyl ester ( $\mathrm{Pv} / \mathrm{Ala} / \mathrm{Me})$, diamond: ethyl ester ( $\mathrm{Pv} / \mathrm{Ala} / \mathrm{Et})$, squire: $n$-propyl ester ( $\mathrm{Pv} / \mathrm{Ala} / \mathrm{nPr})$, circle: isopropyl ester ( $\mathrm{Pv} / \mathrm{Ala} / \mathrm{iPr})$. 

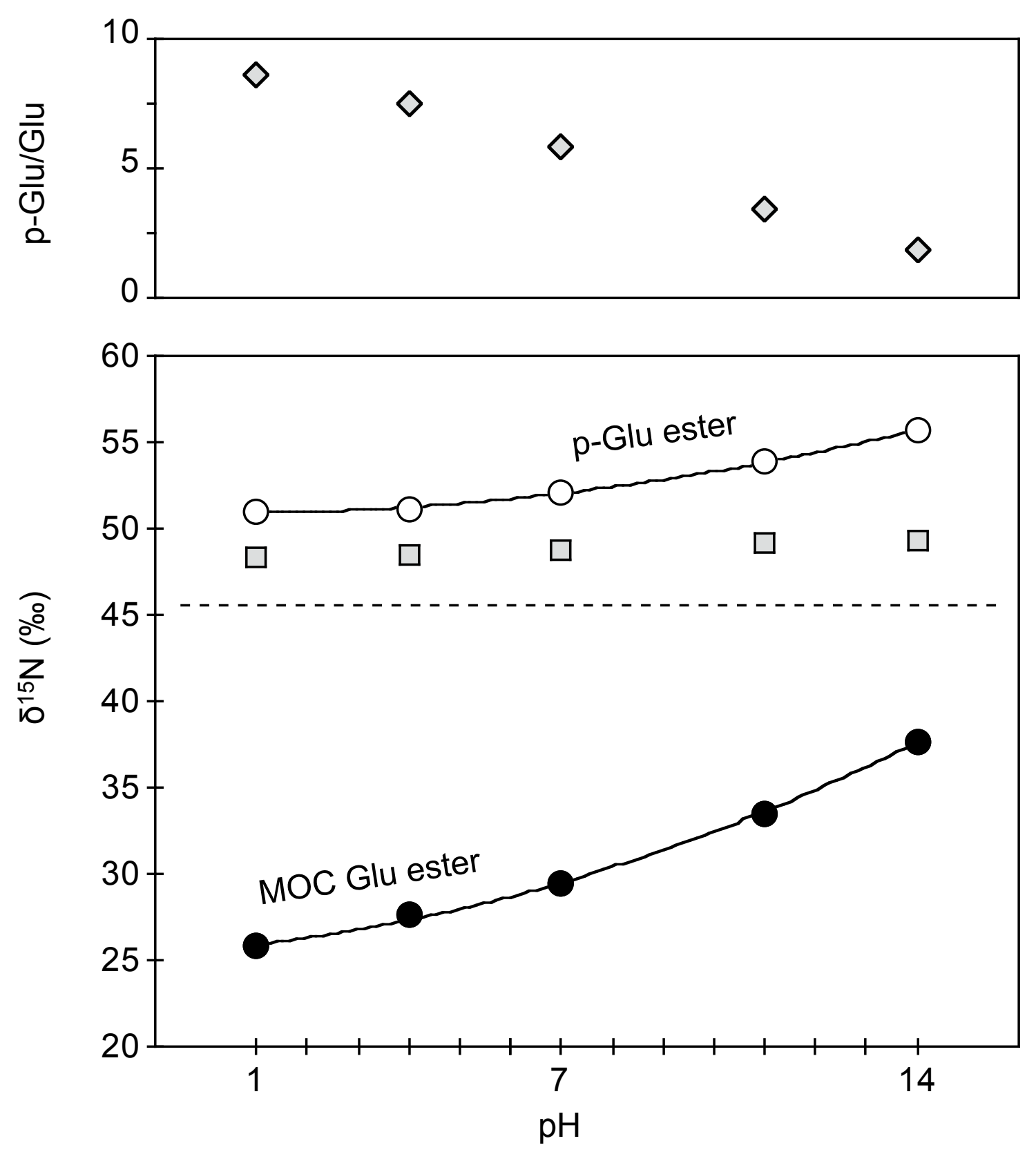

Fig. S2. Isotopic fractionation of MOC ester derivatization of Glu. The MOC ester (MOC Glu ester, filled circle) is depleted in ${ }^{15} \mathrm{~N}$ whereas the cyclic ester ( $\mathrm{p}-\mathrm{Glu}$ ester, open circle) is enriched in ${ }^{15} \mathrm{~N}$. Molar ratio of these two derivatives ( $\mathrm{p}-\mathrm{Glu} / \mathrm{Glu}$ ) has a negative correlation with $p \mathrm{H}$ during the derivatization, however, the mass balanced values (gray square) do not equal to the reference isotopic composition of glutamic acid ( $+45.7 \%$, broken line). 


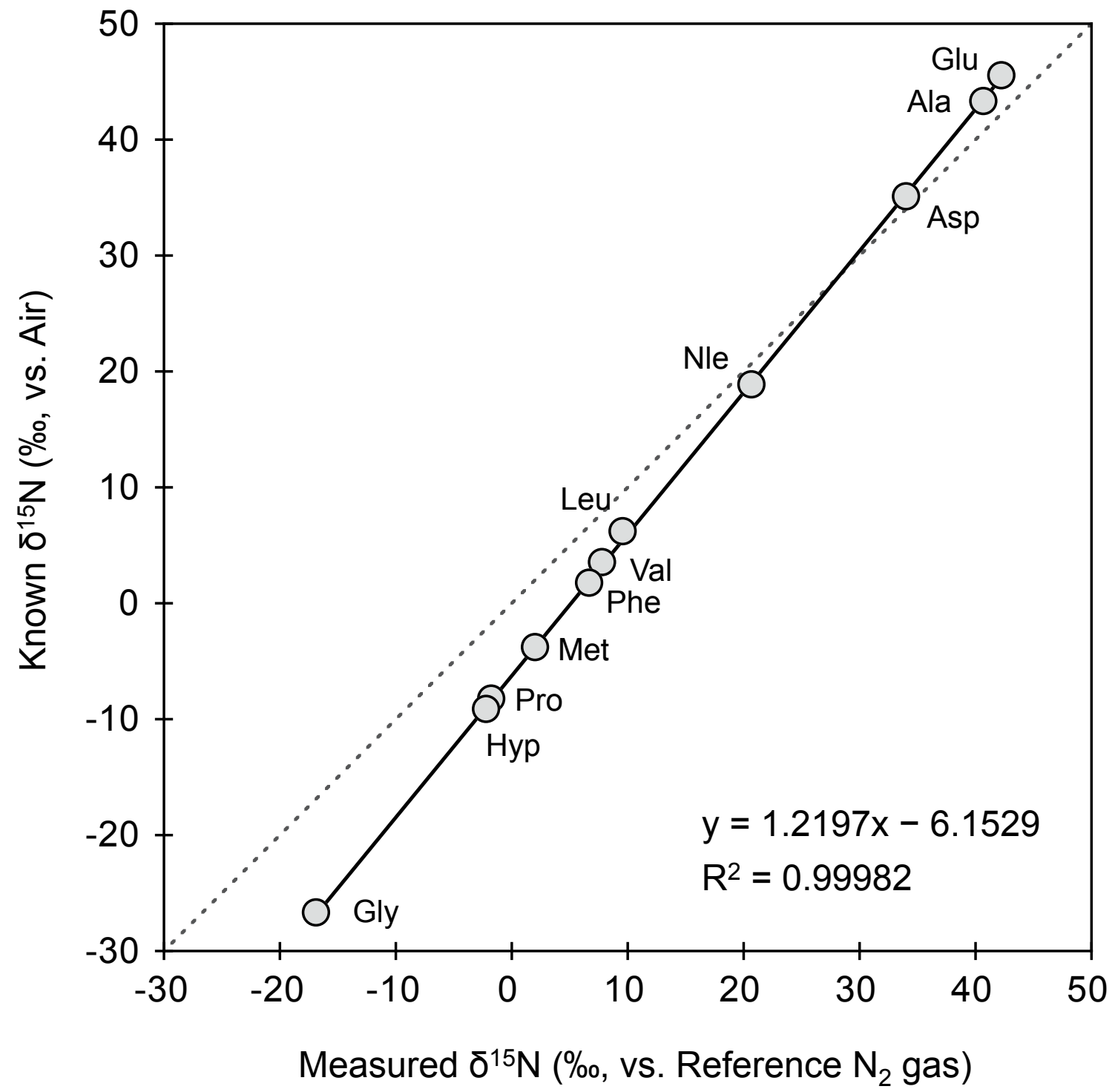

Fig. S3. A regression line between known (\%, vs. AIR) and measured values (\%o, vs. reference $\mathrm{N}_{2}$ gas). 

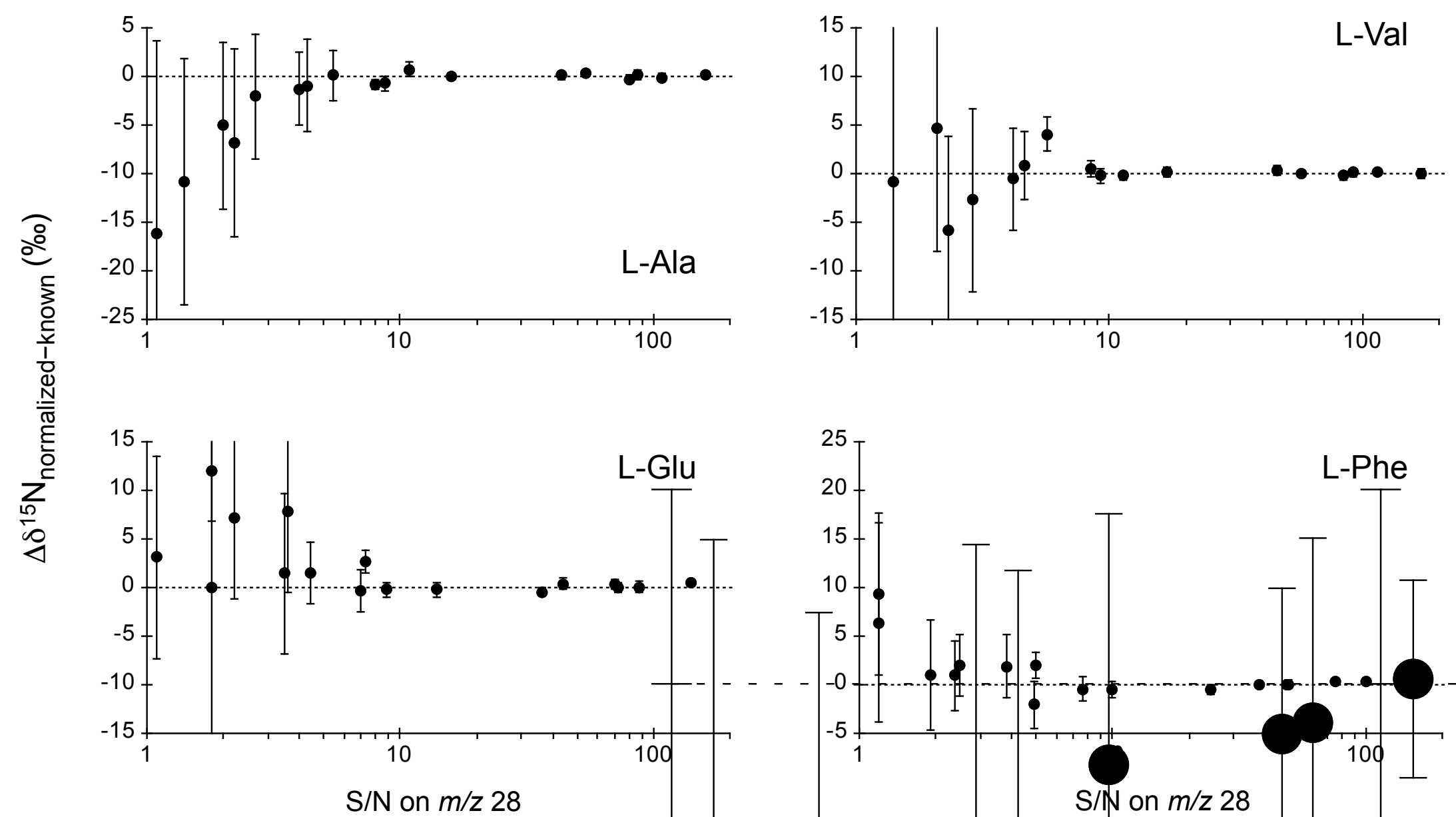

Fig. S4. The accuracy and precision of the nitrogen isotope analysis of amino acids by GC/IRMS with respect to the signal/noise (S/N) ratio (Chan et al., 2016). 